ARGONNE CANCER RESEARCH HOSPITAL 950 EAST FIFTY-NINTH STREET * CHICAGO 37 . ILLINOIS

\title{
Semiannual Report to \\ THE ATOMIC ENERGY COMMISSION
}

MARCH 1959

LEON O. JACOBSON, M.D.

Editor

ANTREEN PFAU

Associate Editor

OPERATED BY THE UNIVERSITY OF CHICAGO

UNDER

CONTRACT AT-(11-1)-69 


\section{DISCLAIMER}

This report was prepared as an account of work sponsored by an agency of the United States Government. Neither the United States Government nor any agency Thereof, nor any of their employees, makes any warranty, express or implied, or assumes any legal liability or responsibility for the accuracy, completeness, or usefulness of any information, apparatus, product, or process disclosed, or represents that its use would not infringe privately owned rights. Reference herein to any specific commercial product, process, or service by trade name, trademark, manufacturer, or otherwise does not necessarily constitute or imply its endorsement, recommendation, or favoring by the United States Government or any agency thereof. The views and opinions of authors expressed herein do not necessarily state or reflect those of the United States Government or any agency thereof. 


\section{DISCLAIMER}

Portions of this document may be illegible in electronic image products. Images are produced from the best available original document. 


\section{LEGAL NOTICE}

This report was prepared as an account of Government spnnsnred work. Neither the United States, nor the Commission, nor any person acting on behalf of the Commission:

A. Makes any warranty or representation, express or implied, with respect to the accuracy, completeness, or usefulness of the information contained in this report, or that the use of any information, apparatus, method, or process disclosed in this report may not infringe privately owned rights; or

B. Assumes any liabilities with respect to the use of, or for damages resulting from the use of any information, apparatus, method, or process disclosed in this report.

As used in the above, "person acting on behalf of the Commission" includes any employee or contractor of the Commission to the extent that such employee or contractor prepares, handles or distributes, or provides access to, any information pursuant to his employment or contract with the Commission.

Price \$2.50. Available from the Office of Technical Services, Department of Commerce, Washington 25, D.C. 

ARGONNE CANCER RESEARCH HOSPITAL 950 EAST FIFTY-NINTH STREET - CHICAGO 37 • ILLINOIS

\section{Semiannual Report to}

\section{THE ATOMIC ENERGY COMMISSION}

MARCH 1959

LEON O. JACOBSON, M.D. Editor

ANTREEN PFAU

Associate Editor

OPERATED BY THE UNIVERSITY OF CHICAGO

UNDER

CONTRACT AT-(11-1)-69 


\section{TABLE OF CONTENTS}

Page

Iron enzymes in iron deficiency.

E. Beutler, R. K. Blaisdell, E. Buttenwieser, and M. Yeh ..........

A study of the fate and phagocytic properties of the antibody-forming cell of the spleen.

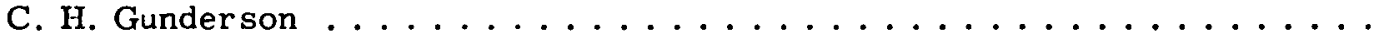

The effect of concurrent feeding of Tween 80 on the carcinogenicity of orallyadministered 3-methylcholanthrene.

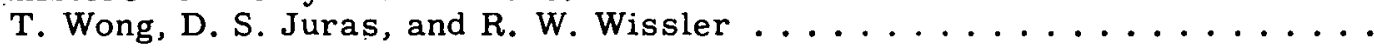

Long-term survival of irradiated mice treated with homologous tissue suspensions.

E. L. Simmons, L. O. Jacobson, E. K. Marks, and E. O. Gaston ........ 66

Isotopes decaying by electron capture: a new modality in brachytherapy.

P. V. Harper, K. A. Lathrop, L. Baldwin, Y, Oda, and L. Kryshtal . . . . .

The distribution of intraperitoneal radiocolloids.

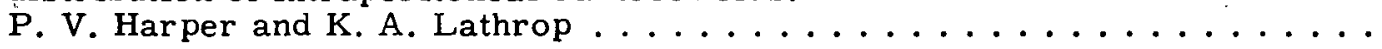

Acquired tolerance to a mouse leukemia in the rat.

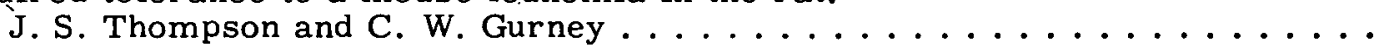

The metabolites of cardiac glycosides in human urine.

J. J. Ashley, B. T. Brown, G. T. Okita, and S. E. Wright..........

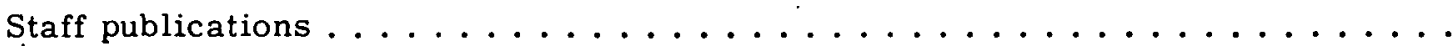




\section{IRON ENZYMES IN IRON DEFICIENCY}

\section{By}

E. Beutler, R. K. Blaisdell, E. Buttenwieser, and M. Yeh

Although iron-deficiency anemia is one of the most common disorders seen in clinical medicine, the symptoms have never been explained satisfactorily. It is usually thought that the fatigue, dyspnea, nervousness, and headaches of these patients arise from the anemia alone. This belief is fortified by a frequently quoted statement by Hahn and Whipple in $1936^{1}$ that the tissue iron enzymes were "inviolate," even when the body's need for iron was very great.

A considerable number of clinical observations do not support the concept that the symptoms of iron deficiency arise from the anemia alone. The severity of symptoms appears to bear little relationship to the severity of the anemia. In $1908, \mathrm{Sahli}^{2}$ reported that some women with subjective symptoms of iron-deficiency anemia had hemoglobin values of 88 to 94 per cent. These symptoms disappeared on administration of iron, just as did those of subjects with severe iron-deficiency anemia with the same symptoms. A slight rise in the hemoglobin concentration of the blood was observed, so that even though the original hemoglobin value was in the normal range, it was not normal for that patient. Thirty years later, Waldenströ ${ }^{3}$ described several patients in whom epithelial signs and symptoms typical of iron deficiency appeared in non-anemic patients. These disappeared when iron therapy was instituted. More recently, Jasinski and Roth ${ }^{4}$ have reported marked success in the treatment with iron of non-anemic women complaining of fatigue, headache, dizziness, and palpitation. It has been observed frequently that iron-deficient patients characteristically show symptomatic improvement within a few days of the initiation of iron therapy. ${ }^{5-7}$ Yet no rise in the hemoglobin level has occurred by that time. Furthermore, the anemia of iron-deficient patients does not account for the changes in the fingernails

* This paper summarizes the contents of the following publications:

Iron Enzymes in Iron Deficiency. I. Cytochrome C. Am. J. Med. Sci., 234(5): 517-27 (November), 1957.

Iron Enzymes in Iron Deficiency. II. Catalase in Human Erythrocytes. J. Clin. Invest., 37(6):833-35 (June), 1958.

Iron Enzymes in Iron Deficiency. III. Catalase in Rat Red Cells and Liver with Some Further Observations on Cytochrome C. J. Lab. Clin. Med., 52(5):694-99 (November), 1958.

Iron Enzymes in Iron Deficiency. IV. Cytochrome Oxidase in Rat Kidney and Heart. Acta Haemat. (In press.)

Iron Enzymes in Iron Deficiency. V. Succinic Dehydrogenase in Rat Liver, Kidney and Heart. (Submitted to Blood.)

Iron Enzymes in Iron Deficiency. VI. Aconitase Activity of Rat Tissue and Citrate Metabolism in Man. (In preparation.) 
and esophagus that have frequently been described in this disorder.

Our clinical observations have in general been in harmony with the published reports of the earlier observers cited above. These observations do not fit well with the concept that hemoglobin is the only functionally important iron compound affected in iron deficiency. Rather, they are best explained as representing the results of tissue iron enzyme changes occurring in iron-deficient subjects.

For this reason, we have re-examined the state of some of the iron enzymes in iron deficiency. In reviewing the evidence supporting the widely quoted ${ }^{8-11}$ assertion of Hahn and Whipple ${ }^{1}$ that iron enzymes were unaffected by iron deficiency, we found that no iron enzymes had been measured by these investigators. Rather, their conclusions were based on the iron content of the ashed tissues of a single perfused dog. Since the amount of iron contributed by some of the very important iron enzymes is exceedingly minute, no valid conclusion about enzyme iron may be reached by this technique. For example, the cytochrome $\mathrm{c}$ iron in a gram of muscle is equivalent to the iron contained in $.006 \mathrm{ml}$ of blood. Apparently the earlier qualitative spectroscopic observations of Cohn and Elvejhem, ${ }^{12}$ suggesting that there might be a decrease in cytochrome $c$ of the tissues of iron-deficient rats, had been all but forgotten.

In the current investigations, iron deficiency has been produced in rats and the activity of a number of iron enzymes has been quantitated. A limited number of studies have been carried out on the erythrocytes and leucocytes of human subjects, and the metabolism of exogenously-administered citrate has been studied.

\section{MATERIALS AND METHODS}

Experimental animals: Holtzman or Sprague-Dawley rats were used throughout these investigations. In some experiments, male animals were used; in others, females. Threeweek-old rats were given a diet consisting of 96 parts of dried whole milk powder, and 4 parts of a Jones and Foster salt mix without iron sulfate. Vitamins were added to the diet to give, per $\mathrm{kg}$ : thiamine $\mathrm{HCl}, 10 \mathrm{mg}$; riboflavin, $20 \mathrm{mg}$; pyridoxine, $10 \mathrm{mg}$; Calcium Pantothenate, $30 \mathrm{mg}$; nicotinic acid, $30 \mathrm{mg}$; 2-methyl-1-4 naphthoquinume, $20 \mathrm{mg}$; choline chloride, $1.5 \mathrm{~g}$; and oleum percomorphum, $0.15 \mathrm{ml}$. Control animals were given an identical diet to which ferrous sulfate had been added, or were given an identical diet but were injected with $25 \mathrm{mg}$ of iron as iron-dextran (Imferon) in 2 divided doses. No difference was apparent in these 2 types of controls, and they are all designated "control rats." At appropriate intervals, animals were anesthetized with ether and exsanguinated by heart puncture. Organs were removed and placed in chilled vessels for enzyme assay. With the exception of catalase assays, which were carried out on frozen tissues, enzyme assay was initiated immediately after the animals were sacrificed.

Hematologic studies: Determinations of hemoglobin, hematocrit, and red blood values were made using standard hematologic techniques. Plasma iron determinations were carried out according to the method of Barkan and Walker. ${ }^{13}$ 


\section{Enzymes assays:}

Cytochrome c-Cytochrome c was determined spectrophotometrically by a modification of the method of Potter and DuBois. ${ }^{14}$ Cytochrome $c$ is extracted from tissue with trichloracetic acid at a $\mathrm{pH}$ of 3.5. After purification and concentration, the difference between the optical densities of the oxidized and enzymatically-reduced enzyme are measured. It was not possible to achieve satisfactory recoveries of added cytochrome $c$ with the method as originally described. Improved recoveries were achieved, however, by car rying out the entire extraction and concentration procedures in the cold and by re-extracting with trichloracetic acid the precipitate produced at $\mathrm{pH} 7$ in the purification process. Results are reported as $10^{-3} \mu \mathrm{M}$ of cytochrome $\mathrm{c}$, based on the known molar extinction coefficients of cytochrome c.

Catalase-Catalase activity was determined by permanganate titration of residual peroxide. ${ }^{15}$ Kat $\mathrm{F}$ units are used as described by Von Euler, but are based on tissue wet weight.

Succinic dehydrogenase (SDH) - Succinic dehydrogenase activity was determined by measuring manometrically the consumption of oxygen by a tissue homogenate with succinate supplied as substrate. ${ }^{16}$ Results are expressed as $\mathrm{QO}_{2}\left(\mu 1 \mathrm{O}_{2}\right.$ consumed/g dry weight of tissue).

Cytochrome oxidase-Cytochrome oxidase activity was measured spectrophotometrically by observing the decrease of the optical density at $550 \mathrm{~m} \mu$ of a solution of reduced cytochrome $\mathrm{c}$ when tissue extract was added. The method, as described originally, ${ }^{17}$ gave somewhat unsatisfactory results because of a change in the reactivity of the reduced cytochrome c substrate during the first few hours after its reduction with sodium hydrosulfite. This difficulty was overcome by readjusting the $\mathrm{pH}$ to 7.4 with sodium hydroxide after the reduction of cytochrome $c$ and by storing substrate for 12 hours in the cold room prior to its use.

In order to assay the cytochrome oxidase content of white blood cells, the bulk of red cells were removed by sedimentation at $4^{\circ} \mathrm{C}$ with fibrinogen. The supernatant plasma, containing the white cells was centrifuged, and the plasma was discarded. The sedimented white cells were disintegrated sonically in a Raytheon, 9-kilowatt sonic oscillator, then transferred to a $1-\mathrm{ml}$ volumetric flask. Duplicate $0.1-$ and $0.2-\mathrm{ml}$ aliquots were assayed for enzymatic activity. When assaying white blood cells for cytochrome oxidase, a blank determination to correct for the color of the hemoglobin included in the white cell suspension was necessary. However, red cells were found to contribute no enzymatic activity. Activity units are given as $\log \Delta$ O.D./min for 1:100 tissue dilution in the case of rat tissues. For human leucocytes, activity is expressed as $\Delta$ O.D. $/ \mathrm{min} / 10^{10} \mathrm{WBC}$.

Aconitase-Aconitase activity was measured by determining the amount of citrate produced when tissue homogenate was incubated with neutralized .01-molar cis-aconitic acid in .20-molar phosphate buffer, pH 7.40, at $37^{\circ} \mathrm{C}$. After 15 minutes, the reaction was stopped. In the case of kidney, liver, and heart homogenates, this was done by adding $1 \mathrm{ml}$ of the reaction mixture to $1 \mathrm{ml}$ of 50 per cent $\mathrm{H}_{2} \mathrm{SO}_{4}$. In the case of brain homogenate, 5 
$\mathrm{ml}$ of 20 per cent trichloracetic acid was added directly to the reaction mixture and filtrate was assayed for citric acid. The other homogenates were assayed for citrate directly after their addition to $\mathrm{H}_{2} \mathrm{SO}_{4}$. One unit of aconitase activity is defined as the amount that will produce $10^{-7}$ moles of citrate/minute in the $5-\mathrm{ml}$ reaction mixture under the conditions described. Enzymatic activity was always measured at 2 tissue concentrations, one grcater than 1 unit, one less than 1 unit. An approximate linear relationship was observed between quantity of tissue added and citrate produced (Figure 1). Citrate determinations were carried out by the pentabromacetone method described by Beutler and Yeh. ${ }^{18}$

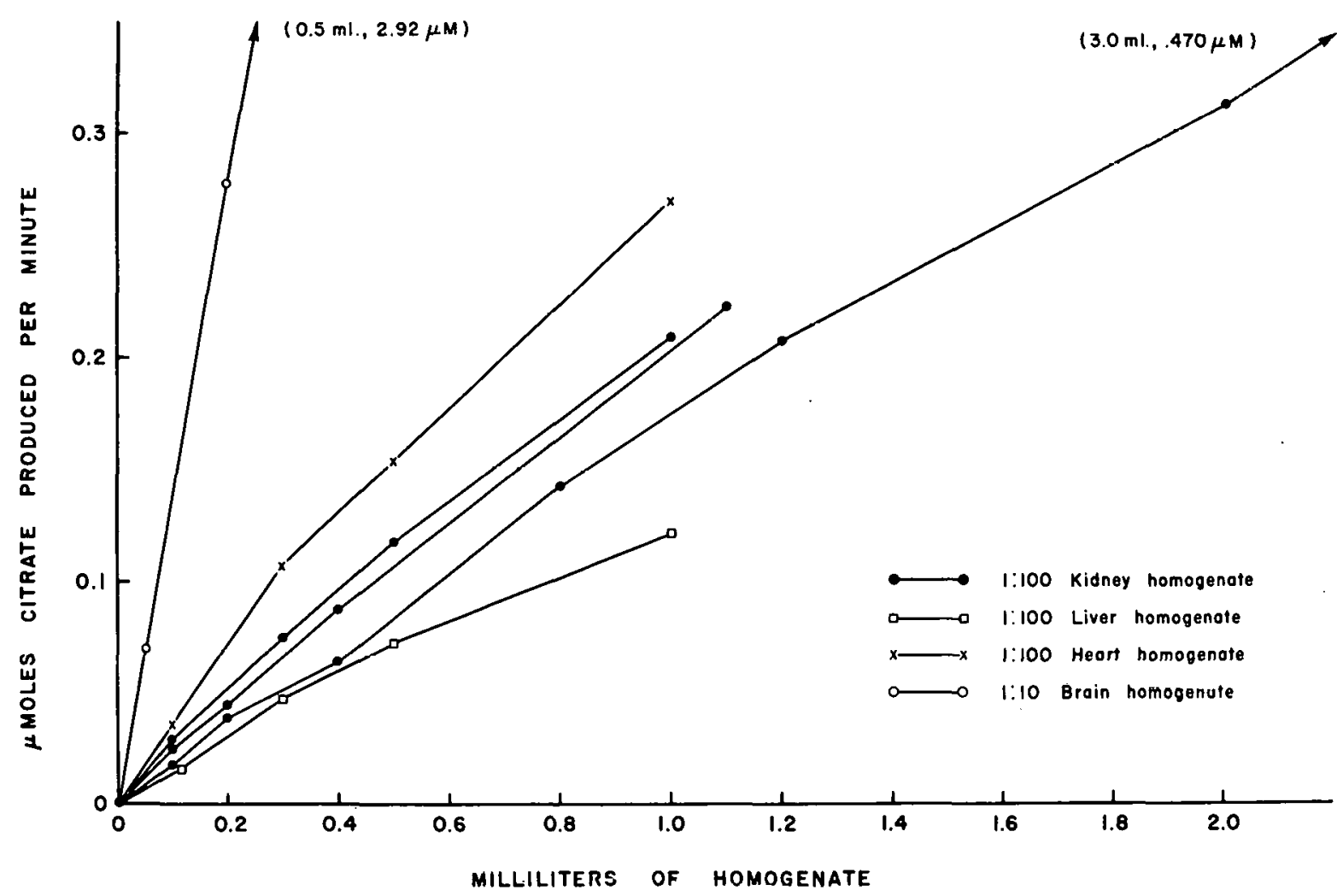

Figure 1. The assay for aconitase-the relationship between volume of homogenate and $\mu \mathrm{M}$ aconitate converted to citrate.

\section{EXPERIMENTAL}

Cytochrome c: The concentration and total amount of cytochrome $c$ in the kidneys of iron-deficient and control rats were determined at intervals. The average values, along with hemoglobin, hematocrit, red blood count, and plasma iron data are presented in Figure 2. The standard error of each mean is given.

Iron deficiency has also been produced by repeatedly bleeding rats fed an iron-poor, otherwise balanced diet (a modification of Wissler's ${ }^{19} 4 \mathrm{C}$ diet). Control animals were bled in an identical fashion, but the diet was supplemented with iron sulfate. Under these conditions, it was possible to demonstrate marked cytochrome c depletion even when the 


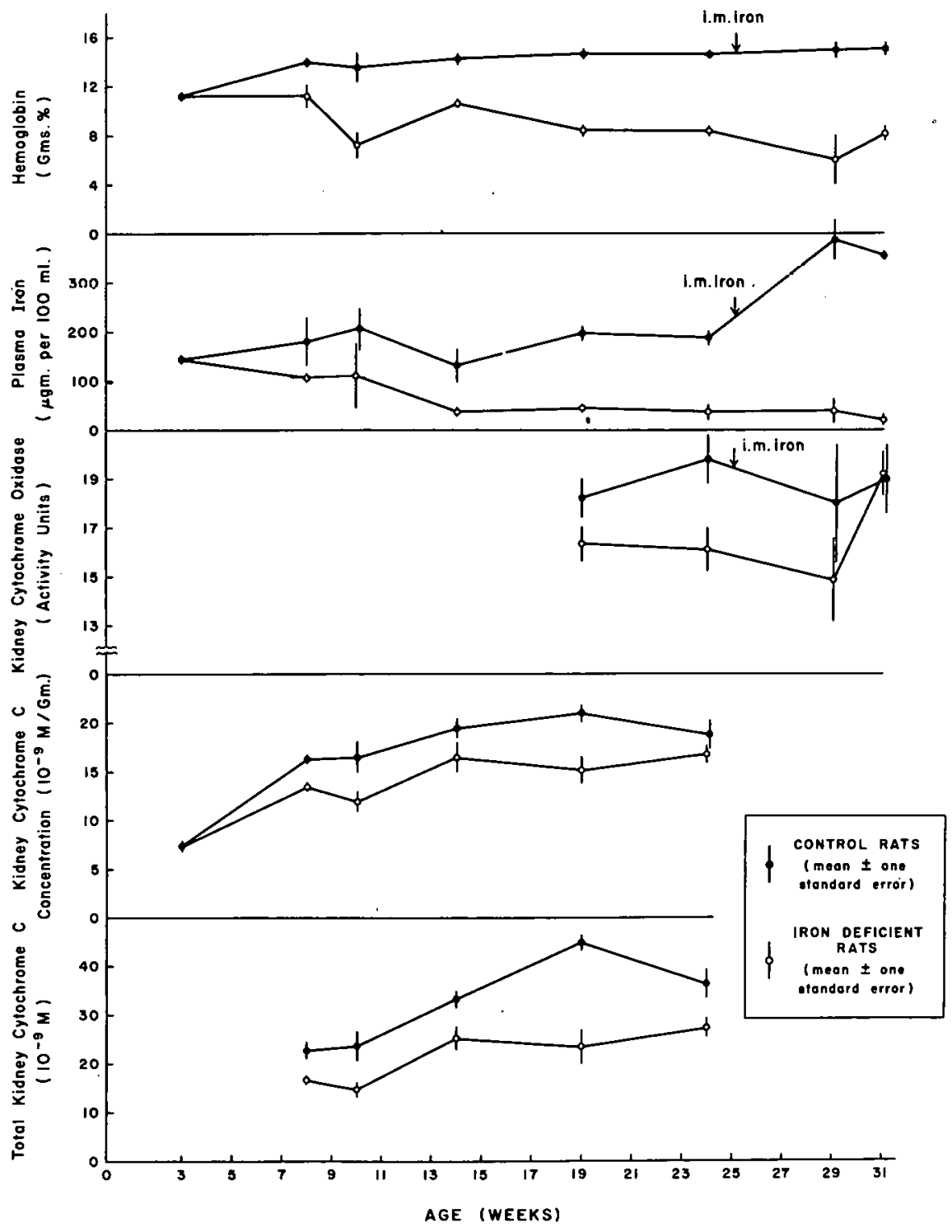

Figure 2. Kidney cytochrome c and cytochrome oxidase in iron-deficient and control rats.

hemoglobin levels were normal or nearly normal (Figures 3 to 8 ).

Cytochrome oxidase: The cytochrome oxidase activity of the kidneys of iron-deficient and control rats has been measured. The mean values obtained in one experiment are also illustrated in Figure 2, and further experimental results are given in Figure 9. The difference observed is somewhat smaller than was the case with cytochrome c. There was also considerable overlap of individual values obtained from iron-deficient and normal animals.

The results of determinations of cytochrome oxidase activity on white cells from normal and iron-deficient human subjects are shown in Figure 10. The average cytochrome oxidase activity of white cells from iron-deficient subjects was reduced but there was con- 


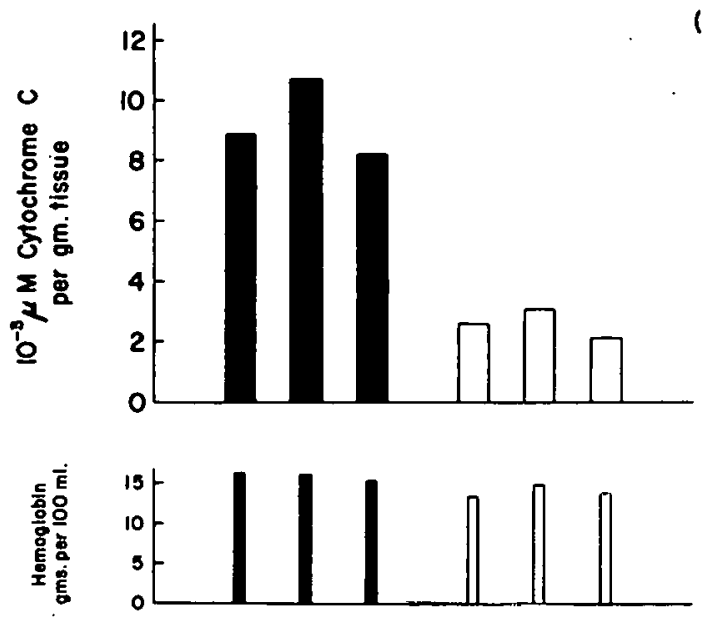

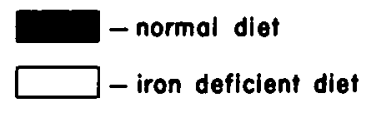

Figure 3. Concentration of cytochrome $c$ in the liver of six bled rats receiving normal and iron-deficient diets.

(EXPERIMENT 1)

Figure 4. Concentration of cytochrome $c$ in the kidneys of six bled rats receiving normal and iron-deficient diets.
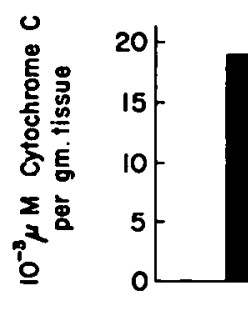

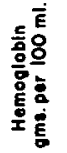

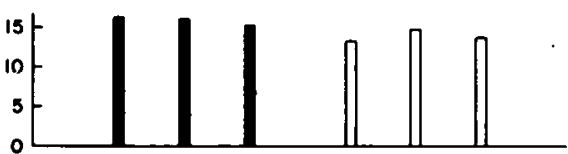

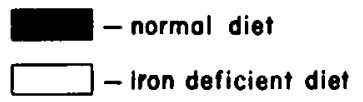

(EXPERIMENT 2)

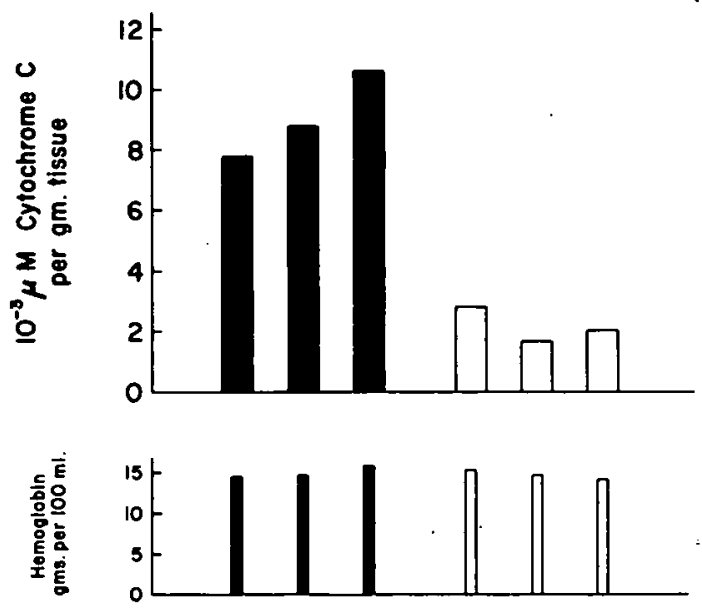

- normal diet - Iron deficient diet
Figure 5, Concentration of cytochrome $c$ in the liver of six bled rats receiving normal and iron-deficient diets. 


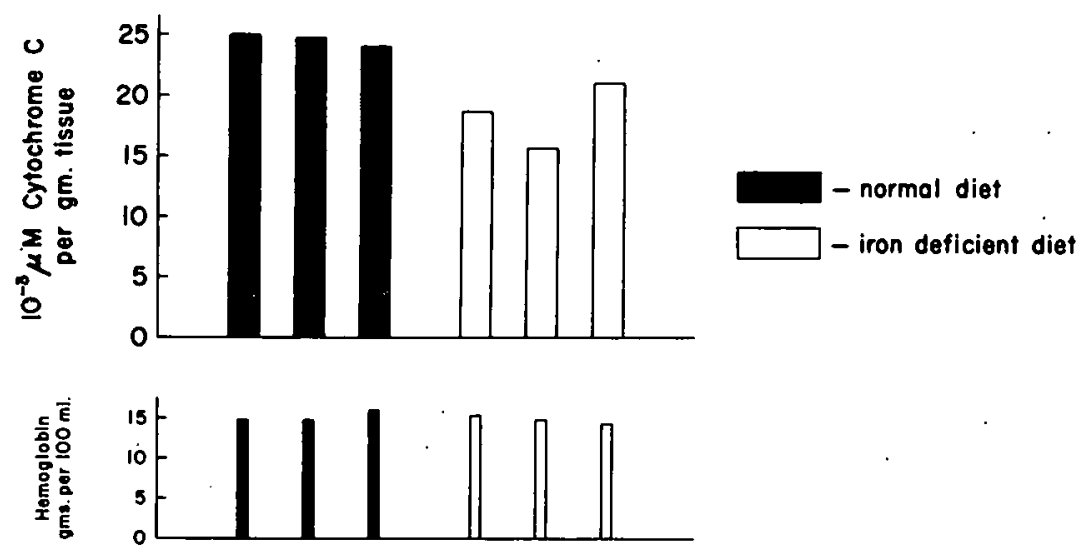

Figure 6. Concentration of cytochrome $c$ in the kidneys of six bled rats receiving normal and iron-deficient diets.

Figure 7. Total liver cytochrome $c$ of six bled rats receiving normal and irondeficient diets.

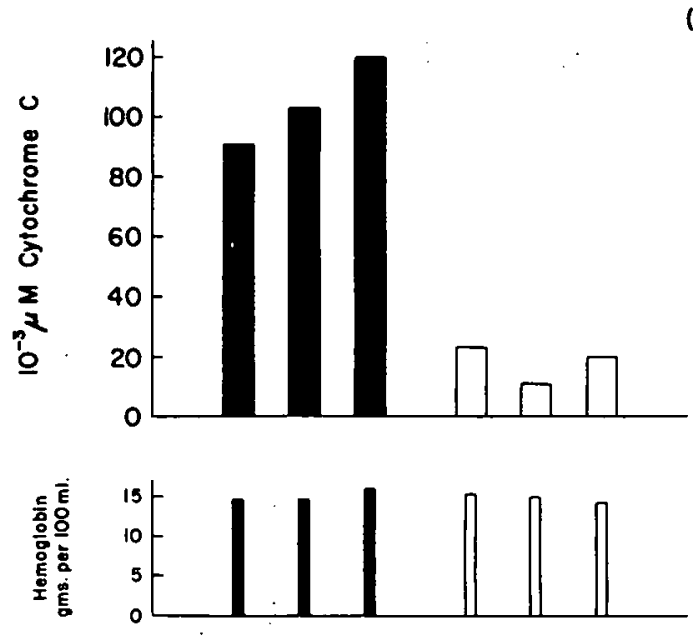

(EXPERIMENT 2)

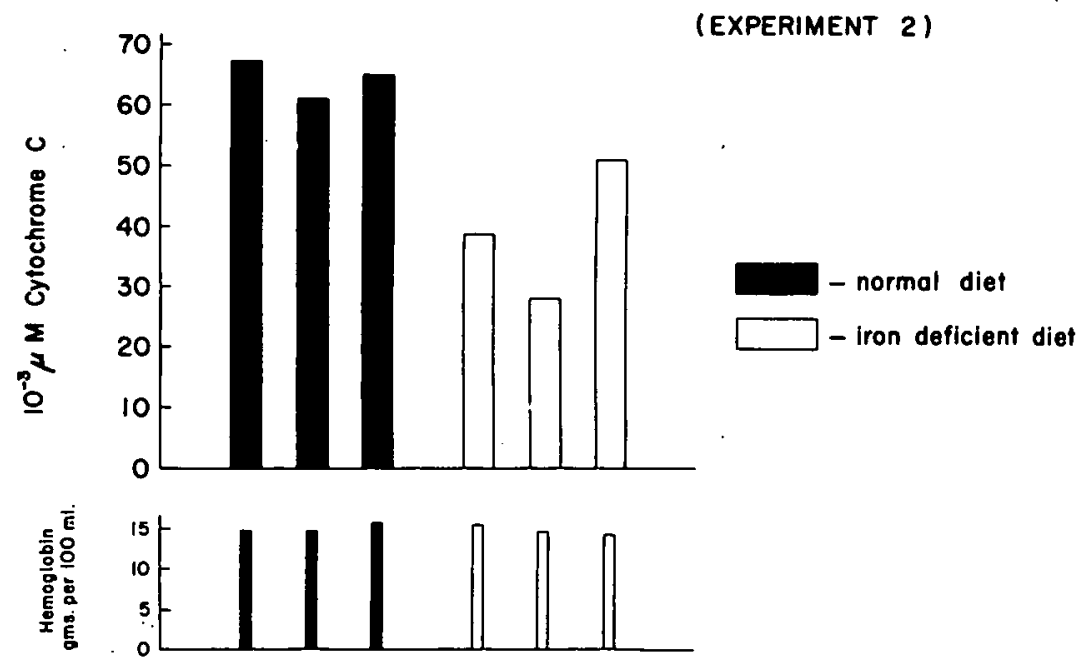

Figure 8. Total kidney cytochrome c of six bled rats receiving normal and irondeficient diets. 
siderable overlap of individual values.

Catalase: No difference could be observed in the catalase activity of human red cells from iron-deficient and normal subjects, as indicated in Figures 11 to 16. Data summarized in Figures 17 to 20 indicate no significant difference between catalase activity of rat red cells or rat liver from iron-deficient and control animals. Marked hypoferremia was present in the iron-deficient group, but body weight was normal.

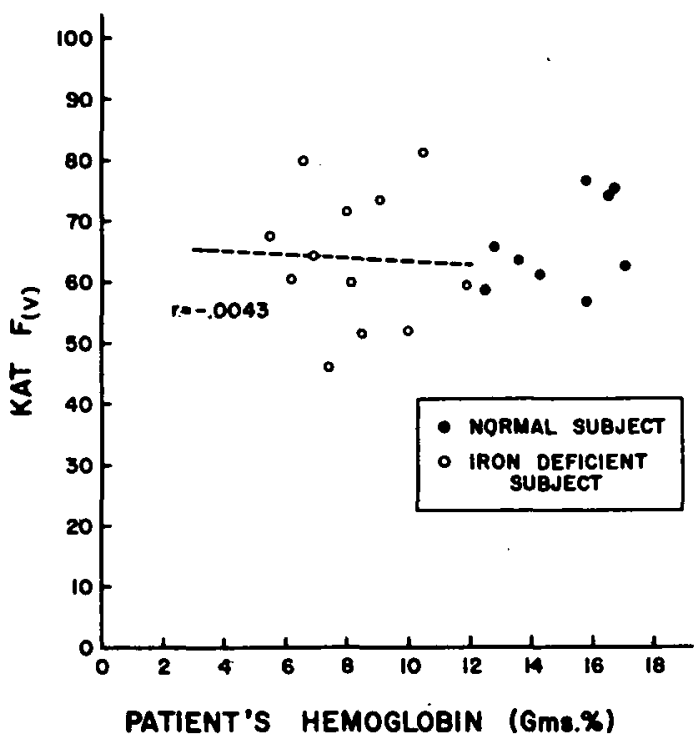

Figure 11. The relationship between the patient's hemoglobin level and catalase activity per milliliter of red cells.
Fig'ure 12. Average catalase activity of red cells of normal and iron-deficient patients.

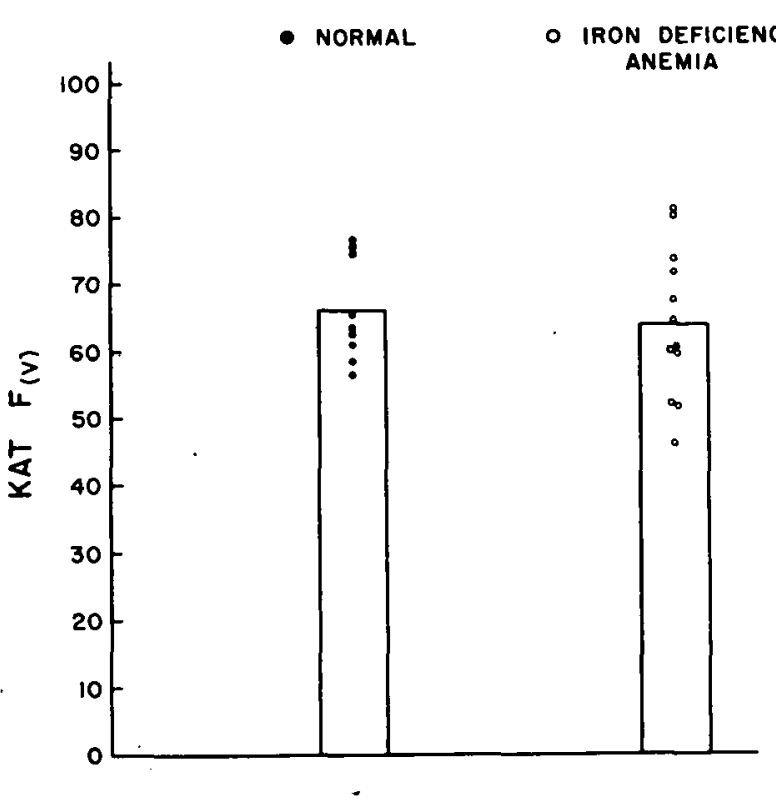




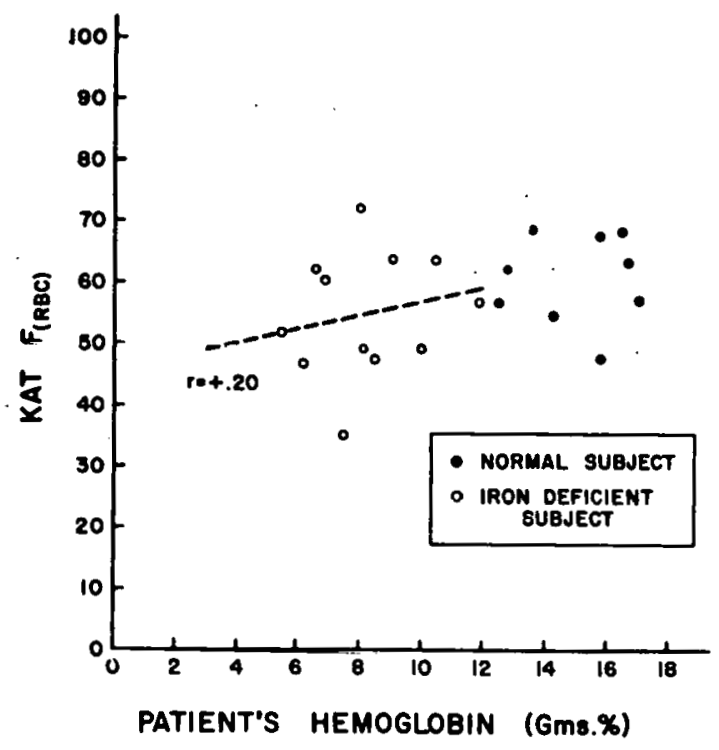

Figure 13. The relationship between the patient's hemoglobin level and catalase activity per $10^{10} \mathrm{RBC}$.
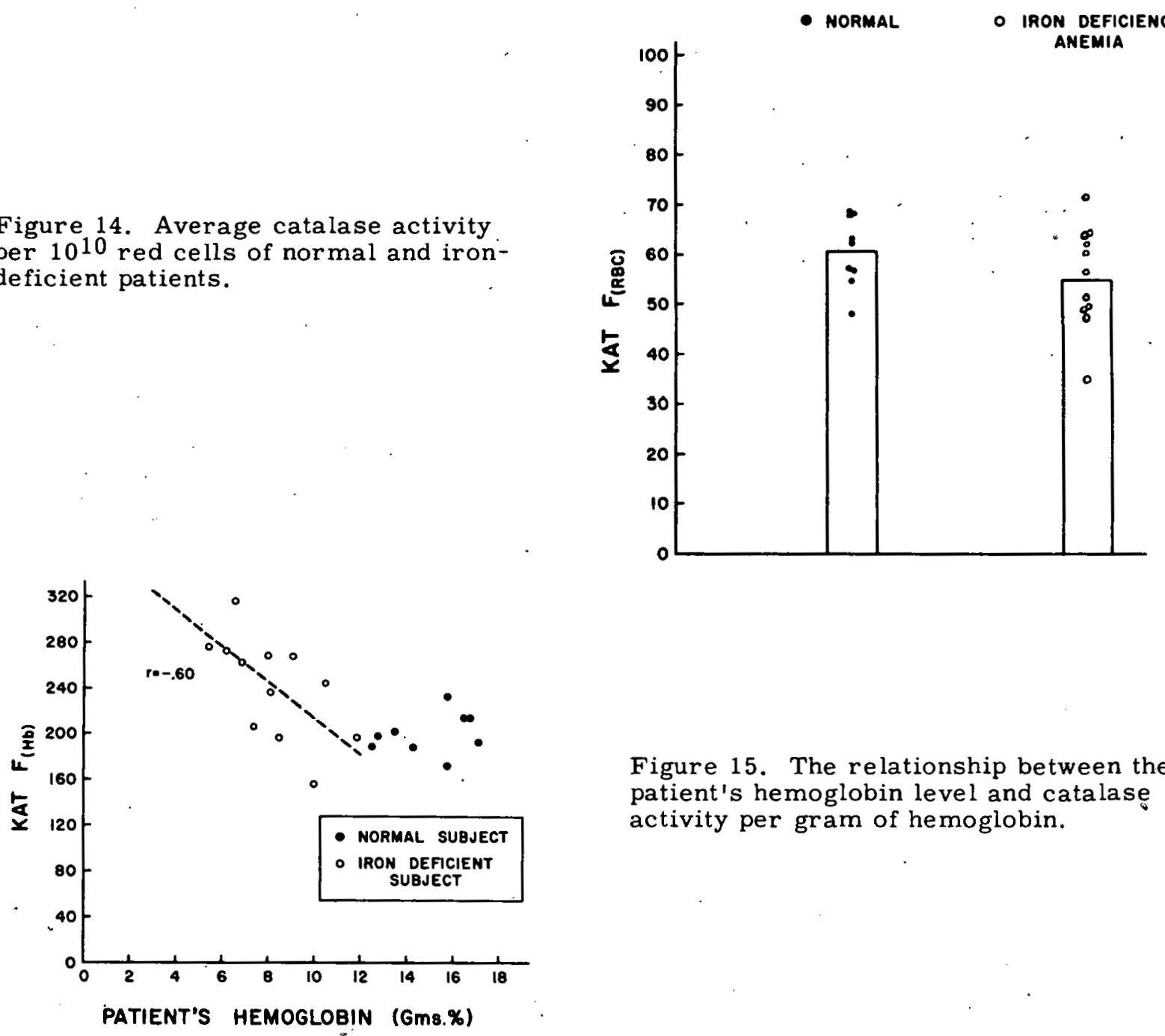

Figure 15. The relationship between the patient's hemoglobin level and catalase activity per gram of hemoglobin. 


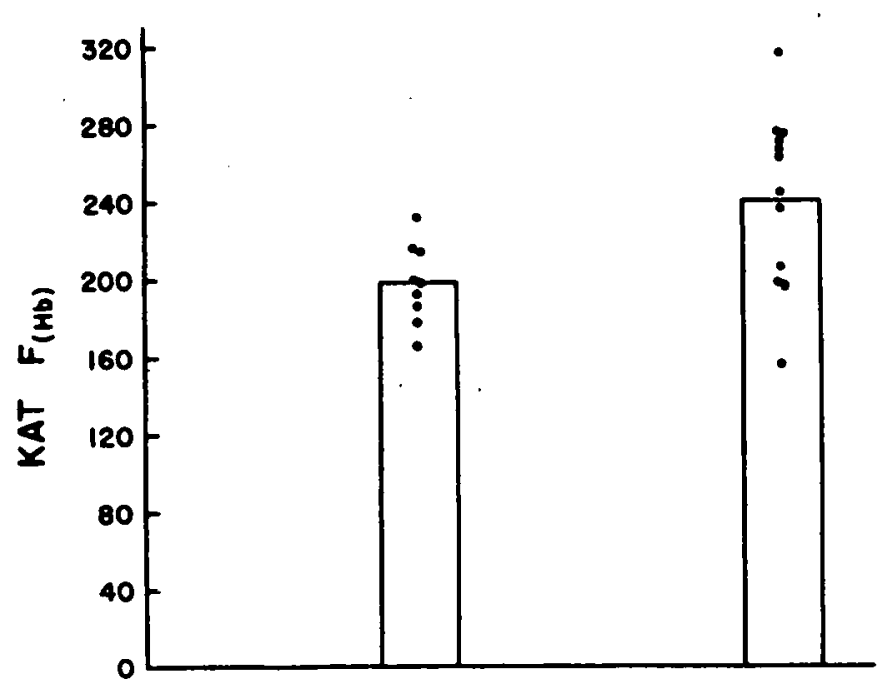

Figure 16. Average catalase activity per gram of hemoglobin of normal and irondeficient patients.

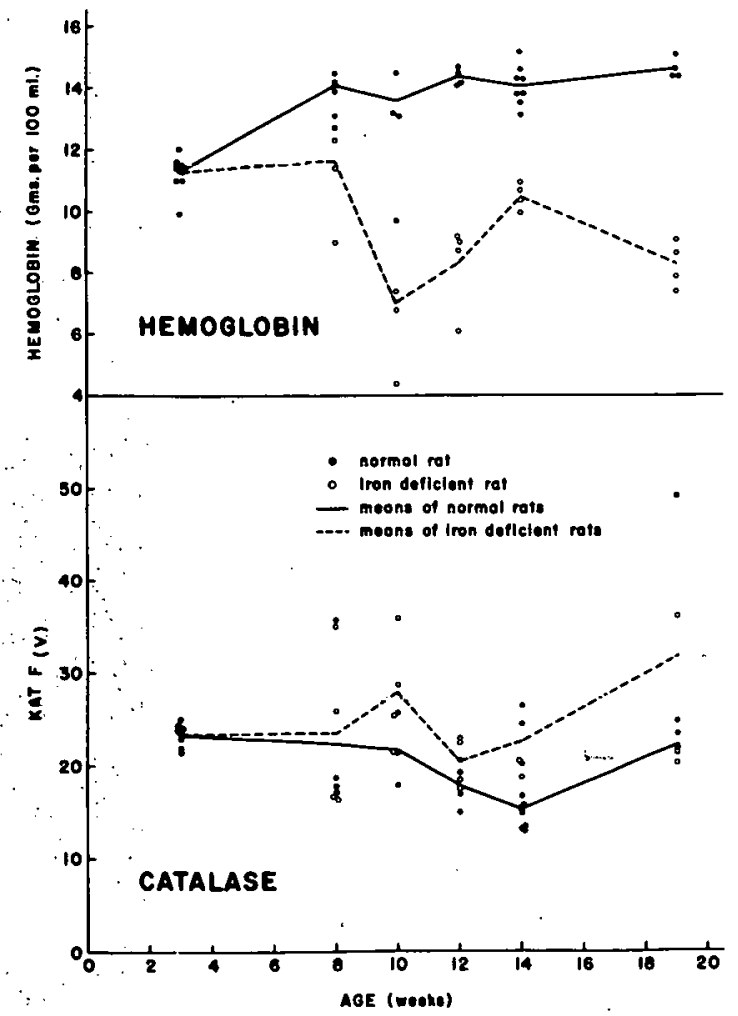

Figure 17. Red cell catalase activity per milliliter of red cells in normal and iron-deficient rats.

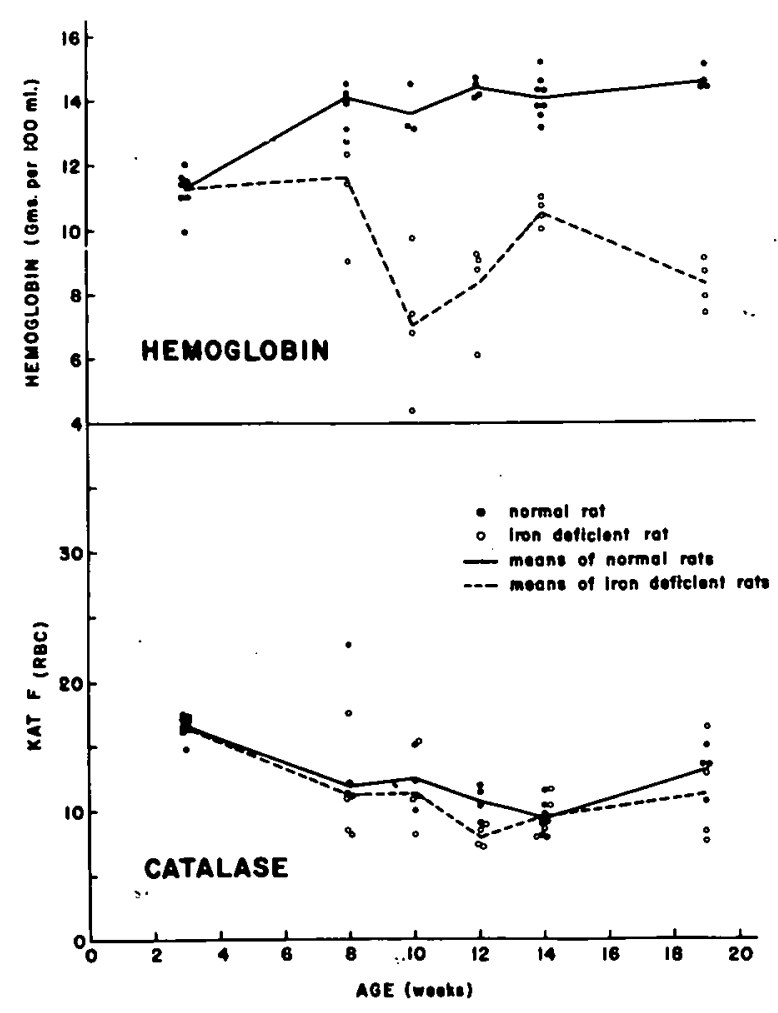

Figure 18. Red cell catalase activity per $10^{10} \mathrm{RBC}$ in normal and irondeficient rats. 


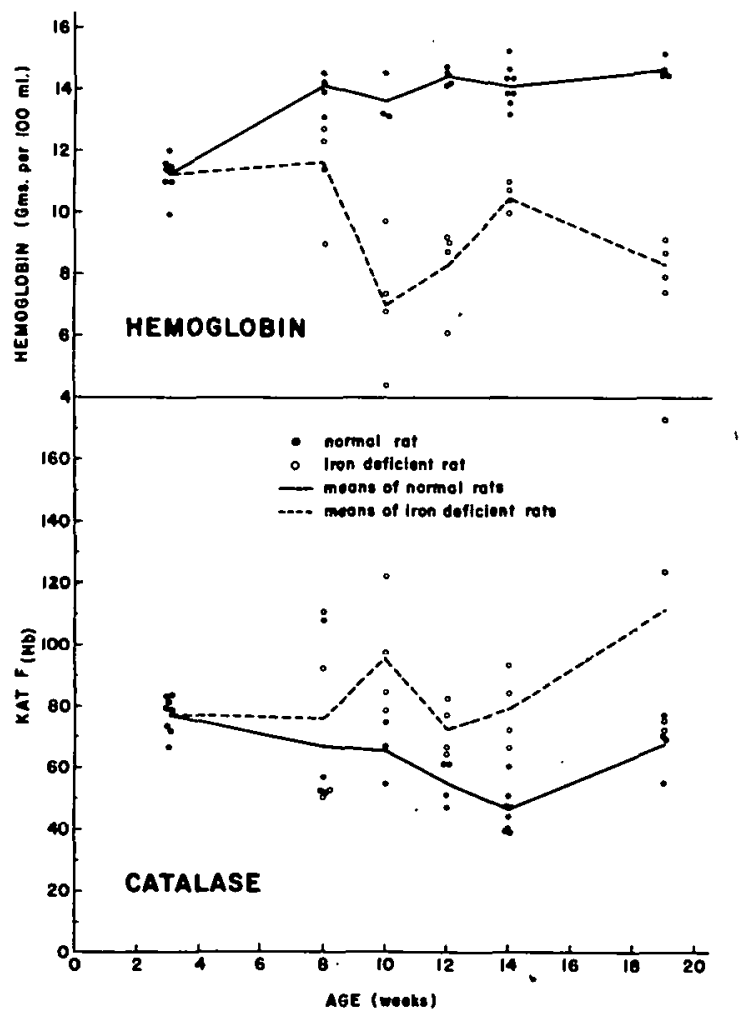

Figure 19. Red cell catalase activity per gram of hemoglobin in normal and iron-deficient rats.

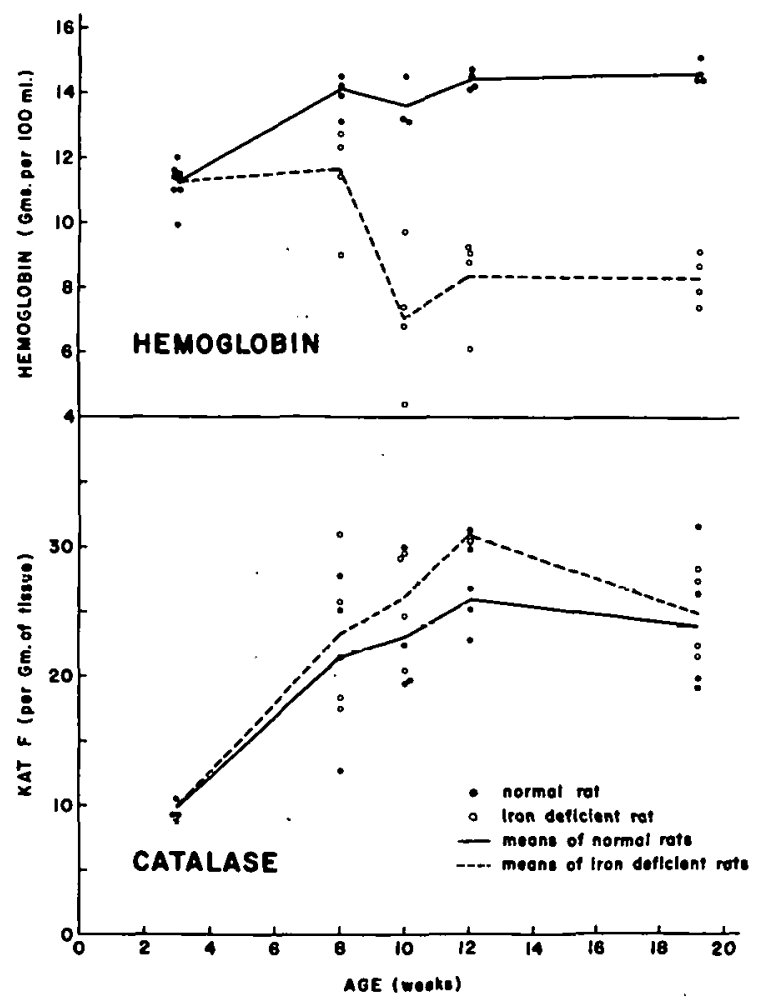

Figure 20. Liver catalase in normal and iron-deficient rats.

Succinic dehydrogenase (SDH): Figures 21 to 23 show the average $Q_{O_{2}}$ (oxygen consumption/g tissue dry weight) obtained in the assays of the livers, hearts, and kidneys of iron-deficient and normal rats for succinic dehydrogenase activity. It is evident that no consistent difference in activity of this enzyme exists between the liver tissue of the two groups. However, when heart and kidney tissue were assayed for SDH activity, a small, but fairly consistent reduction of SDH activity was noted. Plasma iron determinations showed a consistent decrease in the iron-deficient group, but body weights were the same in iron-deficient and control animals.

Aconitase: Unlike the four other enzymes studied, aconitase is not known to be an iron-containing enzyme. It has been demonstrated, however, that the aging or dialysis of solutions of this enzyme results in marked loss of activity and that activity can be restored by the addition of iron and a reducing agent. Iron exerts a specific action in producing reactivation of aconitase since other metallic ions will not produce the same effect. ${ }^{20}$ It appears likely, therefore, that iron represents some type of loosely-bound co-factor of aconitase which diffuses away from the enzyme in dilute solution. ${ }^{21}$

We have been able to confirm readily the observation that iron reactivates aconitase solutions. We found that merely incubating dilute rat-kidney aconitase at $37^{\circ}$ for 1 hour 


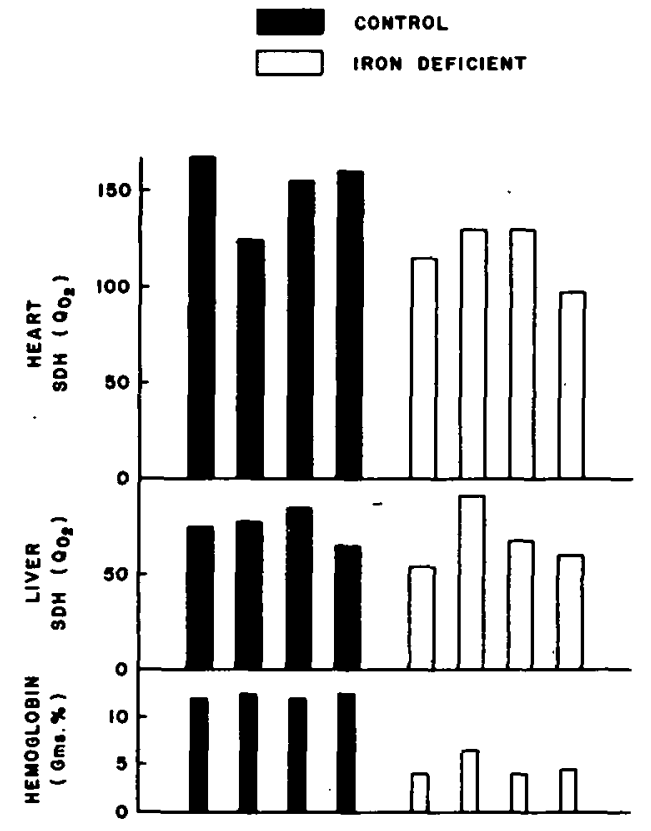

Figure 21. SDH activity of liver and hearts of iron-deficient and control rats. Duration of deficiency state: 8 weeks.

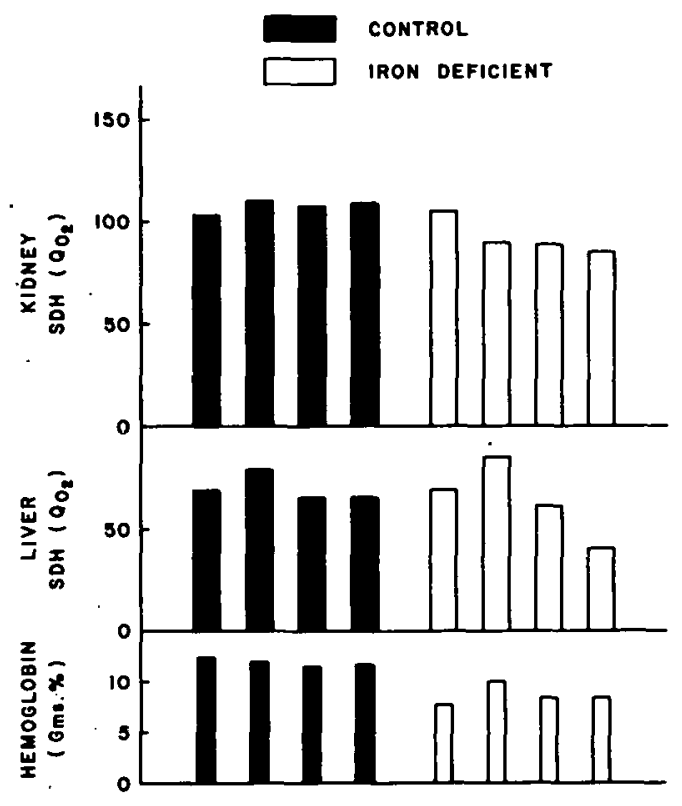

Figure 22. SDH activity of liver and kidneys of irondeficient and control rats. Duration of deficiency state: 4 weeks.

was sufficient to inactivate 70 to 80 per cent of the enzyme in this time. The addition of iron and ascorbic acid to give a final concentration of .003 molar of each was sufficient to produce almost complete reactivation of the enzyme within a short period of time (Figure 24). The effect of .005 molar concentrations of iron and ascorbate was more consistently effective. Neither iron alone nor ascorbate alone produced reactivation.

The aconitase activity of liver, heart, brain, and kidneys of iron-deficient and control rats is presented in Figures 25 to 28. It is apparent that normal or nearly normal levels of aconitase activity were maintained in all organs except the kidney in which there was a consistent decrease in aconitase activity.

It appeared possible that the decreased aconitase activity in this organ might be due to "co-factor lack," if iron represented aconitase co-factor, as has been suggested by Dickman and Cloutier. ${ }^{21}$ An attempt, therefore, was made to reactivate the kidney aconitase of iron-deficient animals by the addition of iron and ascorbic acid in a final concentration of .003 molar. As indicated in Figure 29, no reactivation could be demonstrated. Normal kidney homogenate or normal kidney homogenate inactivated by boiling for 5 minutes, heating to $60^{\circ} \mathrm{C}$ for 30 minutes, or to $37^{\circ} \mathrm{C}$ for 2 hours failed to reactivate iron-deficient kidney.

Our studies of kidney aconitase activity have been extended to demonstrate also the effect of treatment on the aconitase content of the kidneys of iron-deficient animals. Irondeficient animals were treated by intragastric injection of ferrous sulfate to give $1 \mathrm{mg}$ of 


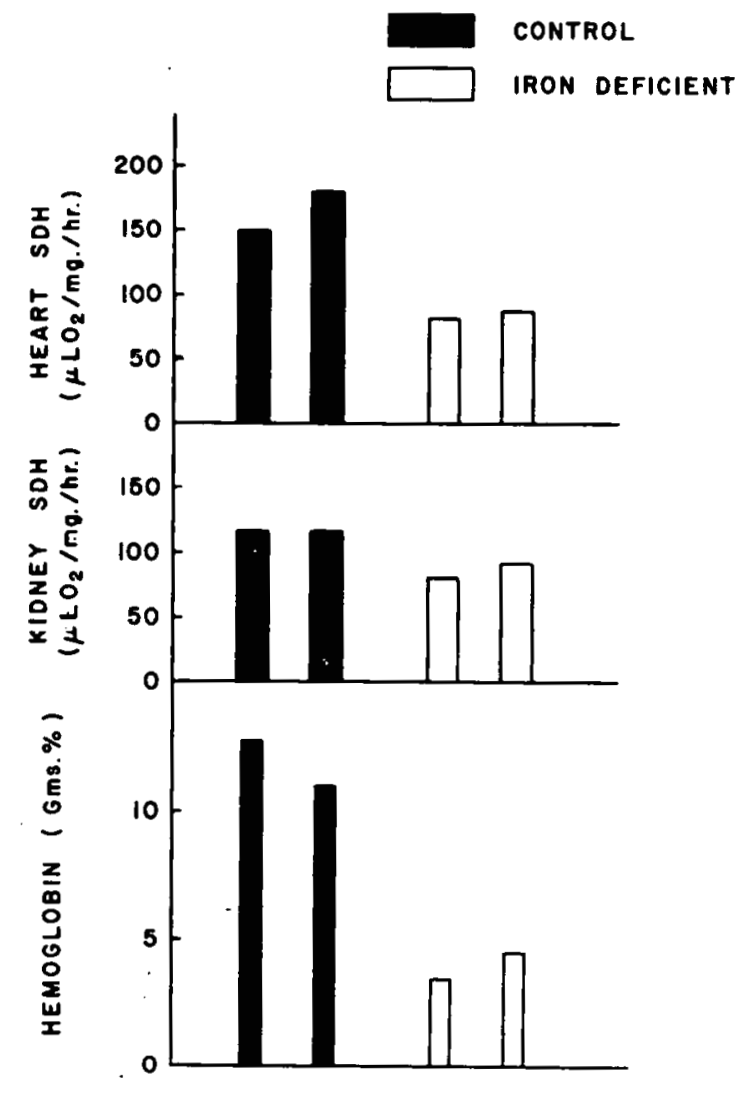

Figure 23. SDH activity of heart and kidneys of iron-deficient and control rats.

Duration of deficiency state: 12 weeks.

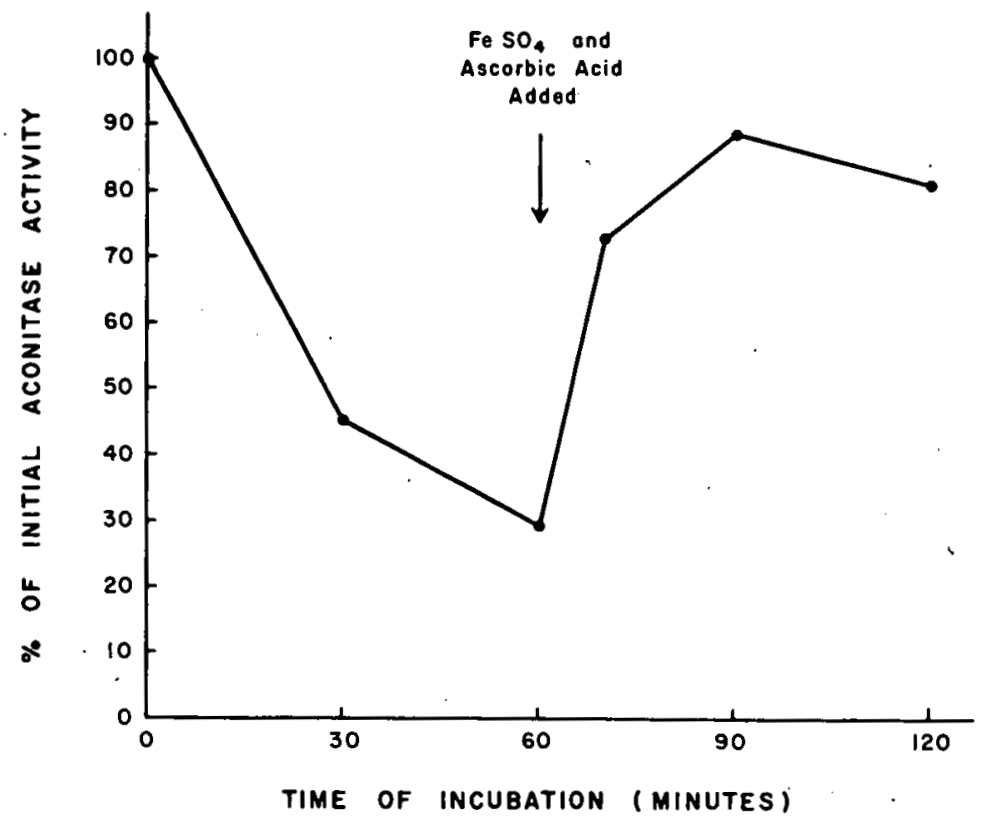

Figure 24. The reactivation of aconitase by $\mathrm{Fe}^{++}$and ascorbic acid, each $.003 \mathrm{M}$. 


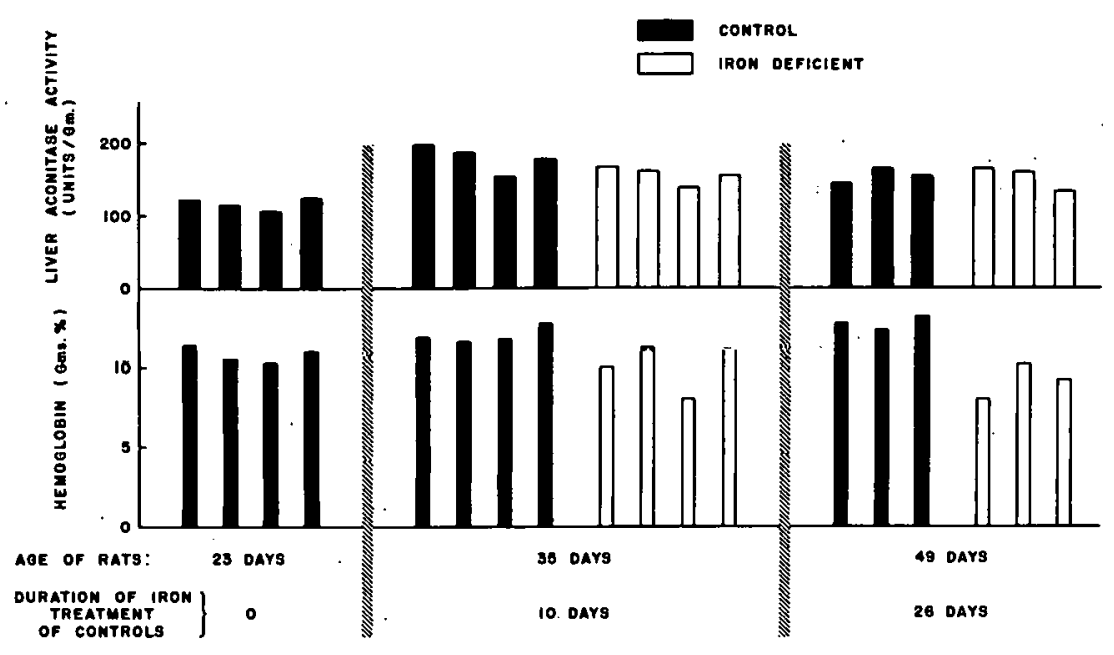

Figure 25. The aconitase activity of livers of irondeficient and control rats.

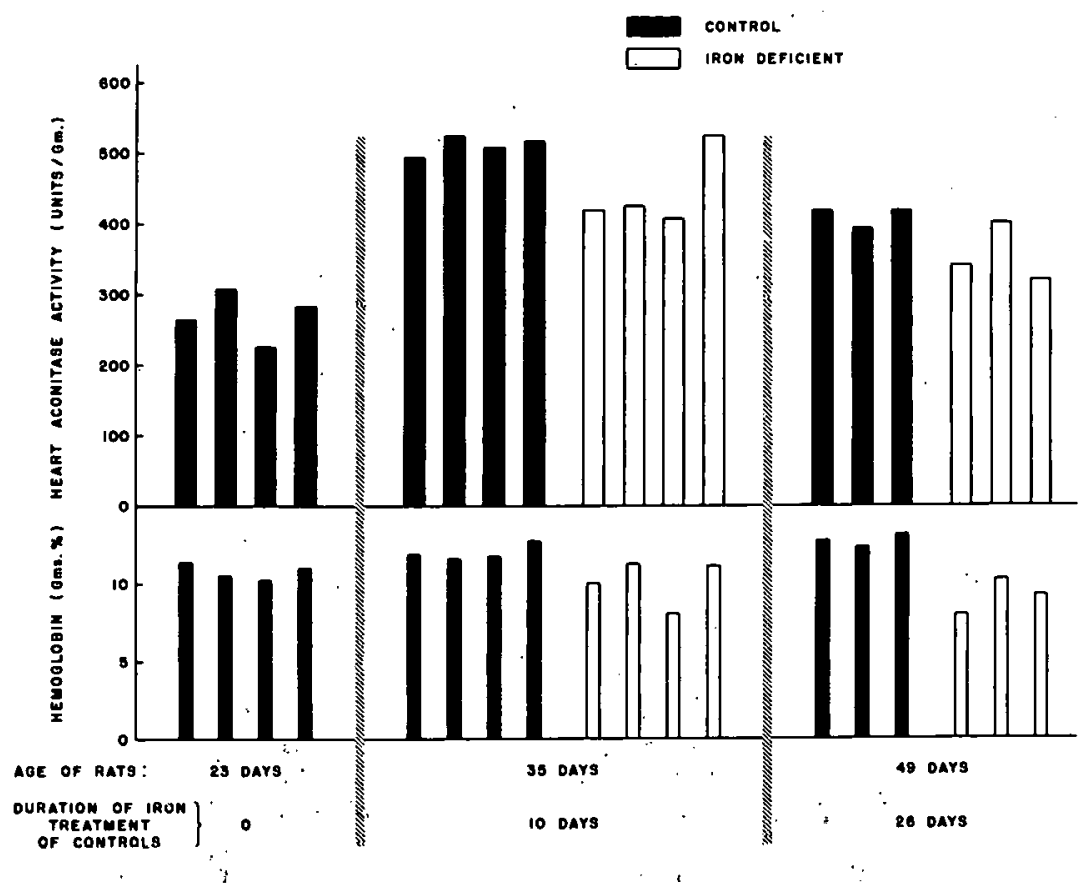

Figure 26. The aconitase activity of hearts of irondeficient and control rats.

iron daily, 5 days a week for 1 week; then $2 \mathrm{mg}$ daily for 5 days a week for 6 additional weeks. The results of this experiment are shown in Figure 30.

In a second experiment, $2 \mathrm{mg}$ of $\mathrm{Fe}$ were given daily to the treatiment group (Figure 31 ). Both of these studies demonstrate that aconitase activity returned toward normal when iron-deficient animals were treated with iron. 


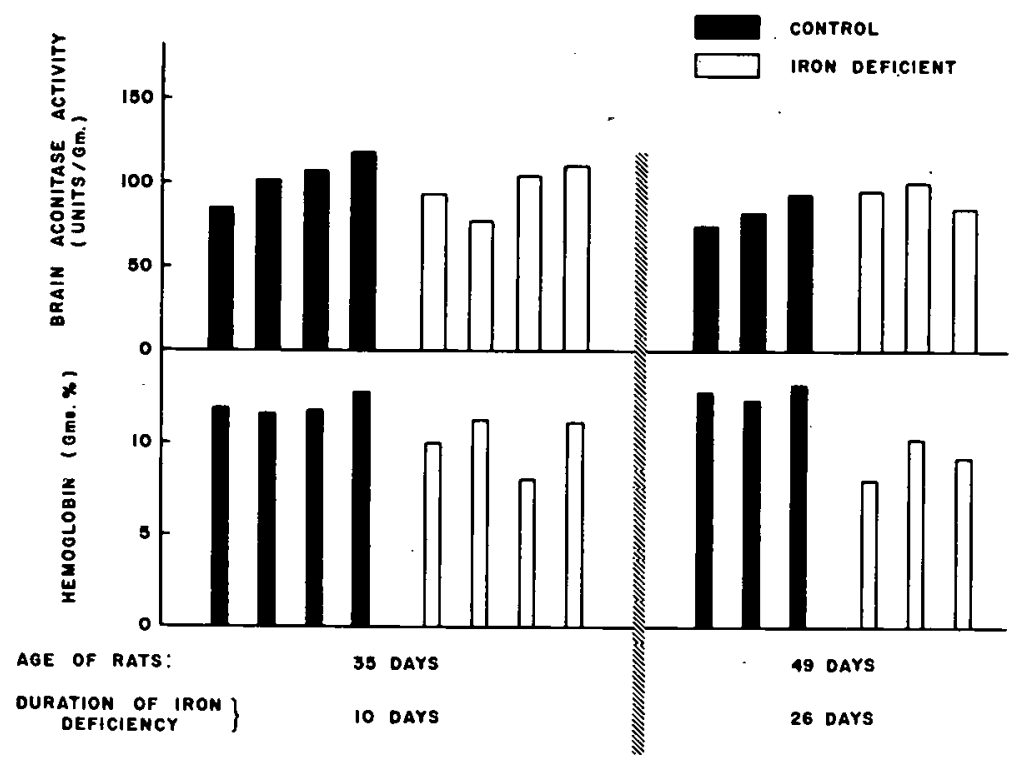

Figure 27. The aconitase activity of brains of irondeficient and control rats.

Because aconitase is known to be intimately involved in intracellular citrate metabolism, studies were carried out to determine whether exogenously-administered citrate was metabolized differently by iron-deficient and by normal subjects.

Six iron-deficient and three control subjects have been studied after the administration of $130 \mathrm{mg}$ of disodium hydrogen citrate per kilogram body weight. Plasma and urine citrate levels were measured before ingestion of the loading dose and at subsequent intervalis (Figure 32 ). In one mildly iron-deficient subject with high urinary citrate excretion,

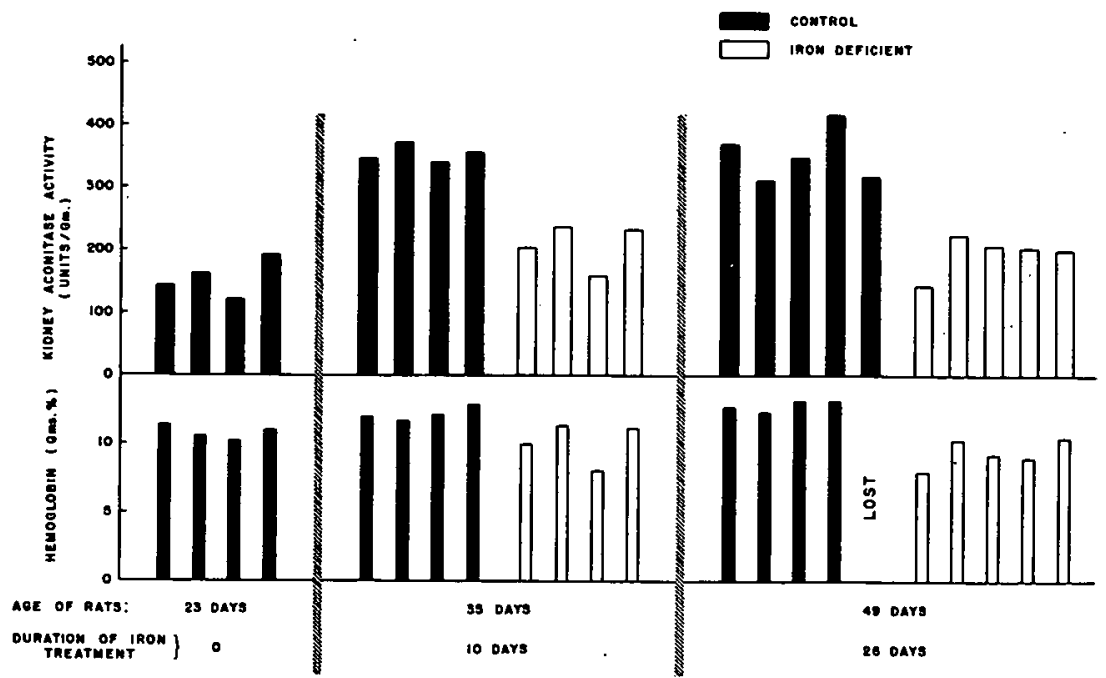

Figure.28. The aconitase activity of kidneys of irondeficient and control rats. 


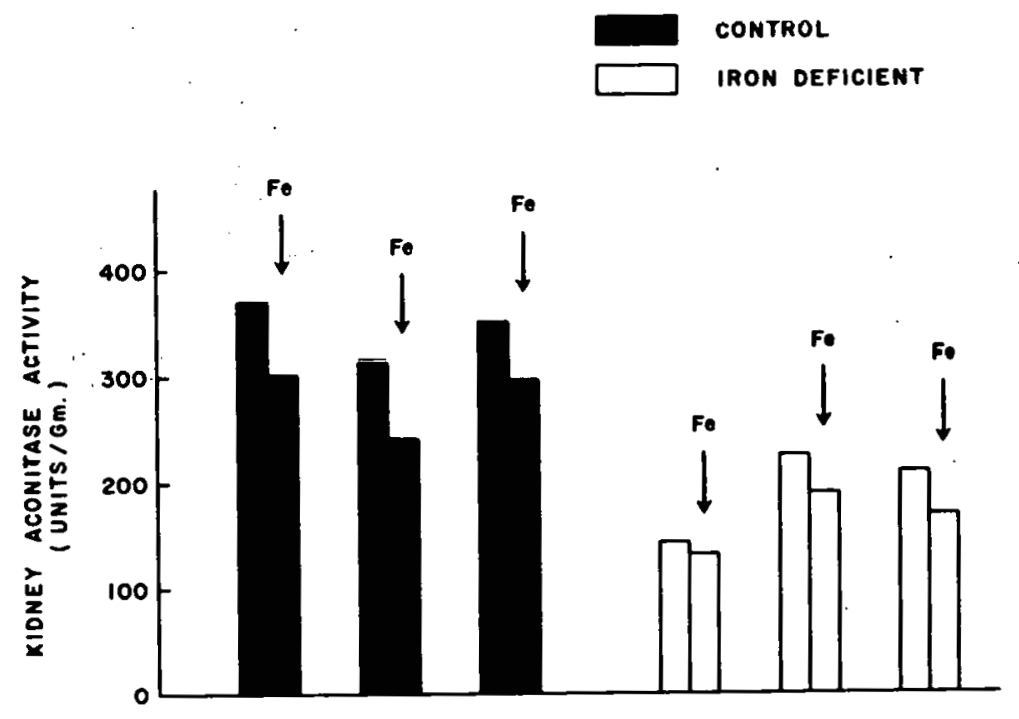

Figure 29. The in vitro effect of $\mathrm{Fe}^{++}$and ascorbic acid, each $.003 \mathrm{M}$, on aconitase activity of the kidneys of iron-deficient and control rats.
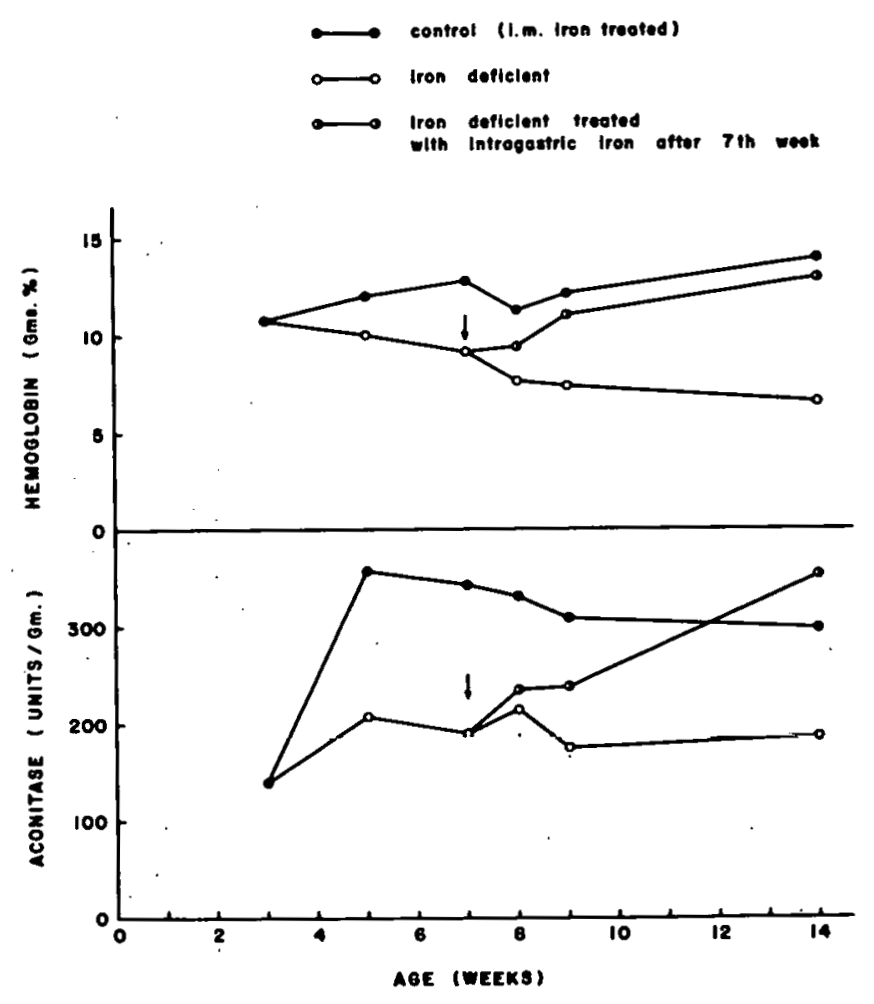

Figure 30. The effect of intragastric treatment with 1 to $2 \mathrm{mg}$ iron daily on the average blood hemoglobin levels and average aconitase content of kidneys of iron-deficient rats. 


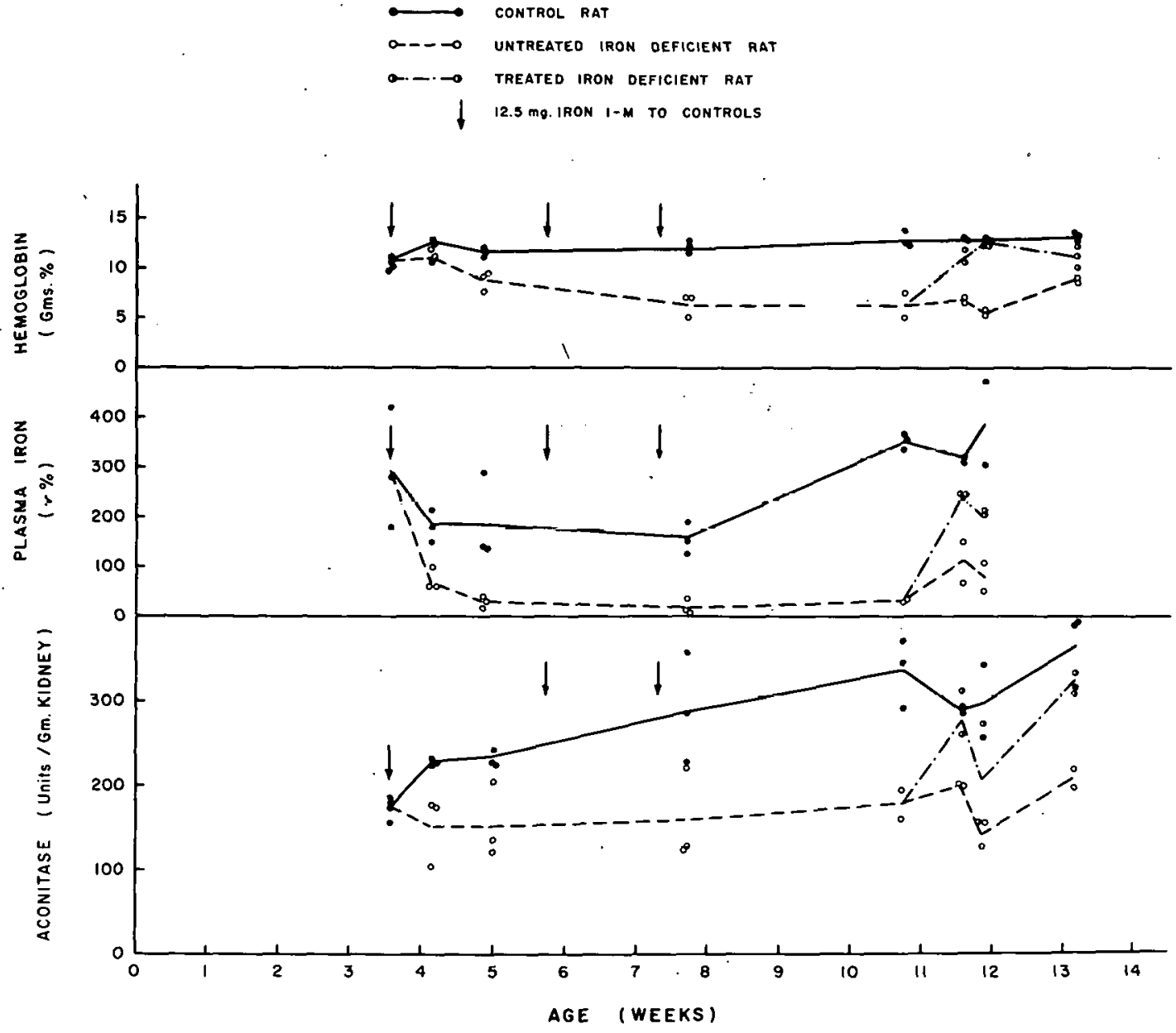

Figure 31. The effect of intragastric treatment with $2 \mathrm{mg}$ iron on the kidney aconitase activity of iron-deficient rats.

repeated measurements were made of six-hour urinary citrate excretion following standard loading, both before and after iron therapy (Figure 33). No consistent abnormality of metabolism of exogenously-administered citrate could be demonstrated in these studies.

\section{DISCUSSION}

It is apparent from the data presented that each iron enzyme must be considered individually. Catalase, at least in the organs examined, appears resistant to depletion, even when the need for iron is great. Cytochrome $\mathrm{c}$ and cytochrome oxidase, on the other hand, are reduced in concentration in iron-deficiency anemia in those organs studied. The results obtained with aconitase and succinic dehydrogenase demonstrate that not only must each enzyme be considered as an individual case, but also each or gan. The decrease of cytochrome $\mathrm{c}$ and aconitase in kidneys and SDH in kidneys and hearts of iron-deficient rats was found to be statistically significant at the .01 level; the decrease in kidney cytochrome oxidase was significant at the .05 level. 


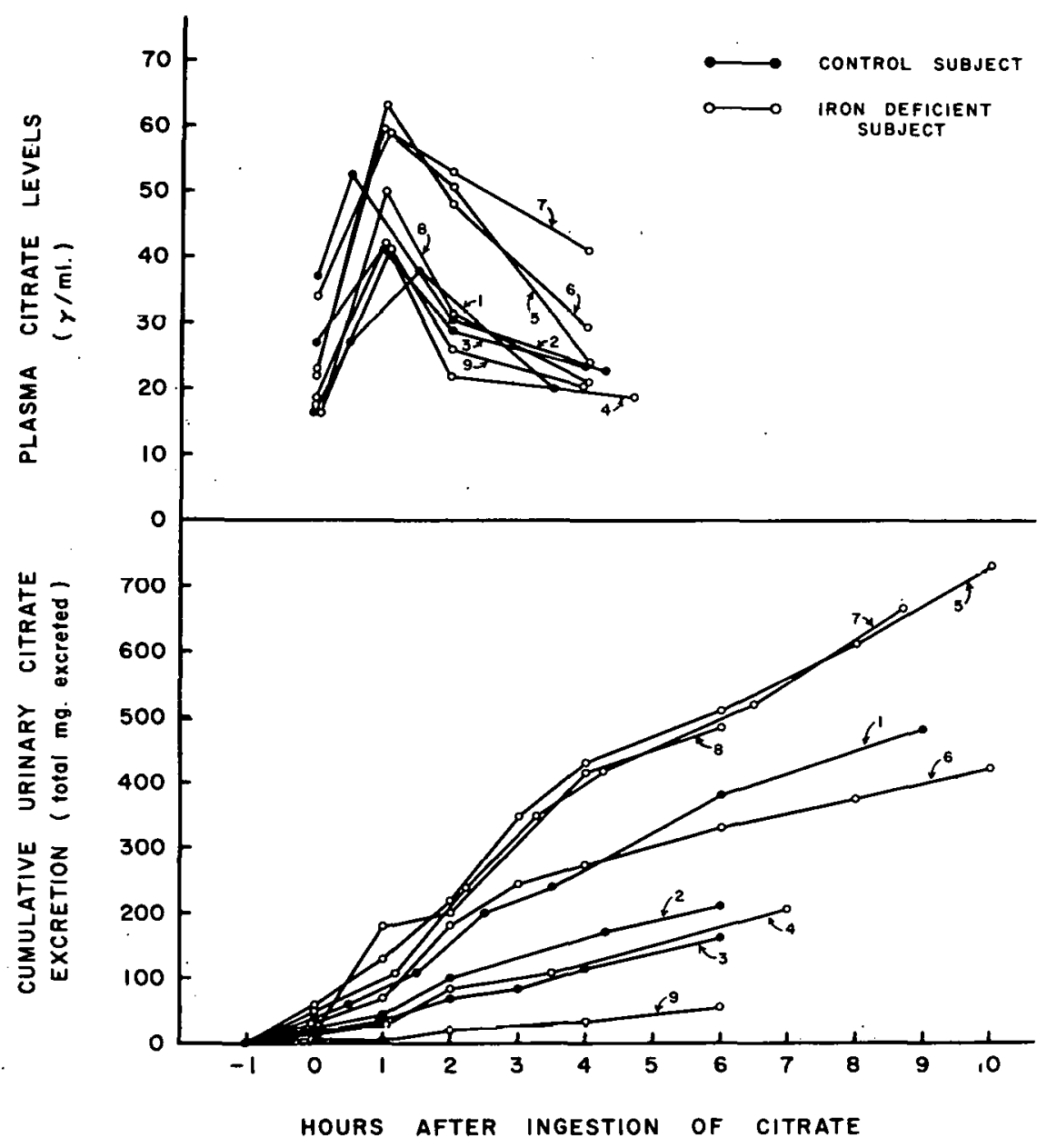

Figure 32. The effect of oral citrate loading and plasma citrate levels on urinary citrate excretion.

The data presented do not permit us to conclude that the symptoms of iron-deficiency anemia are the result of a particular enzyme deficiency alone any more than one may justifiably conclude that the symptoms of iron-deficiency anemia are due to a decrease in hemoglobin alone. The results of these studies clearly indicate, however, that the concentration of iron compounds other than hemoglobin are affected in iron deficiency. The irondeficiency state may therefore justifiably be regarded as a deficiency syndrome potentially capable of influencing function of tissues other than the blood.

\section{SUMMARY}

Clinical observations that suggest that iron-containing compounds other than hemoglobin may be affected in cases of iron deficiency are reviewed.

Iron deficiency has been produced in rats by means of an iron-poor diet consisting of milk with added vitamins and minerals. A consistent decrease in the cytochrome content 


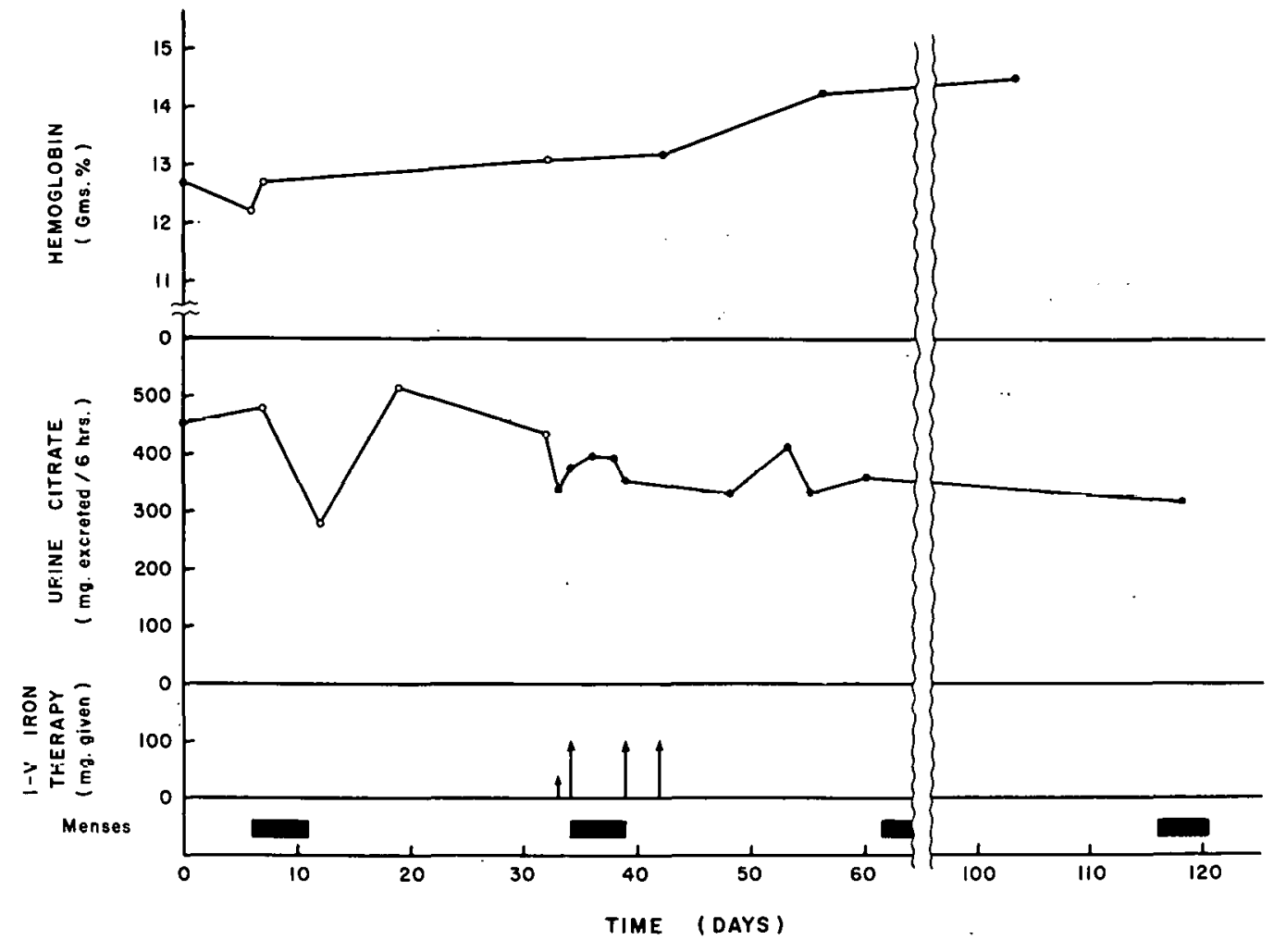

Figure 33. The effect of iron therapy on 6-hour urinary citrate excretion after oral citrate loading. Studies of one mildly irondeficient subject.

of the kidneys of iron-deficient rats has been demonstrated. The cytochrome oxidase activity of kidneys of iron-deficient rats has been found on the average to be less than that of control rats. However, there is considerable overlap of individual values. Similarly, the average cytochrome oxidase activity of white blood cells of iron-deficient subjects was only two-thirds normal. Again, there was considerable overlap of individual values. Iron deficiency was shown to produce no effect on the catalase content of rat red cells, rat liver, or human red cells. The succinic dehydrogenase activity of livers from iron-deficient animals did not differ significantly from that of control animals. However, a small but consistent decrease in succinic dehydrogenase activity of the kidneys and hearts of iron-deficient animals could be demonstrated.

Dilute solutions of rat kidney aconitase rapidly lost activity upon incubation at $37^{\circ} \mathrm{C}$. Reactivation could be produced with $\mathrm{Fe}^{++}$and ascorbic acid. Aconitase activity of liver, heart, and brain of iron-deficient animals did not differ significantly from that of control animals. However, a consistent decrease in aconitase activity could be demonstrated in the kidneys of iron-deficient animals. The activity of enzyme solutions prepared from irondeficient rat kidney could not be restored to normal by the in vitro addition of $\mathrm{Fe}^{++}$. and ascorbic acid: a true deficiency of enzyme, rather than co-factor deficiency, appeared to be responsible. Intragastric treatment of iron-deficient animals with iron resulted in re- 
turn to normal not only of hemoglobin values, but also of kidney aconitase values.

The data presented are interpreted as indicating that in the iron-deficiency state, the tissue iron enzymes as well as the blood hemoglobin level deserve consideration.

\section{LITERATURE CITED}

1. Hahn, P. F., and G. H. Whipple. Am. J. Med. Sci., 191:24, 1936.

2. Sahli, H. Lehrbuch der Klinischen Untersuchungs-Methoden, Franz Deuticke, Leipzig and vienna, pp. 933, 1908.

3. Waldenström, J. Acta Med. Scand. (Suppl.), 90:380, 1938.

4. Jasinski, B., and O. Roth. Benno Schwabe and Co., Verlag-Basel, 1954.

5. Heilmeyer, L. and K. Plötner. Das Serumeisen und die Eisenmangelkrankheit (Pathogenese, Symptomatologie und Therapie). Verlag von Gustav Fischer, Jena, 1937.

6. Brown, E. B., C. V. Moore, C. Reynafarje, and D. E. Smith. J. Am. Med. Assoc., 144: $1084,1950$.

7. Jennison, R. F., and H. R. Ellis. Lancet, 2:1245, 1954.

8. Hahn, P. F. Medicine, 16:249, 1937.

9. Theorell, H., M. Beznak, R. Bonnichsen, K. G. Paul, and A. Akeson. Acta Chem. Scand., 5:445, 1951.

10. Goodman, L. S., and A. Gilman. The Pharmacologic Basis of Therapeutics, 2nd Ed., MacMillan, New York, 1955.

11. Paul, K. G. In the Enzymes, by Sumner, J. B., and K. Myrback, Vol. II, Part I, p. 357, Academic Press, New York, 1951.

12. Cohn, E., and C. A. Elvejhem. J. Biol. Chem., 107:97, 1934.

13. Barkan, G., and B. S. Walker. J. Biol. Chem., 135:37, 1940.

14. Potter, V. R., and K. P. DuBois. J. Biol. Chem., 142:417, 1942.

15. von Euler, H., W. Franke, R. Nilsson, and K. Zeile. In von Euler, H.: Chemie der Enzyme, II. Teil, Spezielle Chemie der Enzyme, Munich, J. F. Bergmann, pp. 72, 1934 .

16. Umbreit, W. W., R. H. Burris, and J. F. Stauffer. Manometric Techniques, Burgess Publishing Co., Minneapolis, 1957.

17. Cooperstein, S. J., and A. Lazarow. J. Biol. Chem., 189:665, 1951.

18. Beutler, E., and M. Yeh. J. Lab. Clin. Med. (In press.)

19. Wissler, R. W., R. L. Woolridge, C. H. Steffe, Jr., and P. R. Cannon. J. Immunol., $52: 267,1946$.

20. Dickman, S. R., and A. A. Cloutier. Arch. Biochem., 25:229, 1950.

21. Dickman, S. R., and A. A. Cloutier. J. Biol. Chem., 188:379, 1951. 
A STUDY OF THE FATE AND PHAGOCYTIC PROPERTIES OF THE ANTIBODY-FORMING CELL OF THE SPLEEN ${ }^{*}$

By

C. H. Gunderson

The production of antibody in the rat spleen, initiated by a single intravenous injection of antigen, appears to involve four cell types: macrophages, which ingest the antigen; a cell type, perhaps the primitive reticular cell which is stimulated to develop into the acute splenic tumor cell (referred to hereon as the antibody-forming cell) that is pyroninophylic; and plasma and small round cells, which may be descendants of the antibody-forming cell.

The purpose of the research described in this text was to observe the derivation, role, and fate of the antibody-forming cell in the rat.

Sprague-Dawley male albino rats, weighing between 150 and $350 \mathrm{~g}$ were fed ad libitum Purina chow. For studies of spleen weight, all of the animals used were taken from the same shipment and were of the same age and weight. Animals were anesthetized with ether prior to sacrifice, which was done by severing the pulmonary artery or opening the right ventricle. If heart blood was to be collected, the chest was opened just before sacrifice. Spleens were removed and weighed on an electromatic balance. Samples were taken and placed in either Carnoy's solution for staining with methyl green pyronine or in buffered formalin for hematoxylin eosin azure staining. Dry weight and hemoglobin values were determined for the remainder of the spleens from animals used in two experiments.

Typhoid "H" vaccine was prepared from bacilli grown twenty-four hours on nutrient agar in large Kolle flasks. The bacilli were killed in 0.4 per cent formalin, and the vaccine was checked for sterility and contaminating organisms before storage. Carbon particles were prepared from India ink. Fresh red blood cells from sheep were stored in Alsever's solution. The day before injection, they were washed three times in $0.87 \cdot$ per cent sterile saline, diluted to the proper concentration, and stored overnight in the ice box. Heat-killed Friedlander's type B (OD 180) vaccine was prepared according to a method used previously in this laboratory.

Blood was withdrawn from the tail vein while the rats were anesthetized. Smears and white blood counts were made either from the free-flowing blood, or, if antibody determinations were to be made, from $1 \mathrm{cc}$ of blood collected in a test tube containing $0.1 \mathrm{cc}$ of dried heparin solution. During the course of each experiment, blood for white cell counts and smears was always collected at the same time of day and in the same manner. Hemostasis was effected by means of ferrous subsulfate solution.

\footnotetext{
* Based on a dissertation submitted to the Faculty of the Division of the Biological Sciences as one of the requirements for the degree of Master of Science.
} 
Portal blood was collected also while the animals were anesthetized. After the sample of tail blood had been collected, the abdomen was opened and the mesenteric veins were ligated below the junction with the splenic vein. The portal vein was then ligated at the porta hepatis. A polyethylene tube (OD .048) was cut diagonally and inserted into the bulging portal vein. Blood for titration, smears, and white.blood counts was collected in heparinized test tubes in amounts of 1 to $2 \mathrm{cc}$.

Crucibles for determination of dry weight were dried at $100^{\circ} \mathrm{C}$ overnight before weighing and storage in a desiccator over $\mathrm{P}_{2} \mathrm{O}_{5}$. Samples of rat spleen were added and minced with Mayo scissors. Enough absolute ethyl alcohol was added to cover the minced spleens. The crucibles were placed in an oven at $80^{\circ} \mathrm{C}$ for 24 hours, then reweighed, and the water loss was computed.

For hemoglobin determination, samples of spleen were weighed, 3 drops of Saponin solution were added, and the mixture was placed in an electrically-driven homogenizer. Ten cc of 1 per cent $\mathrm{NaHCO}_{3}$ was added with intermittent homogenization. The mixture was transferred to a centrifuge tube, allowed to stand for one hour, and spun in an International Clinical centrifuge for 20 minutes (about 2000 RPM, angle head). The supernatant was read in a Coleman Junior Colorimeter, using a $545 \AA$ filter. The curve of optical density versus filter wave length for this preparation was that produced by human blood. Values obtained were compared with the "Hemoglobin Index" which is equal to the optical density of $100 \mathrm{mg}$ of tissue. Optical density $\mathrm{x} .7$ is equal to the concentration of hemoglobin present in $20 \mathrm{cu} \mathrm{mm}$ of whole blood. Hemoglobin per $100 \mathrm{mg}$ of tissue is, therefore, equal to $.2 \mathrm{cc} \times \frac{.7 \text { grams }}{100 \mathrm{cc}} \times$ Hemoglobin Index.

Bacillary adherence studies were done using a modification of methods previously described. Smears were made with either heparinized blood or blood taken directly from the tail. The smears were covered with an OD 580 suspension of formalinized typhoid bacilli and allowed to stand on water-soaked filter paper in large Petri dishes for 40 minutes. Normal rat serum was allowed to flow drop by drop over the slide three times. After the third rinse, the slides were blotted dry on bibulous paper, allowed to dry further in air stained with Wright's stain, and examined under oil immersion.

Antibody determinations were done using methods developed in this laboratory.

The standard deviation for spleen weight ranged between 8.6 and 13.7 per cent of the mean spleen weight in control groups from 5 experiments (Table 1). The rats from which the spleens were obtained varied between two and four months in age. Within each group there was no apparent correlation between average body and spleen weight. This is further demonstrated in a group of 17 control animals divided into five groups of three rats and one group of two rats each arranged in order of ascending body weight (Table 2). Because of this lack of correlation, spleen weights are expressed in mg rather than as percentages of total-body weight.

Following an intravenous injection of bacilli, the spleen weight increase ranged between 160 and $400 \mathrm{mg}$ during the first 24 hours. The increase during the ensuing 24 hours was much less marked although evident. Organ hypertrophy was greatest at four days, but 
Table 1

SPLEEN WEIGHTS - CONTROL ANIMALS

\begin{tabular}{l|c|c|c|c|c}
\multicolumn{1}{c|}{ Experiment } & I & II & III & IV & V \\
\hline Body weight (g) & 241 & 287 & 331 & 264 & 226 \\
Spleen weight (mg) & 640 & 732 & 668 & 707 & 714 \\
$\begin{array}{c}\text { Standard error of mean of spleen } \\
\text { weight (mg) }\end{array}$ & 22 & 15 & 22 & 30 & 19 \\
$\begin{array}{c}\text { Standard deviation of spleen weight } \\
\text { (mg) }\end{array}$ & 65 & 63 & 75 & 97 & 61 \\
Number of rats per group & 9 & 18 & 11 & 10 & 6 \\
\hline
\end{tabular}

the weight added between days 1 and 4 was equal to the weight gain of the first day in only one experiment out of four. Between days 4 and 6 the spleen weight decreased inconsistently. However, even by the 8th day this decrease did not reduce the weight of the experimental rats to that of their controls. In one experiment in which the animals had received $1 \mathrm{cc}$ of $O D 180$ vaccine intravenously, the spleens were enlarged 13 days after injection.

Injection of $1 \mathrm{cc}$ of OD 180 Friedlander's Bacillus type $\mathrm{B}$ also caused an increase in spleen weight except that the change on day 4 was greater both in $\mathrm{mg}$ and as a multiple of the weight gain of the first 24 hours. Weight increase after injection of 1 per cent sheep red blood cells was inconsistent, but injection of 5 per cent sheep red blood cells caused changes that were similiar to those seen after the injection of typhoid and Friedlander's vaccine except that there was no gain during the first 48 hours. Figure 1 summarizes the results of these observations.

In order to learn whether early or day 4 weight gains could be explained on the basis of increase in the inter- or intracellular fluid, weighed samples of spleens from three or four rats $1,2,4$, and 6 days after injection of typhoid vaccine, 1 per cent sheep red blood cells, or 5 per cent sheep red blood cells were dried and the percentage of total weight

Table 2

SPLEEN WEIGHTS - EXPERIMENT II BY GROUPS OF 3 IN ORDER OF ASCENDING WEIGHT

\begin{tabular}{c|c|c|c|c|c|c}
\hline Group & A & B & C & D & E & F \\
\hline Body weight & 232 & 271 & 289 & 296 & 306 & 316 \\
Spleen weight & 728 & 724 & 786 & 722 & 789 & 677 \\
\hline
\end{tabular}

\footnotetext{
* Only 2 animals.
} 
represented by dry weight was computed. The results are summarized in Figure 1, B and C. There was no definite change in the ratio of dry weight to total weight at any period; the value remained constant at approximately 23 per cent. This may mean that all changes in or gan weight are reflections of increased non-volatile and volatile matter in similar proportion to that found in the normal spleen.

A
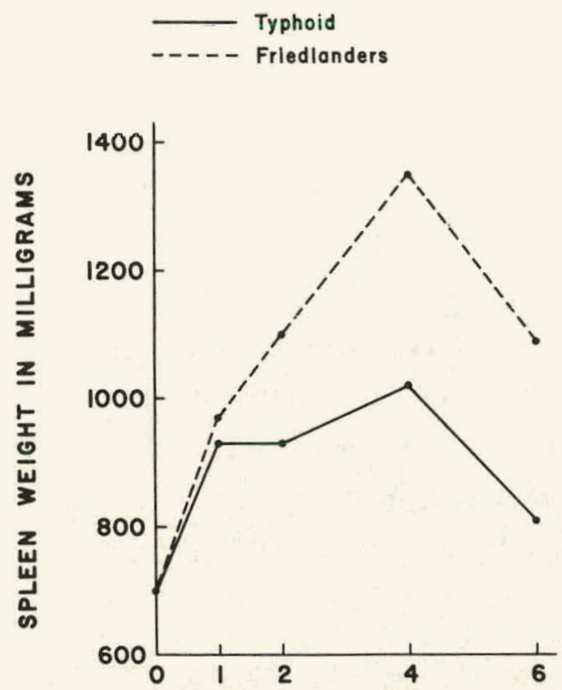

$\frac{\text { DRY SPLEEN WEIGHT }}{\text { TOTAL SPLEEN WEIGHT }} \times 100 \%$

HEMOGLOBIN INDEX (see text)
B
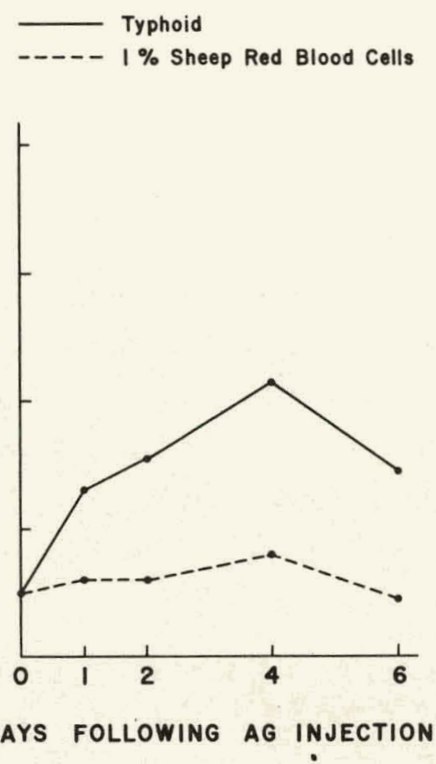

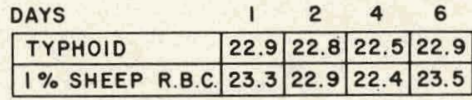

CONTROL $=22.7 \%$

DAYS
\begin{tabular}{|l|c|c|c|c|}
\hline TYPHOID & 1 & 2 & 4 & 6 \\
\hline $1 \%$ SHEEP R.B.C. & 16.1 & 11.3 & 9.0 & 12.8 \\
\hline
\end{tabular}

CONTROL $=16.5$
C
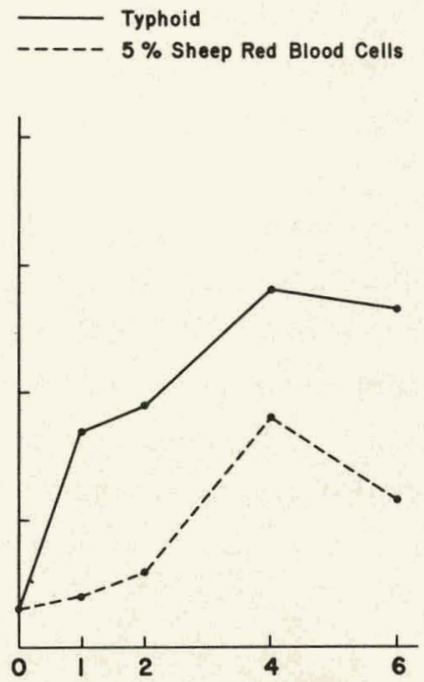

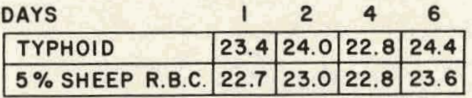

CONTROL $=23.2 \%$

DAYS
\begin{tabular}{|l|c|c|c|c|}
\hline TYPHOID & \multicolumn{1}{c}{2} & 4 & 6 \\
\hline $5 \%$ SHEEP R.B.C. & & 20.8 & 20.7 & 17.9 \\
\hline
\end{tabular}

CONTROL $=18.8$

Figure 1. Six-day graphs of spleen weight in rats injected intravenously comparing the effect of typhoid vaccine to Friedlander's vaccine, 1 per cent sheep red blood cells, and 5 per cent sheep red blood cells. Tables give Hemoglobin Index and dry weight comparisons on the same animals. Each point represents values for 3 rats except in $\mathrm{C}$ in which each point represents values from 4 rats.

Other samples of these same spleens were analyzed for hemoglobin content to test whether the 24-hour weight increase might be explained on the basis of hyperemia. Results are recorded as Hemoglobin Index in Figure 1, B and C. A fall in Index signifies a decrease in the concentration of hemoglobin per unit of spleen weight. This decrease is observed in typhoid-injected animals as the size of the organ increased around day 4 . Since all animals were sacrificed by exsanguination, this may represent a greater bleed- 
ing out of the organ in its tense capsule following accumulation of protoplasm associated with antibody production.

Within six hours after injection of the typhoid vaccine, changes were recognizable in the spleen. The marginal zone, which in the control was equal in width to the diameter of the germinal centers, was thinner, and the remainder of the red pulp was distinctly less cellular. In the germinal centers, the small lymphocytes that were a prominent feature in the control animals had for the most part disappeared, and the white pulp of the spleen was populated almost exclusively by faintly pyroninophylic cells that were in contact with the marginal zone. These changes were more pronounced at 12 hours and the germinal centers were larger and more deeply pyroninophylic (Figures 2 and 3). This enlargement of the follicles had progressed at 20 hours. By this time, the marginal zone had begun to enlarge and the red pulp appeared to be slightly more cellular and in greater quantity. At 28 hours, the brilliant pyroninophylia of the white pulp had faded and many small lymphocytes were evident. The marginal zone appeared almost normal in thickness. The white pulp, however, appeared more widely separated by red pulp which seemed to have increased more in volume than in cellularity. At 33 hours the white pulp was reconstituted and germinal centers had begun to reappear (Figure 4). Fifty-six hours after injection, small dark cells appeared again as the predominant cell type of the white pulp (Figure 5). Not until after 4 days are

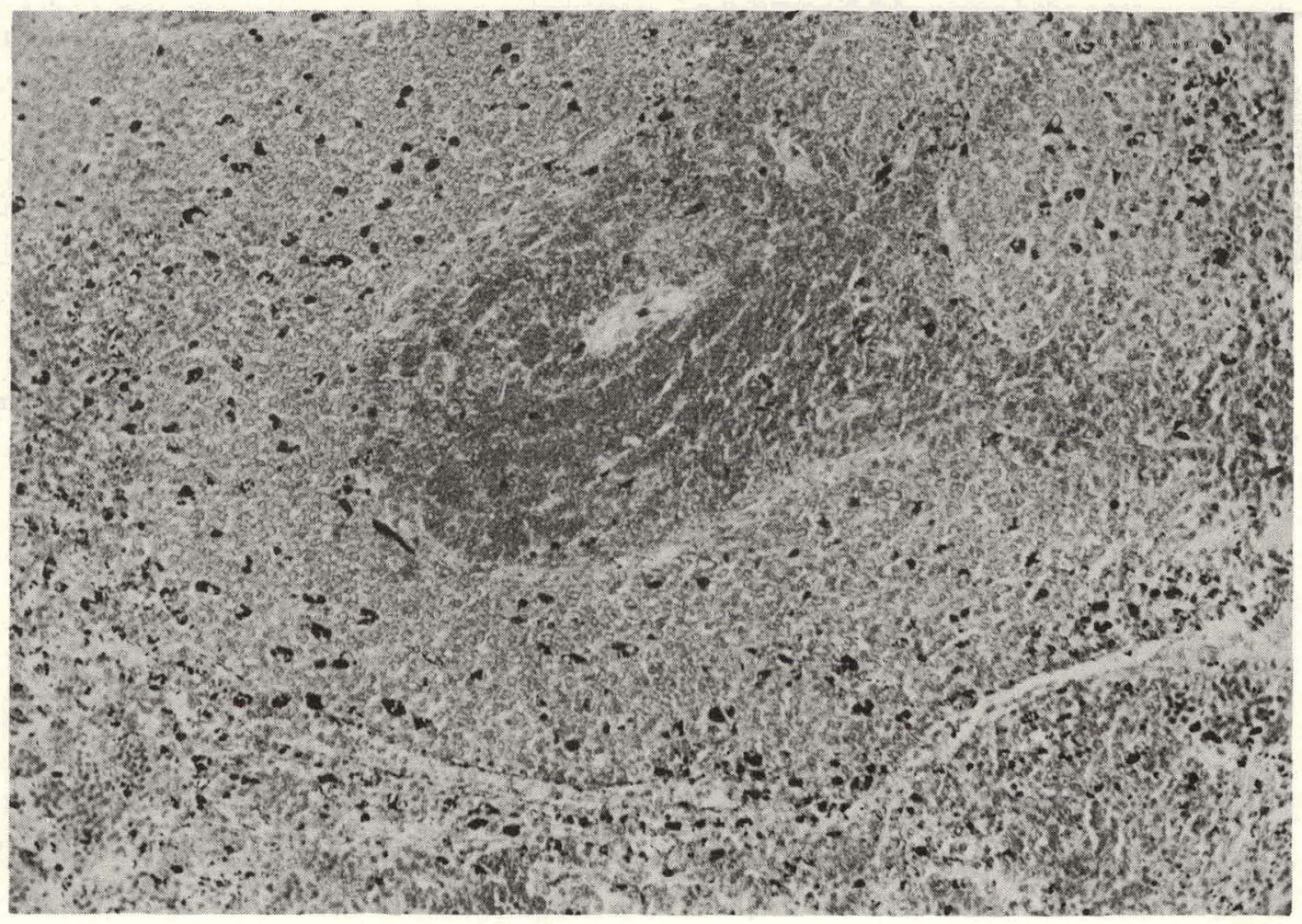

Figure 2. Rat spleen showing distribution of carbon particles 1 hour after their intravenous injection. 


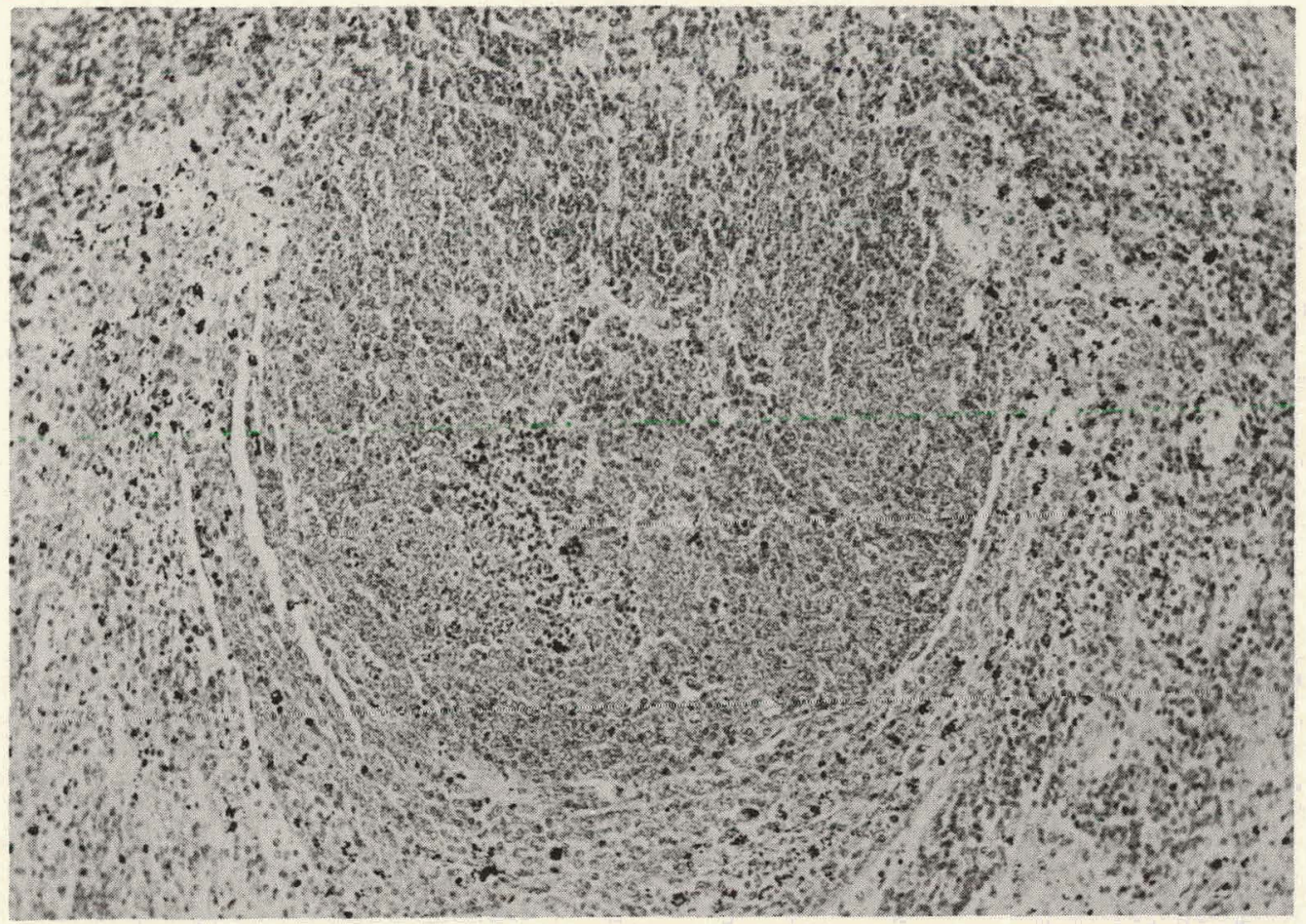

Figure 3. Rat spleen 6 hours after intravenous injection of mixed carbon particles and typhoid vaccine showing pattern of dispersing carbon, disappearance of small round cells from the germinal center, and shrinkage of the mantle zone.

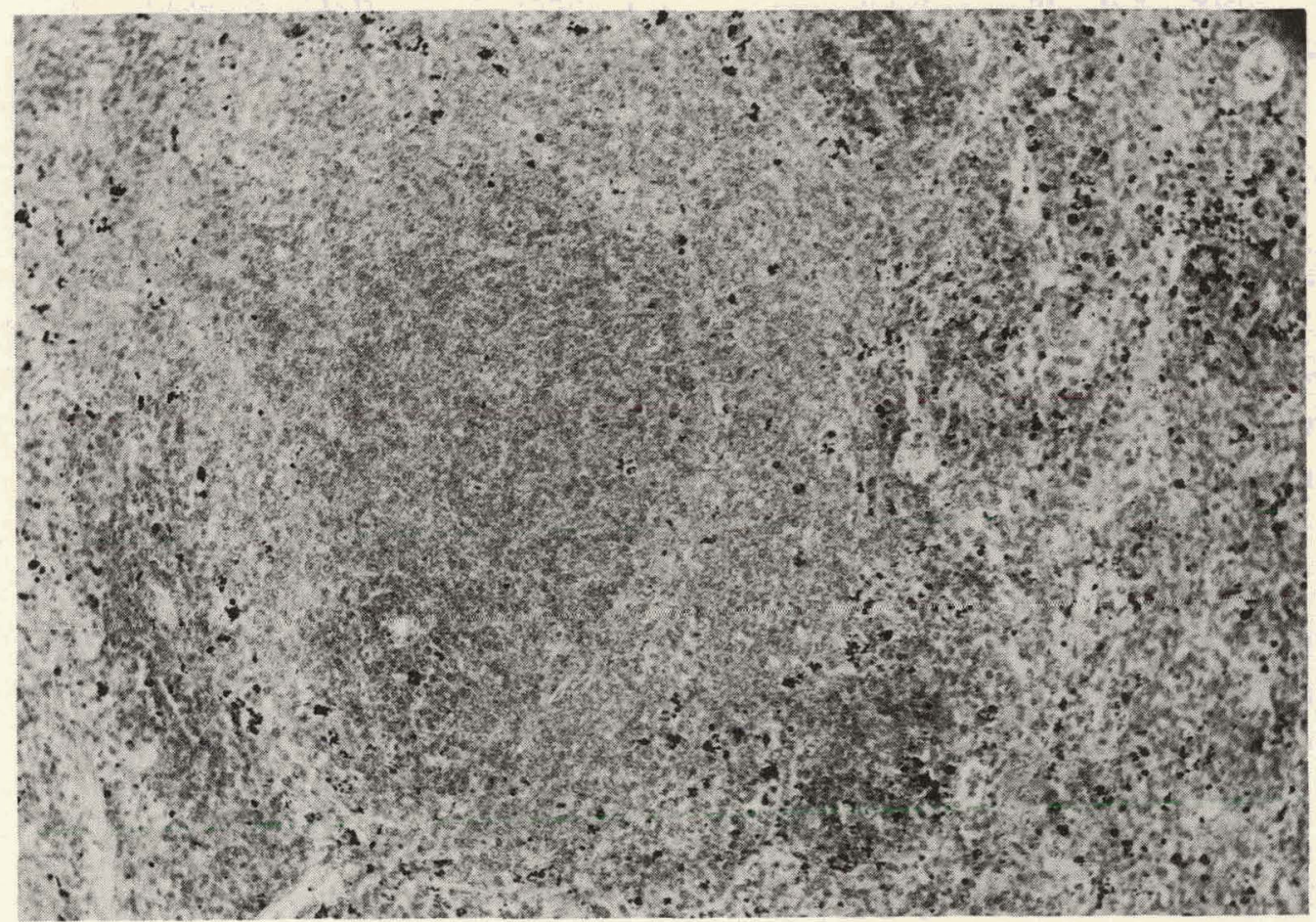

Figure 4. Rat spleen 33 hours after intravenous injection of mixed typhoid vaccine and carbon particles showing regeneration marginal zone, concentration of carbon particles in the red pulp, and continued absence of small round cells (lymphocytes) from the germinal center. 


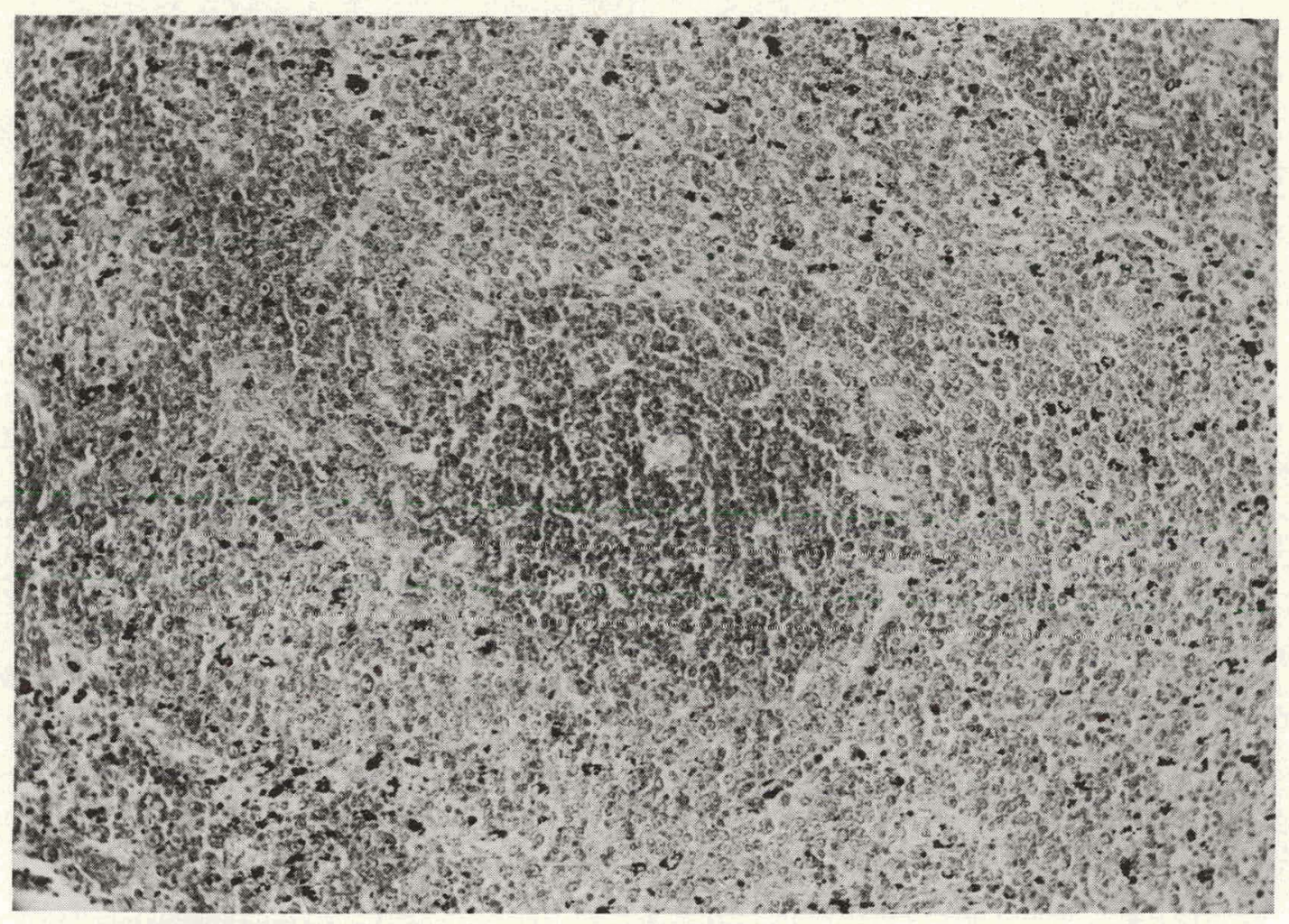

Figure 5 . White pulp of spleen 56 hours after intravenous injection of mixed typhoid vaccine and carbon particles showing reappearance of small round cells in the germinal center.

these structures seen to resemble the normal (Figure 6).

By the third day the large pyroninophylic or "antibody-forming" cells of the spleen were the predominant cell type in the red pulp (Figure 7). There were, however, islands of small dark cells with scant cytoplasm resembling small lymphocytes scattered throughout the red pulp. During the next two days the nuclei of the antibody-producing cells became more pyknotic and the cytoplasm more deeply pyroninophylic. The antibody-producing cells became less numerous, the small dark cells became more common, but did not appear to accumulate in the now shrinking organ. On the eighth day there was an occasional plasma cell and a few small round cells, but otherwise the red pulp very closely resembled that of the normal spleen (Figures 8-10). The presence of these small round cells in the red pulp was the principal reason for searching for small round cells in portal and peripheral blood.

In order to test the phagocytic properties of the antibody-forming cell, $1 \mathrm{cc}$ of 1 per cent washed India ink was injected intravenously 30 minutes before sacrifice into the control rats and into rats that had been immunized with $1 \mathrm{cc}$ of OD 180 formalinized typhoid vaccine $2,3,4$, or 6 days previously. Immediately after injection of the carbon particles the nose, eyes, feet, ears, and tails of each animal turned dark grey, but their normal color reappeared soon. In this respect there was no difference in clearance time between im- 
munized and control animals. At autopsy the spleen, liver, and bone marrow of all of these rats were black, the lungs grey, and the abdominal lymphatics a very light grey.

Microscopic sections revealed localization of the carbon in the Küpfer cells of the liver and in the red pulp of the spleen. About 80 per cent of carbon particles in the red pulp localized in the central area of the marginal zone and 20 per cent or so was scattered in small islets in the loose red pulp. There was no relationship between the developing antibody-forming cells and carbon deposit in the macrophages. No phagocytosis could be recognized on the part of the antibody-producing cells. Carbon-containing cells did not appear to be undergoing mitosis.

In another study, a mixture of $0.5 \mathrm{cc}$ of OD 180 formalinized typhoid bacilli and 0.5 cc of 1 per cent carbon particles were injected into the rats. These animals, other animals injected with typhoid vaccine and carbon only, and noninjected ones were sacrificed at various intervals. Again, none of the antibody-producing cells appeared to contain carbon particles at any time. The carbon, however, appeared to migrate as the germinal centers were changing. At 12 hours the distribution of carbon in the marginal zone was somewhat more dense than in the marginal zone of the controls. At 33 hours there was somewhat more carbon in the loose red pulp than in the marginal zone. By 3 days post-injection, about 80 per cent of the carbon was in the loose red pulp which was now filled with antibody-forming cells. The carbon particles in macrophages were frequently but not always surrounded by nests of pyroninophilic cells. At 56 hours most of the carbon particles in the spleen of the control rats were found in the red pulp as was the case in the experimental animals (Figures 2-7).

Agglutinins to Salmonella typhosa usually appeared in the peripheral blood in sufficient amounts to be detected by the agglutinin test 3 days after immunization. Peak titers were reached on the sixth day, and then began to fall gradually. In one group of 9 animals bled on days 6 and 13 after typhoid immunization, a decline in agglutinin titer from $1 / 3413$ to $1 / 1151$ was observed.

The escape of "lymphocytes" from lymph nodes engaged in antibody formation has been reported, and a higher concentration of antibody in these cells than in their surrounding lymph has been demonstrated. Since small round cells resembling small lymphocytes had been observed to occur transiently in rat spleens as antibody is released, an attempt was made to identify these small round cells in the circulating blood. Counts of lymphocytes in the portal, heart, and tail blood all revealed a low grade lymphocytosis on days 4 and 5 after immunization with 0.5 to $1 \mathrm{cc}$ of formalinized typhoid vaccine. In order to amplify these findings a modification of the bacillary agglutination technique was devised. This permitted identification in dried smears and organ imprints of cells capable of attracting typhoid bacilli to their cell walls. A thick reticulum of bacilli was seen covering the red pulp areas, but not those areas composed of cells from white pulp on spleen imprints prepared from animals 4 days after typhoid immunization. There was no difference in bacilli agglutination between the red and white pulp imprinted areas from control animals.

Similar trials with portal blood smears made from animals 4 or 6 days post-injection 


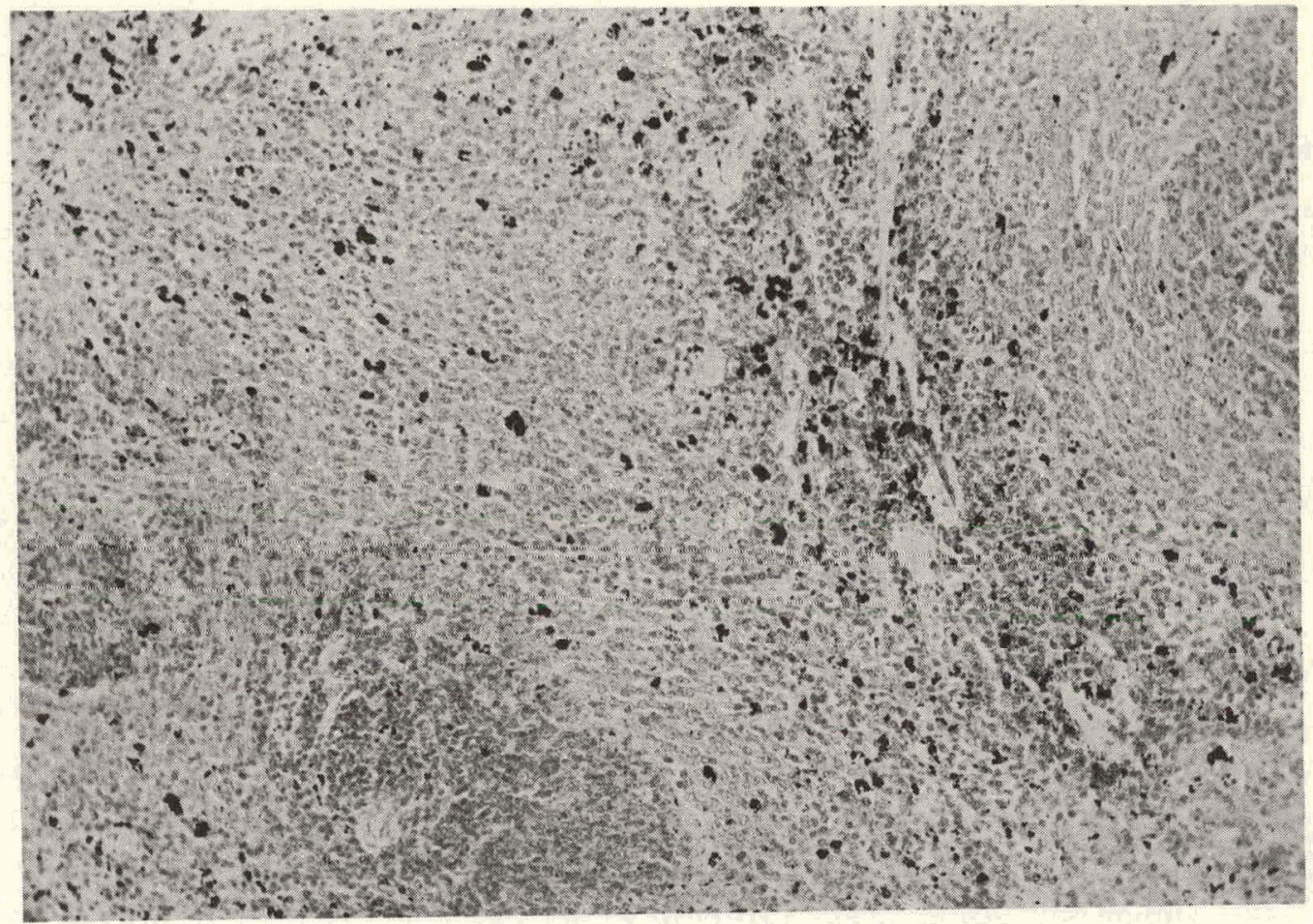

Figure 6. Rat spleen 123 hours after injection intravenously of mixed carbon particles and typhoid bacilli showing carbon localization, regenerated germinal centers and marginal zones, and antibody-forming cells in red pulp.

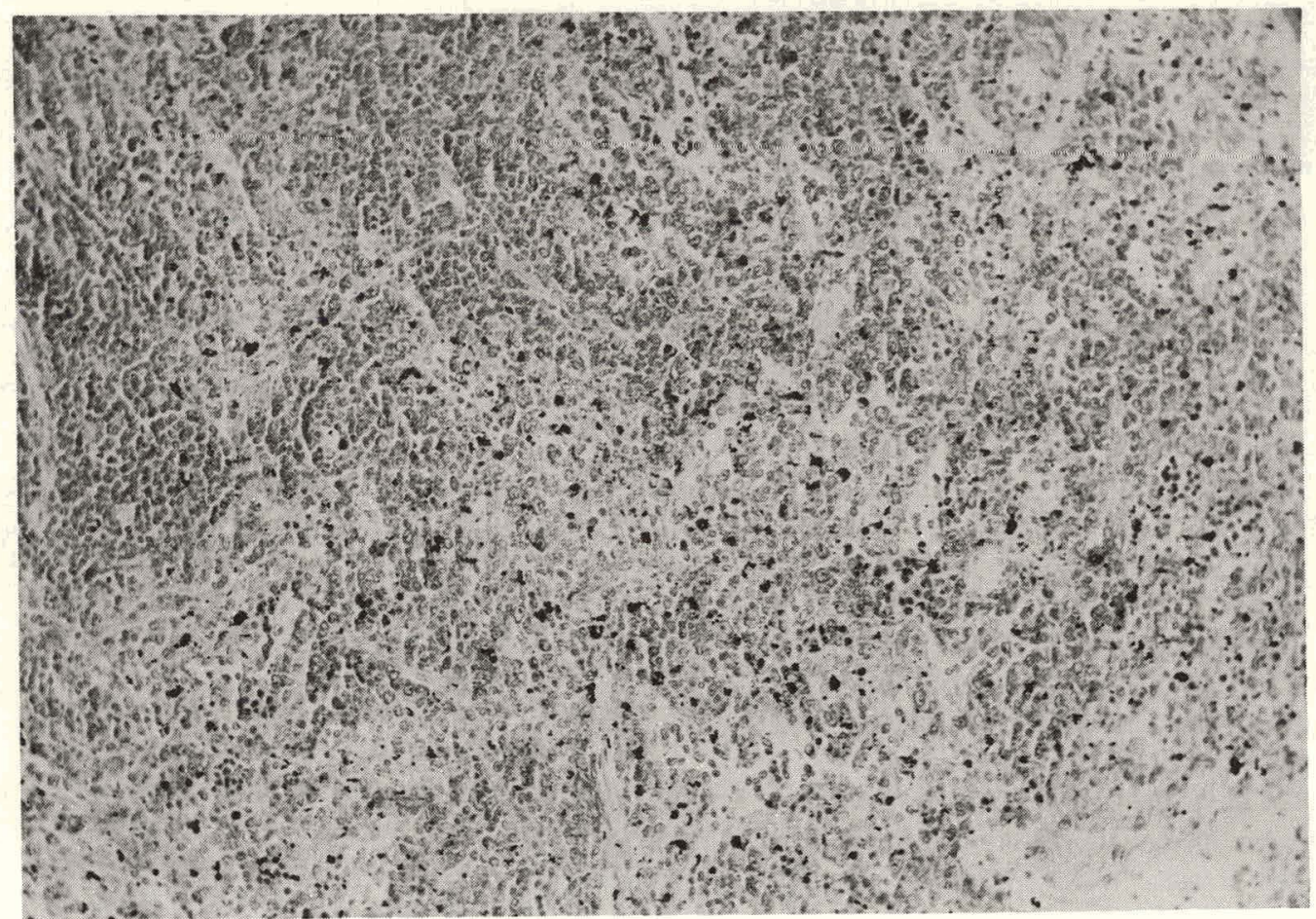

Figure 7. Red pulp of spleen 56 hours after injection of mixed typhoid vaccine and washed carbon particles showing localization of carbon particles and developing antibody-forming cells. 




Figure 8. Loose red pulp of spleen from control rat.

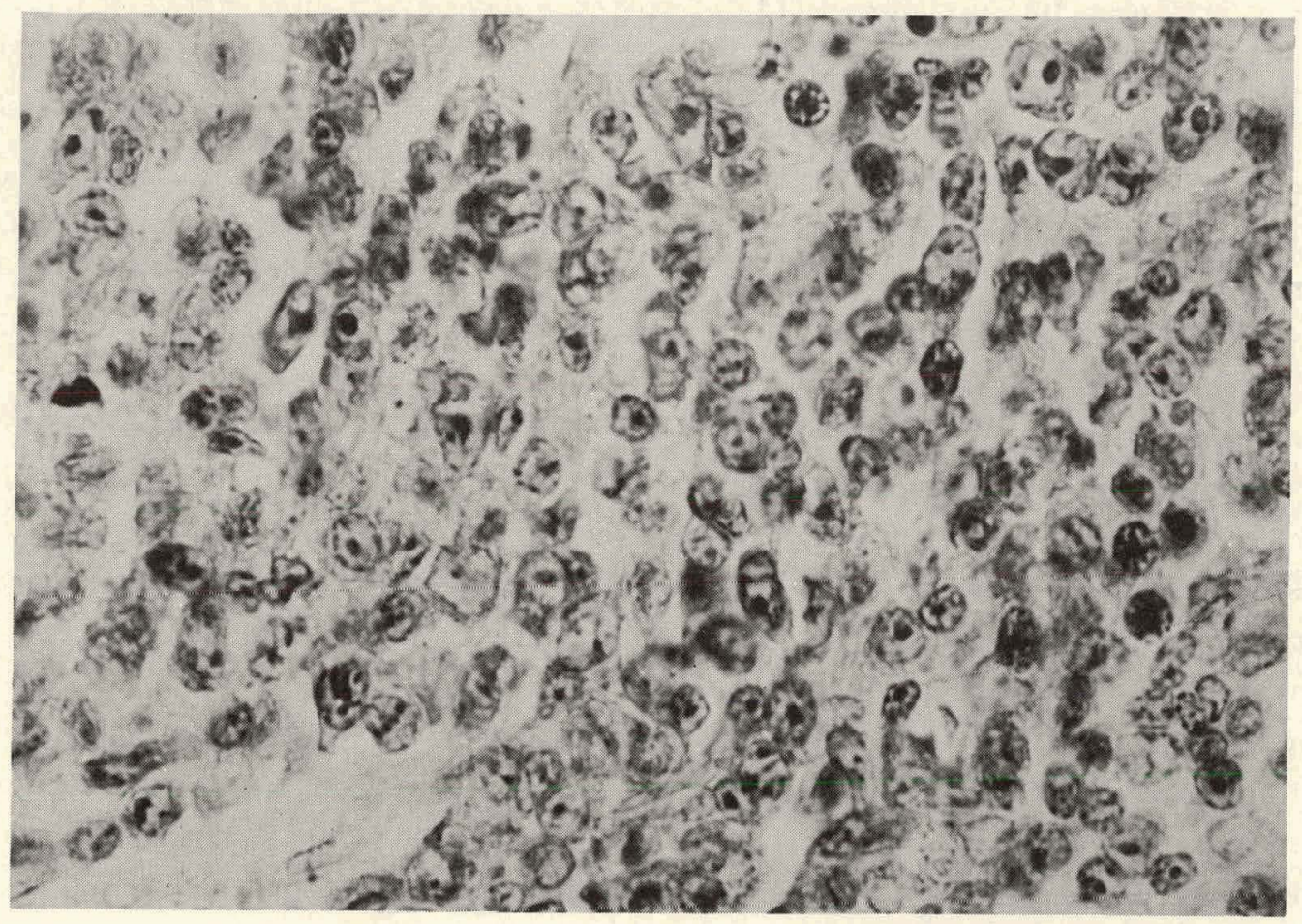

Figure 9. Loose red pulp of spleen 4 days after intravenous injection of typhoid vaccine showing antibody-forming cells at the peak development. 


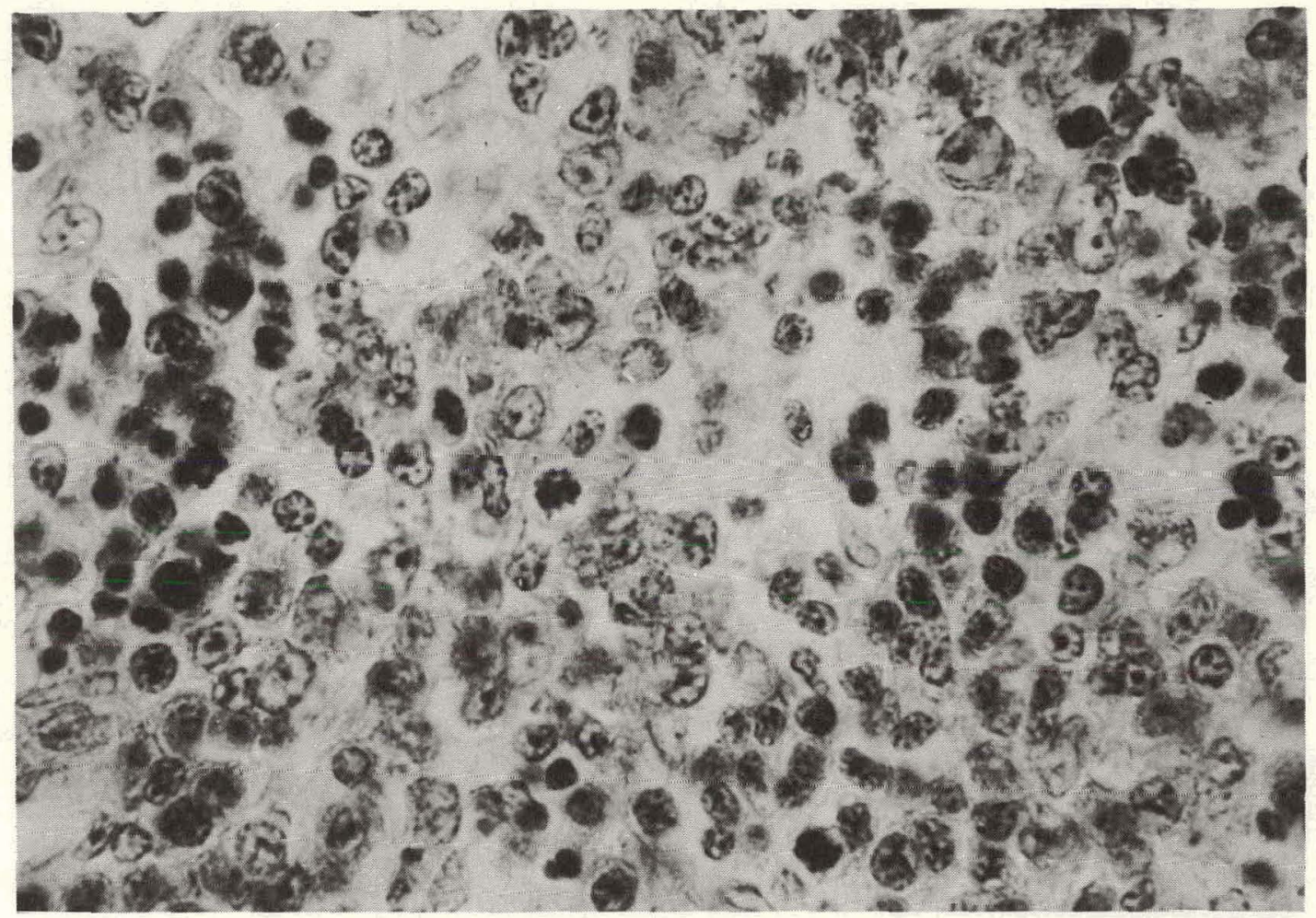

Figure 10. Loose red pulp of spleen 5 days after intravenous injection of typhoid vaccine showing development of small round cells among antibody-forming cells.

indicated that certain cells attracted bacilli and certain others did not. Interpretation was made difficult by the fine reticulum of bacilli deposited on control and experimental slides. One or more of these bacilli were in contact with about half of the cells present. A preliminary experiment (Figure 11) demonstrated that up to 4 or 5 bacilli could be associated on a random basis with a cell in normal and control animals. However, five or more bacilli in contact with the cell wall, or over laying the cell, were very seldom seen in control animals though frequently in animals 5 days after antibody injection. The manner of adherence also differed. In some cells the bacilli were present at all angles to the cell wall and in others the bacilli seemed more tightly attached. This tight adherence was rarely observed in control slides (Figures 12-14).

In one experiment the portal and tail blood smears were treated with bacilli and stained, and 200 cells per slide were counted differentially by cell type and the number of bacilli adhering to cells of each cell type. Figure 11 shows the distribution of small lymphocytes attracting 5 or more bacilli in portal and tail blood. In another experiment, rats were bled from their tails on successive days. Ten typhoid-immunized and 6 control rats were used. All slides were keyed at the time of bleeding. Studies of slides were reported by slide number, and only after all counts had been made were the intervals and the immunization history of the animal made known. Slides were evaluated in terms of numbers 


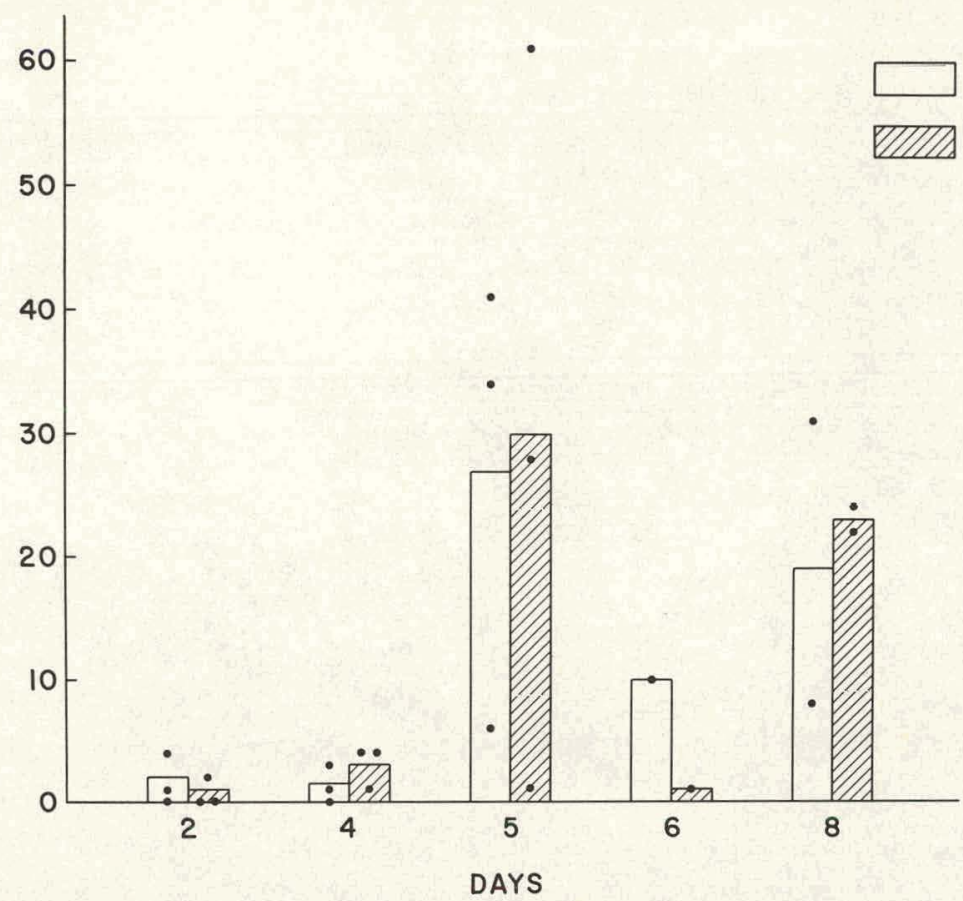

PORTAL BLOOD

TAIL BLOOD

Figure 11. Bar graph by days of the numbers of small round cells per 200 counted cells seen in portal and peripheral

blood of typhoid-injected animals which had 5 or more typhoid bacilli adhering to their cell walls. Control animals had 4 or less adhering cells per 200 cells counted. Each point represents 1 animal.

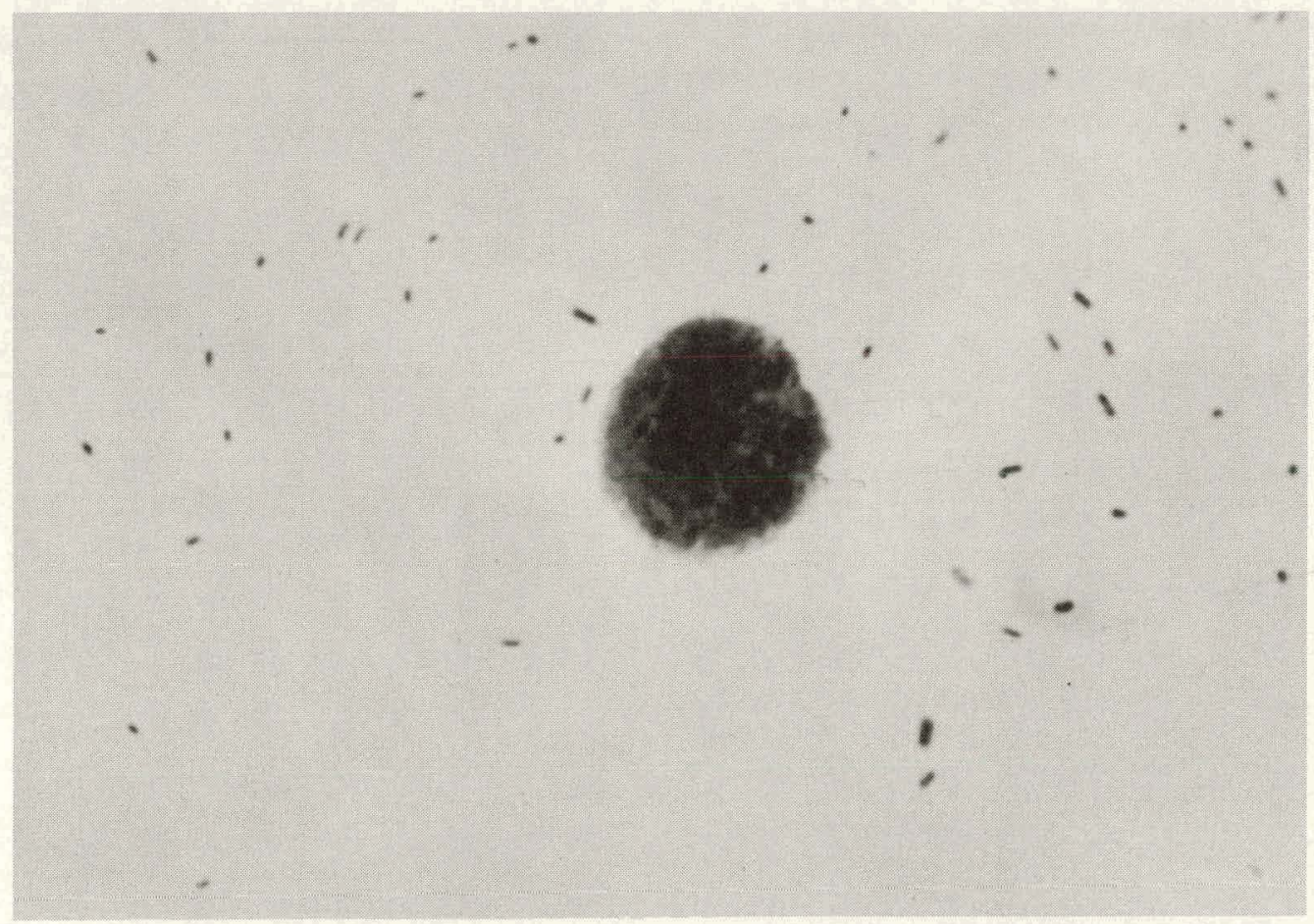

Figure 12. Small round cell in peripheral blood of a rat 5 days after immunization with typhoid vaccine. There is no bacillary adherence (Wright's stain). 


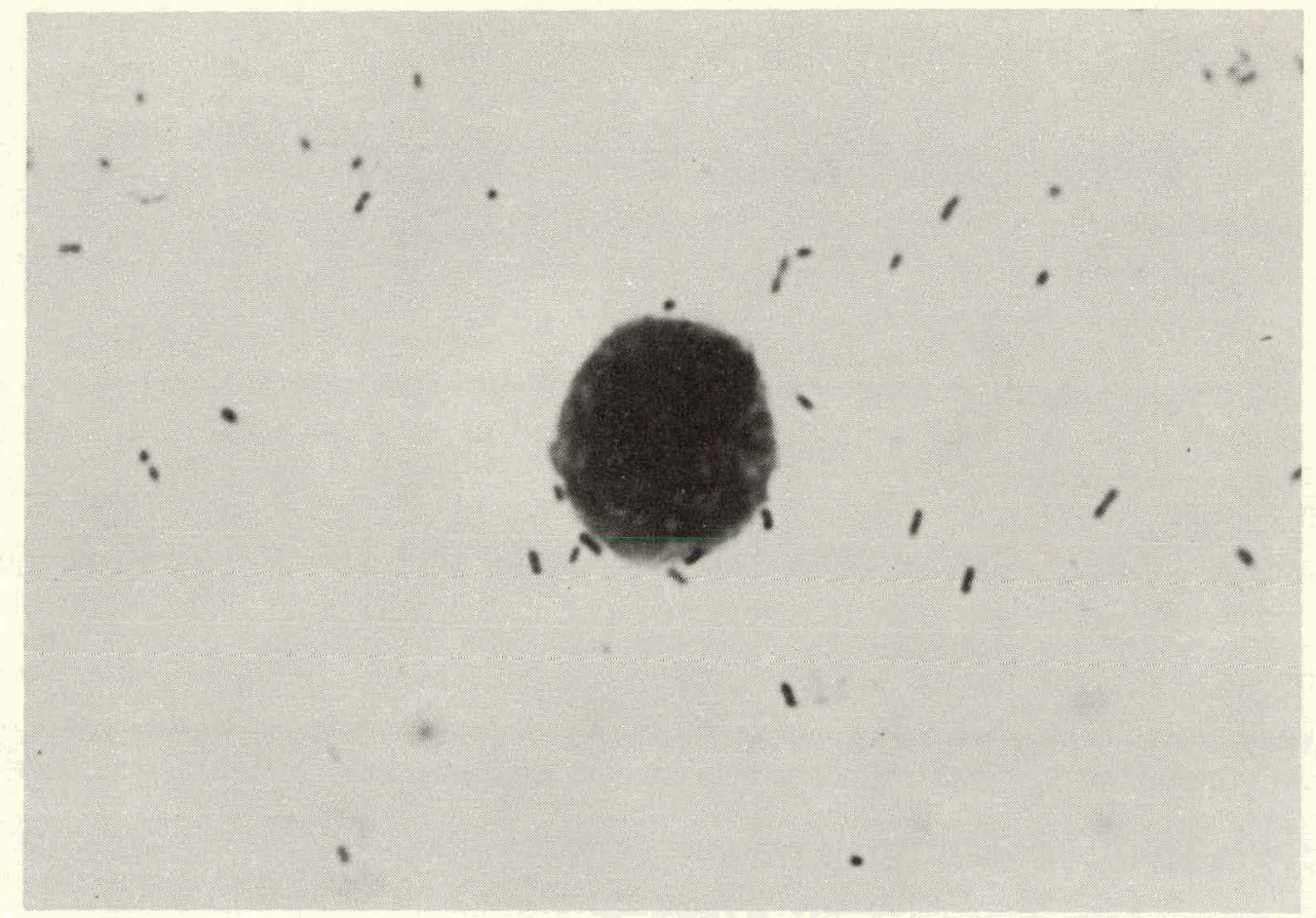

Figure 13. Small round cells in peripheral blood of a rat 5 days after immunization with typhoid vaccine. There is positive adherence of bacilli (Wright's stain).

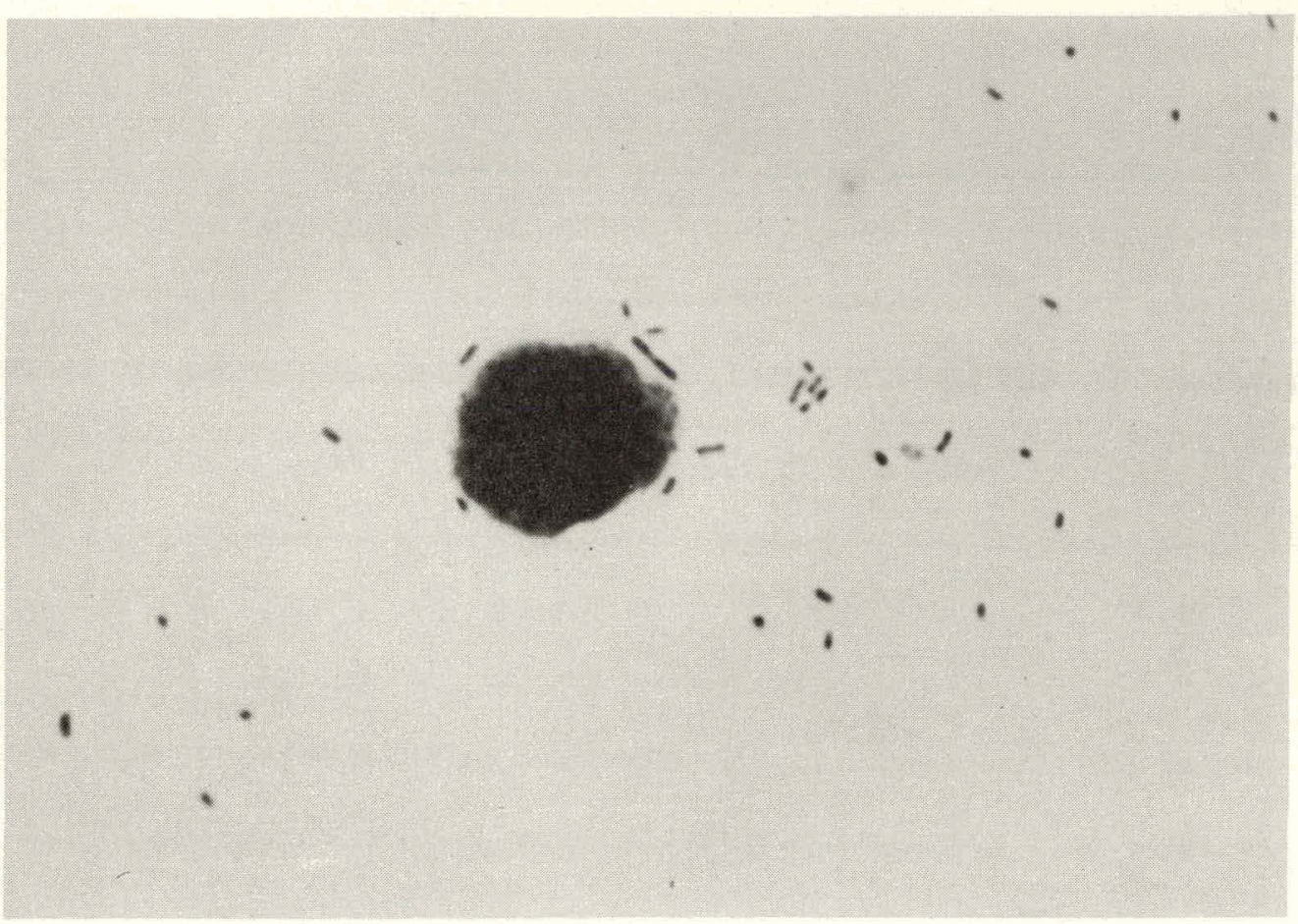

Figure 14. Small round cells in peripheral blood of a rat 5 days after immunization with typhoid vaccine. There is positive adherence of bacilli (Wright's stain). 
of positive, negative, and questionable lymphocytes and granulocytes among 200 cells counted. Positive cells had 4 or more bacilli parallel to the cell wall. All cells associated with 7 or more bacilli were also included in this group unless they were covered with clumps of bacilli, which did not appear directly related to them. Between 4 and 7 irregularly adhering bacilli led to the classification of questionable unless the number was found in a field where there were few other bacilli. In this case, the specimen was described as positive. The results of this experiment are summarized in Figure 15. In both experiments there were increases in bacilli-attracting lymphocytes on day 5 , one day before the antibody titer reached its peak.

INJECTED WITH SALMONELLA TYPHI INJECTED WITH SALINE

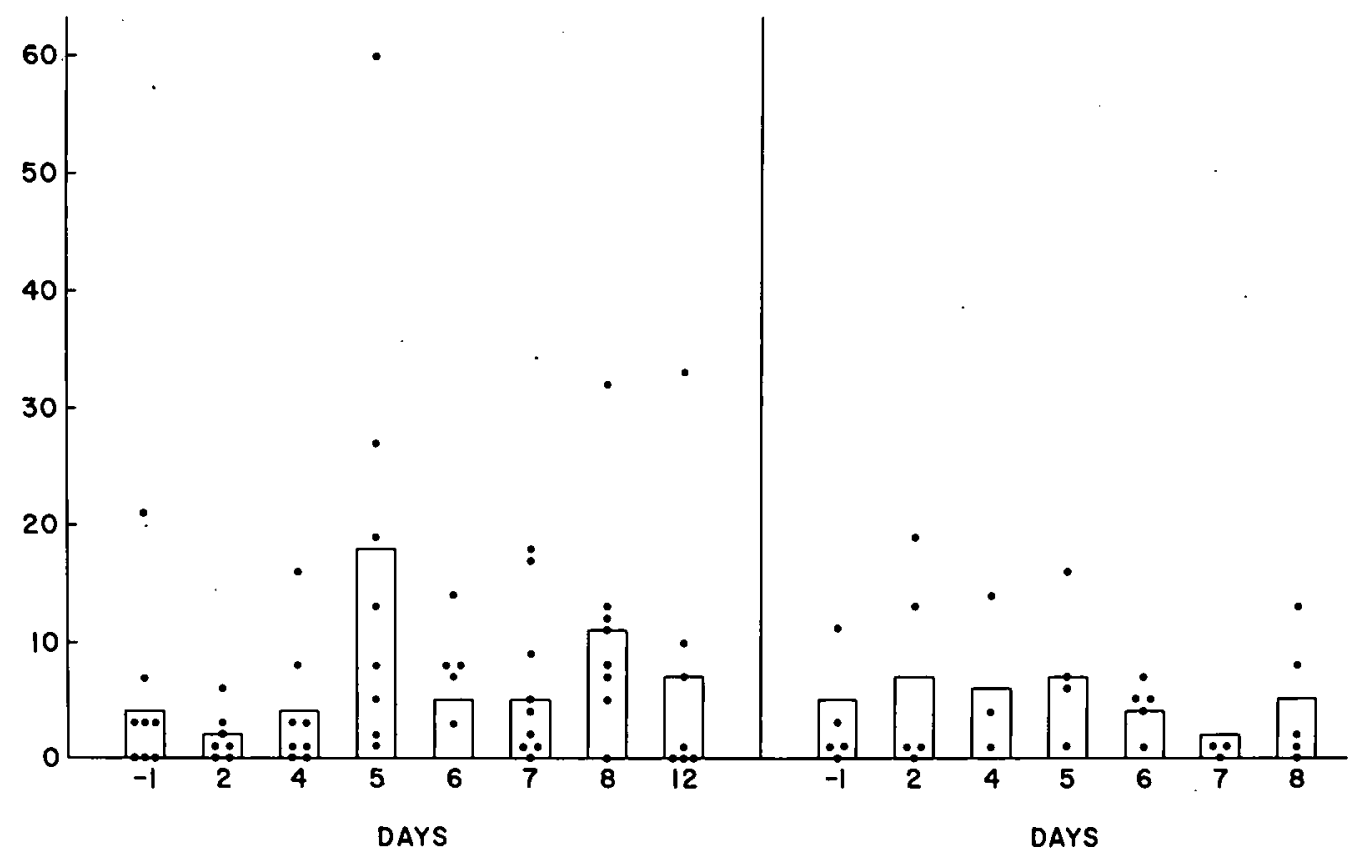

Figure 15. Bar graph by days of number of positive typhoidagglutinating small round cells in tail blood following intravenous injection of typhoid vaccine and saline. Each point represents one animal.

The weight curve for the rat spleen in which antibodies are being produced depends in part on the type of particulate antigen employed. Friedlander's vaccine, typhoid vaccine, and 5 per cent sheep red blood cells all result in a maximum spleen weight at 4 days. The bacterial antigens, however, induce weight increases during the first 24 hours that cannot be attributed to hyperemia or increased fluid within the organ. The increase in weight seems to be related to an increase in amount of splenic red pulp and not to any change in the white pulp, which is reduced. If this reflects an essential part of the antibodyforming process, one would expect it to have occurred after injection of 5 per cent sheep red blood cells. This, however, was not the case. The spleens from rats immunized with 
sheep red blood cells seemed quite capable of producing quantities of antibody without such early red pulp increase.

There are two theories that have been proposed which explain how the antibody-forming cell is stimulated to form antibody to a particulate antigen. 1) The precursor of the antibody-forming cell may phagocytose the antigen, or, 2) another entirely different cell type may ingest the antigen and then transfer a stimulus to the antibody-forming cell. In either case, the stimulation occurs very soon after injection. It has been demonstrated that antibody-producing cells in the popliteal lymph nodes of rabbits were activated 10 minutes after injection of Shigella organism into the foot pad of the animal. In our experiments, no in vivo phagocytosis of particulate matter could be demonstrated by antibodyproducing cells. The carbon-containing cells were not observed to be undergoing mitotic activity. Antibody-producing cells were not seen to contain carbon when this had been injected mixed with the antigen. Previous reports from this department indicate that the carbon particles and particulate antigen are phagocytosed by the same cells. Therefore, if the precursor of the antibody-forming cell is phagocytic, it must ingest very small quantities of material. In any case, our evidence indicates that the precursor of the antibody-forming cell is not of the cell type primarily responsible for clearing the circulating blood of foreign particulate matter.

Another aspect of the early phase of the splenic reaction to antigenic stimulation is the displacement of phagocytized carbon particles in the immunized and non-immunized animal from the marginal zone into the loose red pulp. This might indicate either a movement of phagocytic cells from the marginal zone toward the red pulp, or it may represent a release of phagocytosed material and reingestion by other red pulp macrophages. If the former were true, this might be the means of physiologic replacement of prinitive red pulp stroma. If the latter were true, then it might be an example of release of macrophageprocessed particulate matter and might reveal a part of the mechanism by which the antibody-forming cell is stimulated by macrophage-released products. The adjacent location of carbon-containing macrophages to pyroninophylic cells could represent either the migration of cells from the marginal zone or the carbon particles that were diffusely scattered in the red pulp after their injection.

In an investigation of antibody-formation in rabbits it was demonstrated that the regional lymph node contained the bulk of antigen injected into the homolateral foot pad and that in the first 4 days after antigen injection, this node increased in weight by 180 per cent. RNA in this node increased 214 per cent over the same period. Microscopically, pyroninophylic cells resembling lymphoblasts were seen in lymph nodes and in the medulla of the node. These resembled plasmoblasts and plasma cells. Efferent lymph from these nodes contained demonstrable antibody as early as day 2 and had a higher titer of antibody than blood serum until the sixth day. The cell count in the efferent lymph rose from 17,000 per cu mm in the control animals to 50,000 to 60,000 per cu $\mathrm{mm}$ on the third day after immunization. These samples contained 90 per cent or more "lymphocytes." Cells from these samples were lysed by alternate freezing and thawing after they had been 
carefully washed free of the suspending lymph. The antibody titer of this lysate was consistently 1 to 4 tubes higher than that of the serum in which they had been suspended. In this connection, it was shown that thymectomy with its great loss of lymphoid tissue in the rabbit had no effect on antibody production, which suggests that only lymphocytes located in tissue that had previously localized antigen were active in making or transporting antibody.

These facts indicate that antibody-forming cells in lymph nodes may be released to circulate in the efferent lymph and peripheral blood. They also indicate that while the cells are circulating, they may still contain formed antibody. Because of their form, these circulating elements are designated "lymphocytes."

There is recent strong evidence that implicates the plasma cell in the immune phenomenon. This is based on the demonstration of an increase in plasma cells in hyperimmune animals.

Evidence concerning the fate of the antibody-forming cell in the white rat may be summarized as follows: Splenectomized rats produce antibody only in low titer following intravenous injection of particulate antigen. On the second day after injection of antigen, the mitotic activity of spleen red pulp cells is at its maximum. Starting at the same time and reaching a peak on the fourth day, large numbers of pyroninophylic cells develop. The mass of these cells is reflected in the spleen weight peak reached on the fourth day. Circulating antibody titer reaches its peak on the sixth day, when the number of pyroninophylic cells is decreasing. Special fluorescent staining techniques indicate that cells similar to the pyroninophylic cells contain antibody in stainable amounts 4 days after the first injection, using rabbit-lymph-node-foot-pad system. In tissue cultures, similar cells have been found to release antibody. The staining and tissue culture techniques reveal the development of cells resembling plasma cells near the end of this process. However, as the antibody-forming cells disappear, a number of small round cells appear. On the fifth day, between the day when there are the most antibody-forming cells in the spleen and the day when the antibody titer in the peripheral blood reaches its peak, these cells reach their greatest number.

It thus appears that the plasma cell and the small round cell are products of antibody formation. The small round cells in the peripheral blood, termed lymphocytes, are believed to be produced in the germinal centers of the spleen and other lymphatic tissue. They are multipotential but have no known relationship to antibody production.) Another small round cell seen in the peripheral blood is apparently produced in the splenic red pulp. It contains antibody and is related intimately to antibody synthesis. Its fate is unknown. In terms of site of production and function these two cells appear unrelated. 


\title{
THE EFFECT OF CONCURRENT FEEDING OF TWEEN 80 ON THE CARCINOGENICITY OF ORALLY-ADMINISTERED 3-METHYLCHOLANTHRENE*
}

By

\author{
T. Wong, ${ }^{\dagger}$ D. S. Juras, ${ }^{\dagger}$ and R. W. Wissler
}

Tweens are a series of non-ionic surface-active agents containing sorbitan and polyoxyethylene groups combined with various fatty acids. As such, they are both hydrophilic and lipophilic and have properties that are characteristic of "wetting agents" and emulsifiers. Recently, they have been undergoing intengive study because of their potential use in foods and medicinal preparations. Some of our previous studies ${ }^{1,2}$ have indicated that under certain conditions dietary Tween 20 may increase iron absorption from the intestinal tract, and that the Tweens have possible co-carcinogenic properties. The penetration of a carcinogen, 3,4-benzpyrene, into the stomach wall of mice and cats has been shown to be enhanced by the presence of Tweens. ${ }^{3}$ The co-carcinogenic effect of Tweens in the induction of skin tumors in mice has also been reported. ${ }^{4}$ The carcinogen 9,10 -dimethyl1,2-benzanthracene, when dissolved in Tweens, is capable of producing a higher incidence of skin tumors when painted on the skin than when it is dissolved in an inert vehicle such as paraffin oil.

The investigation described in this text was undertaken to study two possible effects of Tween-feeding in relation to carcinogenesis: 1) its effect on the activity of an orallyadministered carcinogen on the gastro-intestinal tract mucosa, that is, its local co-carcinogenic effect, if any; and 2) its effect on the absorption and transportation of an orallyadministered carcinogen across the gastrointestinal mucosa, as judged by the incidence of neoplasms in tissues distant from the gastrointestinal tract.

Both of the factors have important relationships to the observations of others. For example, Lorenz and Stewart ${ }^{5-8}$ have shown that feeding other "wetting agents" enhances the carcinogenic activity of dietary methylcholanthrene and dibenzanthracene in the forestomach of mice. That Tweens may influence the gastrointestinal absorption of phenanthrenelike substances is indicated by the work of Kellner et al. ${ }^{9}$ and Payne and Duff. ${ }^{10}$ Their work demonstrated that dietary Tween 80 enhanced the gastrointestinal absorption of cholesterol in rabbits. Oil fed with the cholesterol appeared to augment this effect.

In our study, 3-methylcholanthrene, a phenanthrene-related carcinogen, was fed to mice, with and without Tween 80 , in high fat diets. The chronic effect of Tween 80 on the carcinogenicity of 3-methylcholanthrene was evaluated by the difference in tumor inci1959.

* Based on a paper that appears in the Journal of the National Cancer Institute, 22:363,

The Department of Pathology, The University of Chicago 
dences among the various diet groups.

Male C57 black mice, about 19 to 20 weeks old and weighing between 20 to $30 \mathrm{~g}$, were used. The mice were divided into four groups, each one of which was fed a specific diet (Table 1). The detailed compositions of the individual diets are given in Table 2.

Special care was taken to insure an even distribution of the small amount of methylcholanthrene in the diets supplemented with the carcinogen. The specified amount of methylcholanthrene was added to the liquid ingredients of the diet and then the mixture was heated to approximately $100^{\circ} \mathrm{C}$ until all of the carcinogen was dissolved. This oily solution

Table 1

DIET GROUPS

\begin{tabular}{c|c|l}
\hline Group & $\begin{array}{c}\text { Mice } \\
\text { (No.) }\end{array}$ & \multicolumn{1}{c}{ Diet } \\
\hline I & 23 & Basal diet \\
II & 27 & Basal diet + methylcholanthrene \\
III & 28 & Basal diet + Tween 80 \\
IV & 27 & Basal diet + methylcholanthrene + Tween 80 \\
\hline
\end{tabular}

Table 2

DETAILED COMPOSITION OF EXPERIMENTAL DIETS FOR VARIOUS GROUPS

\begin{tabular}{l|c|c|c|c}
\hline \multirow{2}{*}{ Dietary components } & \multicolumn{4}{|c}{ Grams per 100 g of diet } \\
\cline { 2 - 5 } & Group I & Group II & Group III & Group IV \\
\hline Casein & 10 & 10 & 10 & 10 \\
Dextrin & 40 & 40 & 40 & 40 \\
Sucrose & 10 & 10 & 10 & 10 \\
Salt mixture (O\&M) & 4 & 4 & 4 & 4 \\
Dried Brewer's yeast & 5 & 5 & 5 & 5 \\
L-Cystine & 0.5 & 0.5 & 0.5 & 0.5 \\
Alphacel & 10 & 10 & 5 & 5 \\
Cottonseed oil & 19.5 & 19.5 & 19.5 & 19.5 \\
Wheat-germ oil & 1 & 1 & 1 & 1 \\
Tween 80 & - & - & 5 & 5 \\
Oleum percomorphum & 1 drop & 1 drop & 1 drop & 1 drop \\
3-Methylcholanthrene & - & 0.03 & - & 0.03 \\
\cline { 2 - 5 } Total & 100.0 & 100.03 & 100.0 & 100.03 \\
\hline
\end{tabular}


was then added to the dry ingredients and mixed mechanically. Those who handled the car cinogenic diets wore rubber gloves.

Each mouse was given $2 \mathrm{~g}$ of the diet each day, a quantity representing the maximum amount of daily diet that could be consumed constantly and equally by all groups of mice over a prolonged period of time. Anything left uneaten at the end of the day was discarded. Water was given ad libitum.

The amount of methylcholanthrene consumed by each mouse in Group II and Group IV was $0.6 \mathrm{mg}$ daily, each mouse in Group III and Group IV consumed $100 \mathrm{mg}$ of Tween 80.

All four groups of mice were fed their experimental diets for the first 10 weeks. They were then fed the basal diet for the subsequent 8 weeks (week 10 to week 18). At the end of the eighteenth week, the basal diet was discontinued and all mice were fed Purina Laboratory Chow ad libitum for the remainder of the experiment. Animals that died before termination of the experiment were autopsied. Heart, lungs, stomach, small intestine, large intestine, liver, spleen, and kidneys were taken for histologic examination. The stomach was opened along the greater curvature and spread out in its entirety on a piece of cardboard for fixing. Later on, multiple longitudinal sections were taken for histologic examination. Other tissues, such as the skin, were studied microscopically only when gross pathologic changes were observed at the time of autopsy. All of the tissues were fixed in neutral buffered formalin, embedded in paraffin, and stained with hematoxylin and eosin. Special stains, e.g., Congc red for amyloid and periodic acid Schiff's stain for glycogen, were used in some instances. In the 51 st week of the experiment, all of the survivors were killed with ether and autopsied; the same tissues as mentioned above were taken for histologic examination.

In a preliminary experiment it was found that continuous feeding of the carcinogencontaining diets to mice for more than 4 months resulted in a high degree of early mortality in these animals. The few survivors eventually developed anasarca and died in approximately 6 months or shortly thereafter. Ascites was particularly prominent. In some of these animals, the ascitic fluid was clear. In others, the ascitic fluid was thick, white, and opaque and had a chylous appearance. Ascitic fluid of intermediate composition was also observed. In a few cases of chylous ascites, there was associated bilateral chylous effusion into the pleural cavities. Because of these findings, the carcinogenic diets were fed to the mice for approximately 2 months only.

The curves, Figures 1 and 2, reveal that dietary methylcholanthrene increased mortality. The addition of Tween 80 to the diets at a level of 5\% seemed to have no deleterious effect on the lifespan or the body weight of the animals. The unusually high mortality of Group II in the early part of the experiment, especially after the 8th week, was associated primarily with the development of severe amyloidosis in such vital organs as the liver, spleen, and kidneys. A Salmonella infection, with multiple hepatic abscesses, was also observed in some of these animals dying in the early part of the experiment. In general, how ever, the incidence of concurrent infection and amyloidosis was not great enough to indicate any relationship between the two. 


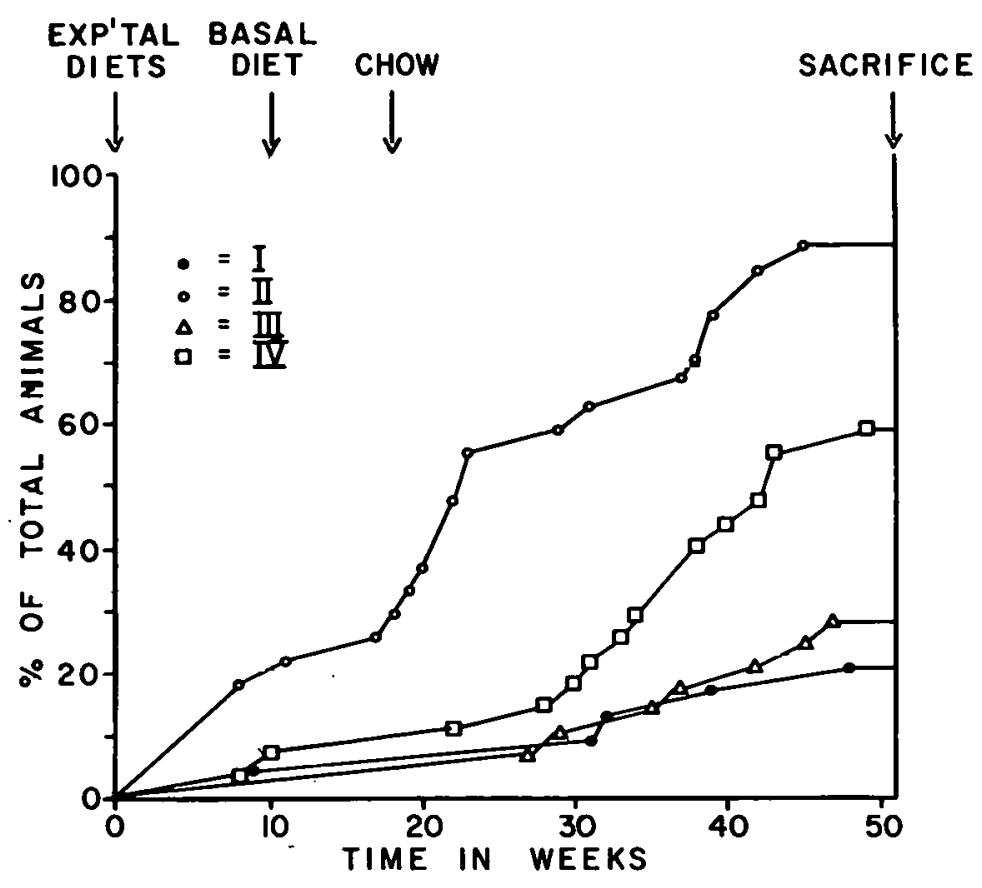

Figure 1. Mortality rate of various groups.

There was no significant difference in the dietary consumption between Group II and Group IV animaIs, indicating that the amount of carcinogen consumed by these two groups of animals was approximately the same. The difference in the incidence of neoplastic

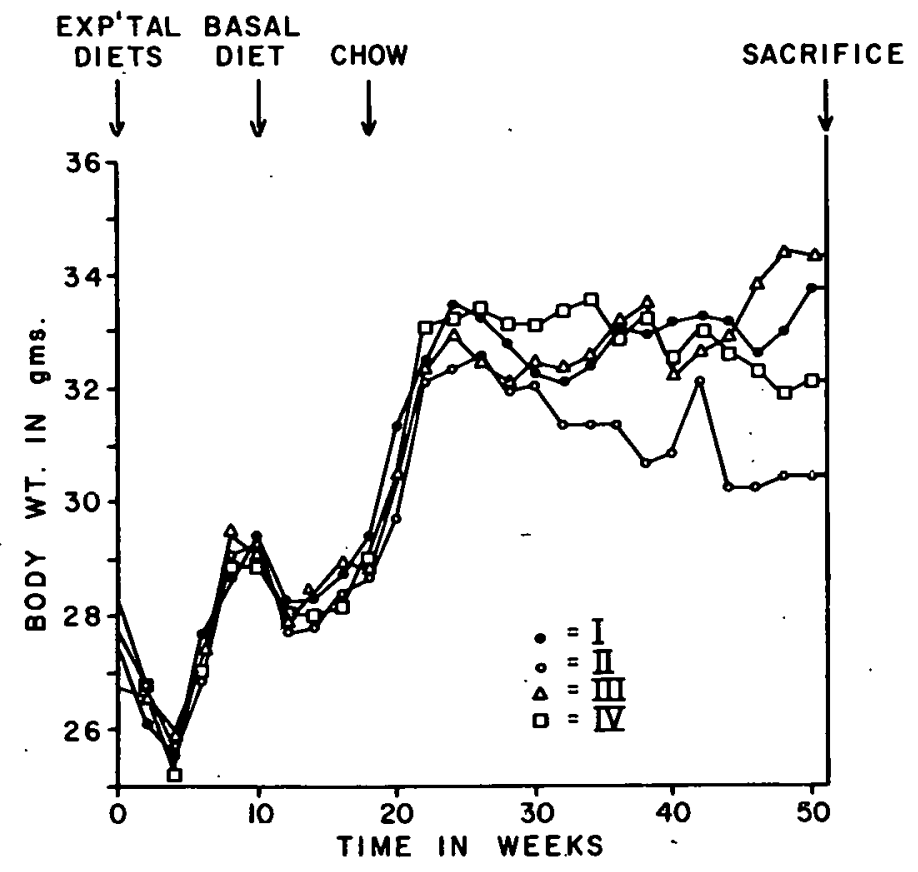

Figure 2. Average body weight plotted against time. 
changes between these two groups of animals was therefore in all probability due to factors other than the amount of carcinogen ingested.

Since tissues were taken for histologic studies only after the animals had died or at the time the experiment was terminated, the'so-called time of appearance of any pathologic lesion obviously depended to a considerable extent on the time of death of the animal bearing the particular lesion. Similarly, the apparent incidence of a pathologic lesion at any specified interval of time depended heavily on the incidence of mortality at the time. In order to avoid difficulties in interpretation, it would have been necessary to conduct an experiment in which animals were sacrificed periodically for histologic examination. Since the present experiment was not conducted on such a basis, interpretation of the frequency of various pathologic findings was made with reference to the incidence of mortality at the time.

Animals in Group I and Group III, which were not fed methylcholanthrent, were found to be completely free of lung neoplasms; whereas animals in Group II and Group IV, which had methylcholanthrene or methylcholanthrene plus Tween 80 in their diets, developed multiple lung tumors (Figure 3).

Microscopic examination of the smaller lung tumors showed a solid mass of cuboidal tumor cells derived apparently from the alveolar lining (Figure 4). Some of the larger tumors were better differentiated and showed a papillary structure (Figure 5). The individual papillae were composed of thin connective tissue cores covered by cuboidal or low columnar tumor cells. The size of the tumor increased with time so that some of the tumors occasionally occupied an entire lobe of the lung. Frequently, the cells in the larger tumors also showed an increase in mitotic figures, suggesting accelerated growth. The total number of such tumors in each pair of lungs otherwise increased with time so that toward the end of the experiment, it was not unusual to find as many as 50 to 100 in the lungs of a single animal.

By comparing data from the animals in Groups II and IV (Figure 3), we see that, starting with 27 mice in each group, the total incidence of lung tumors at the end of the experiment was $44.4 \%$ in Group II and $74.1 \%$ in IV, expressed as per cent of total animals. More animals in Group II died during the initial period of the experiment when there was insufficient time for the lung tumors to develop, thus leaving fewer animals to develop these tumors later on in the experiment (Figure 3). Nevertheless, it is obvious, by comparing the curves for Groups II and IV, that in the last half of the experiment, when for a period of time before the final sacrifice the incidence of mortality in the two groups was very similar, the incidence of lung tumors in Group IV remained greater than that in II.

The first lung tumor to be observed in the mice in Group II was found during the 18th week, while that of Group IV was found in the 22nd week (Figure 3). This difference in the time of appearance of the lung tumors may be more apparent than real, because a closer examination of the curves in Figure 3 reveals that the incidence of mortality at about this period of time was markedly different in the two groups. Whereas the incidence of mortality for Group II from week 18 to week 22 was $18.5 \%$, that for Group IV was $3.7 \%$. If more 
animals in Group IV had succumbed during this period of time, we might have discovered the first lung tumor in Group IV at an earlier date.

Mice in Groups I and III, not fed methylcholanthrene, were free of papillomas and carcinomas of the squamous stomach (Figure 6). On the other hand, mice in Groups II and IV, which had methylcholanthrene or methylcholanthrene plus Tween 80 in their diets, developed these lesions (Figures 6,7 , and 8 ). Tween 80 plus methylcholanthrene did not seem

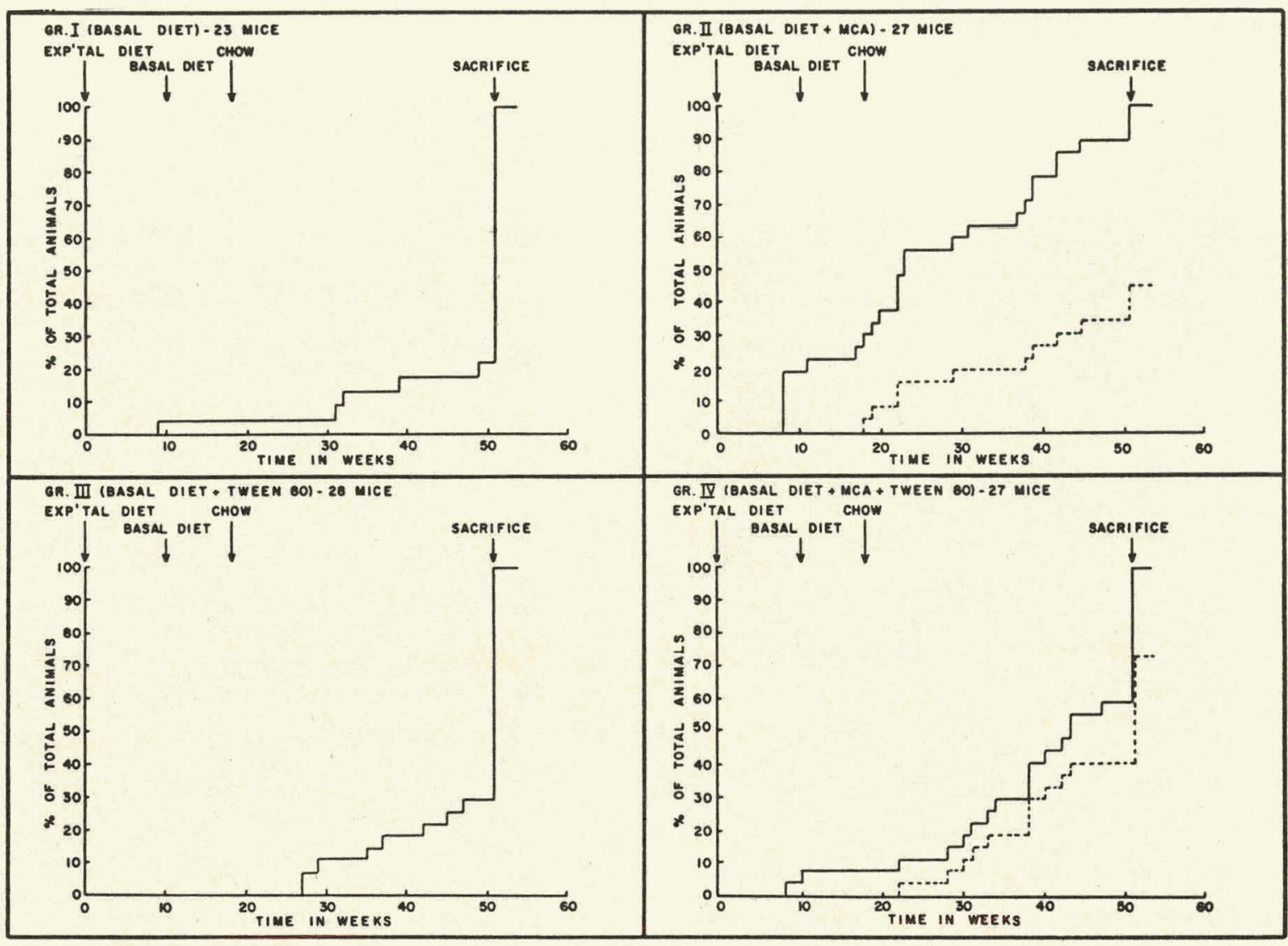

CUMULATIVE MORTALITY
CUMULATIVE LUNG TUMOR INCIDENCE

Figure 3. Mortality and lung-tumor incidence plotted as per cent of total animals against time.

to reduce the induction time for squamous papilloma of the forestomach, as the first such lesion was found during the 19th week in Group II and during the 30 th week in IV (Figure 6). However, as with the lung tumors, the marked difference in the incidence of mortality of the 2 groups from about the 19th to the 30 th week may have misled us. The final incidence of squamous papilloma was $14.8 \%$ in Group II and $25.9 \%$ in IV. The incidence of squamous papilloma followed the incidence of mortality much more closely in Group IV than in II.

The final incidence of carcinoma of the squamous stomach was $3.7 \%$ in Group II and 
$7.4 \%$ in IV (Figure 6). Since these percentages represented 1 animal and 2 animals, respectively, they are not thought to be statistically significant.

Mice in Groups I and III, not given methylcholanthrene, revealed no pathologic changes in the glandular stomach throughout the experiment (Figure 9). A typical histologic picture of the glandular stomach from mice of Groups I and III is shown in Figure 10. Mice from Groups II and IV, the diets of which contained methylcholanthrene or methylcholanthrene plus Tween 80 , showed both atrophic and proliferative changes in the glandular stomach (Figure 9).
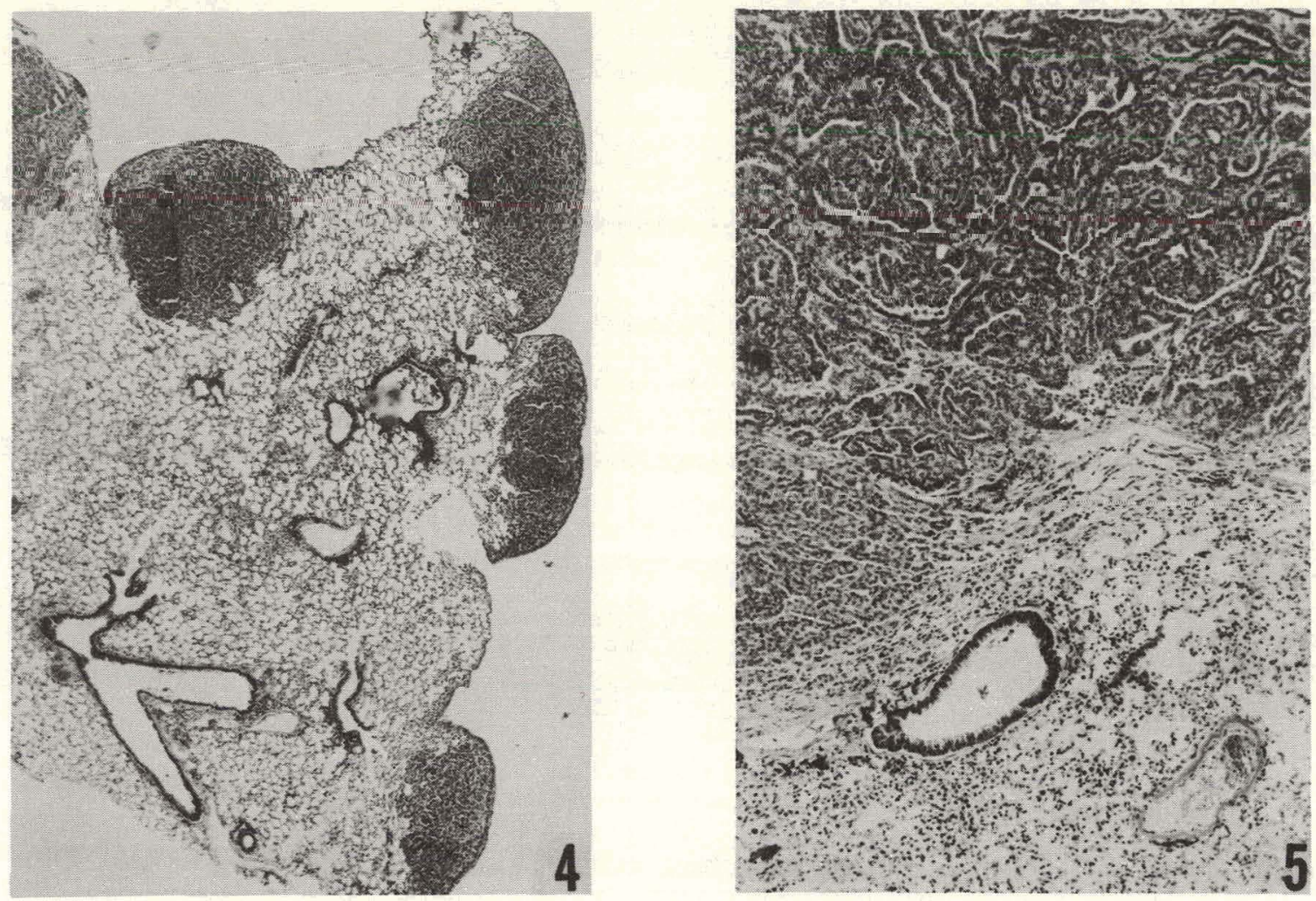

Figure 4. Multiple lung tumors, in early stage of development, from Group IV animal dying in 38th week of experiment. Tumors are derived from alveolar lining cells rather than from bronchial epithelium. Note multicentric nature of the tumors and their predilection for growing in peripheral zones of lung. The individual tumors are composed of solid masses of cuboidal tumor cells.

Figure 5. Lung tumor, in late stage of development, from Group IV animal killed at end of experiment. Note papillary structure of a portion of the tumor.

The atrophic changes consisted of a decrease in the thickness of the mucosa, loss of parietal cells, replacement of normal gastric glands by mucus-secreting glands of the intestinal type, and a slight to moderate increase of fibrous tissue in the mucosa, muscularis mucosae, and submucosa. An example of the atrophic changes is shown in Figure 11. 
These changes, whenever present, were found uniformly throughout the entire length of the multiple longitudinal sections taken routinely from each stomach, and were never observed in similar sections of the stomach from control animals.

The proliferative changes consisted of an increase in the thickness of the mucosa, at times to as much as 4 times the normal thickness (Figures 12 and 13). The glands were also of the intestinal type, but instead of being short and atrophic, hypertrophy and hyperplasia had taken place, giving rise to tortuosity of the glands and disruption of the normal

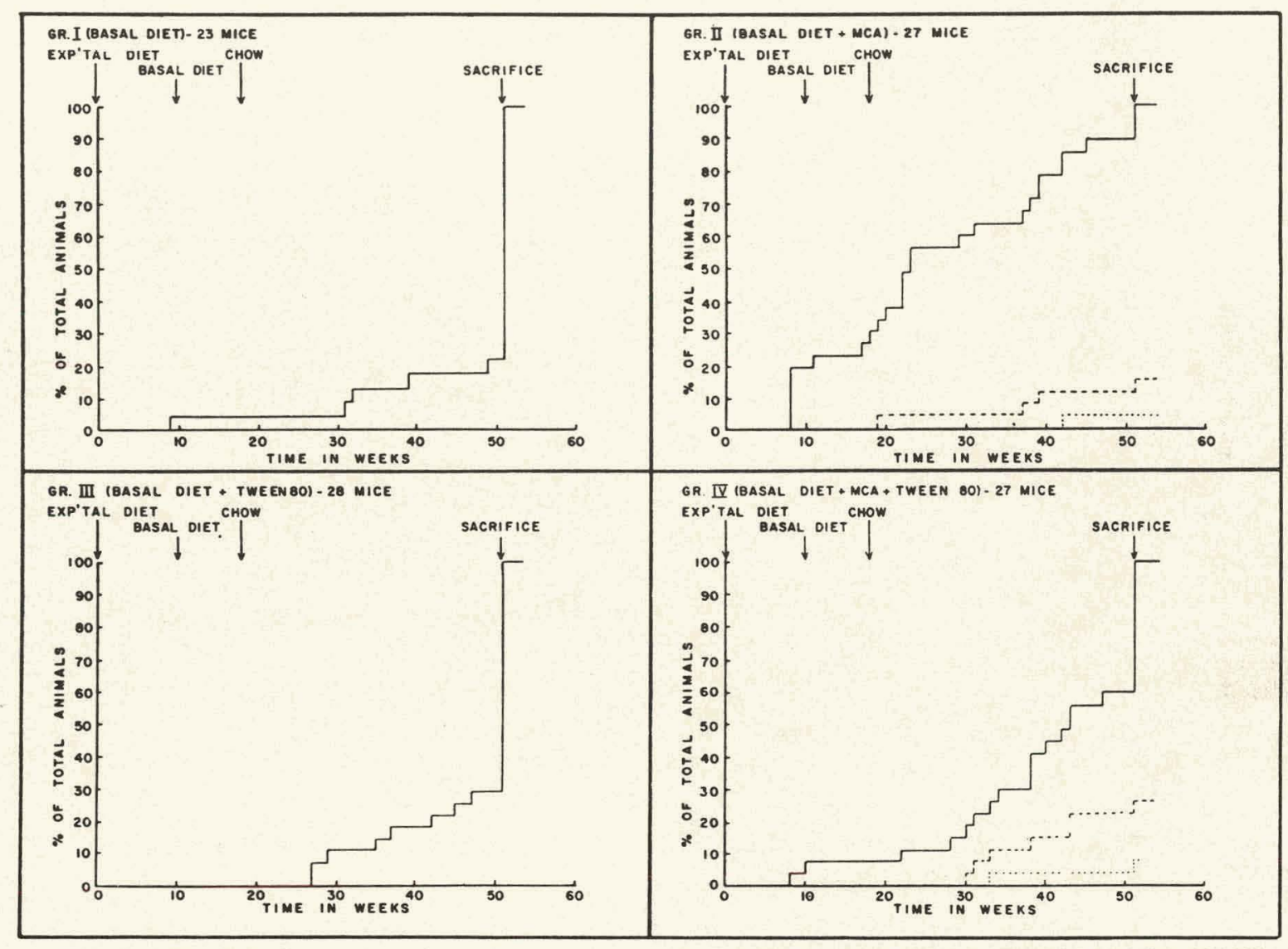

- CUMULATIVE MORTALITY

CUMULATIVE INCIDENCE OF PAPILLOMA OF SOUAMOUS STOMACH

Figure 6. Mortality and incidence of papilloma and carcinoma of squamous stomach plotted as per cent of total animals against time.

regularity of the glandular pattern. The glands were frequently hyperchromatic and showed crowding and depolarization of the nuclei. There was often an increase in the number of mitotic figures. As with atrophic changes, a loss of parietal cells was observed. Cystic degeneration of the glands was also seen.

As shown in Figure 9, the appearance of atophic changes preceded that of proliferative changes in both Groups II and IV. In point of fact, the appearance of the atrophic changes seemed to be limited to the earlier part of the experiment, whilc the appearance 
of the proliferative changes seemed to be limited to the later part. The course of action of the carcinogen, judging from the sequence of pathologic changes observed, would seem to be an initial suppressive effect followed by a late enhancing effect on cell growth. The result was that the mucosa of the glandular stomach underwent an initial phase of atrophic changes, together with conversion of the highly specialized gastric glands to the simple intestinal type of glands, and then progressed to a final phase of proliferative changes. A
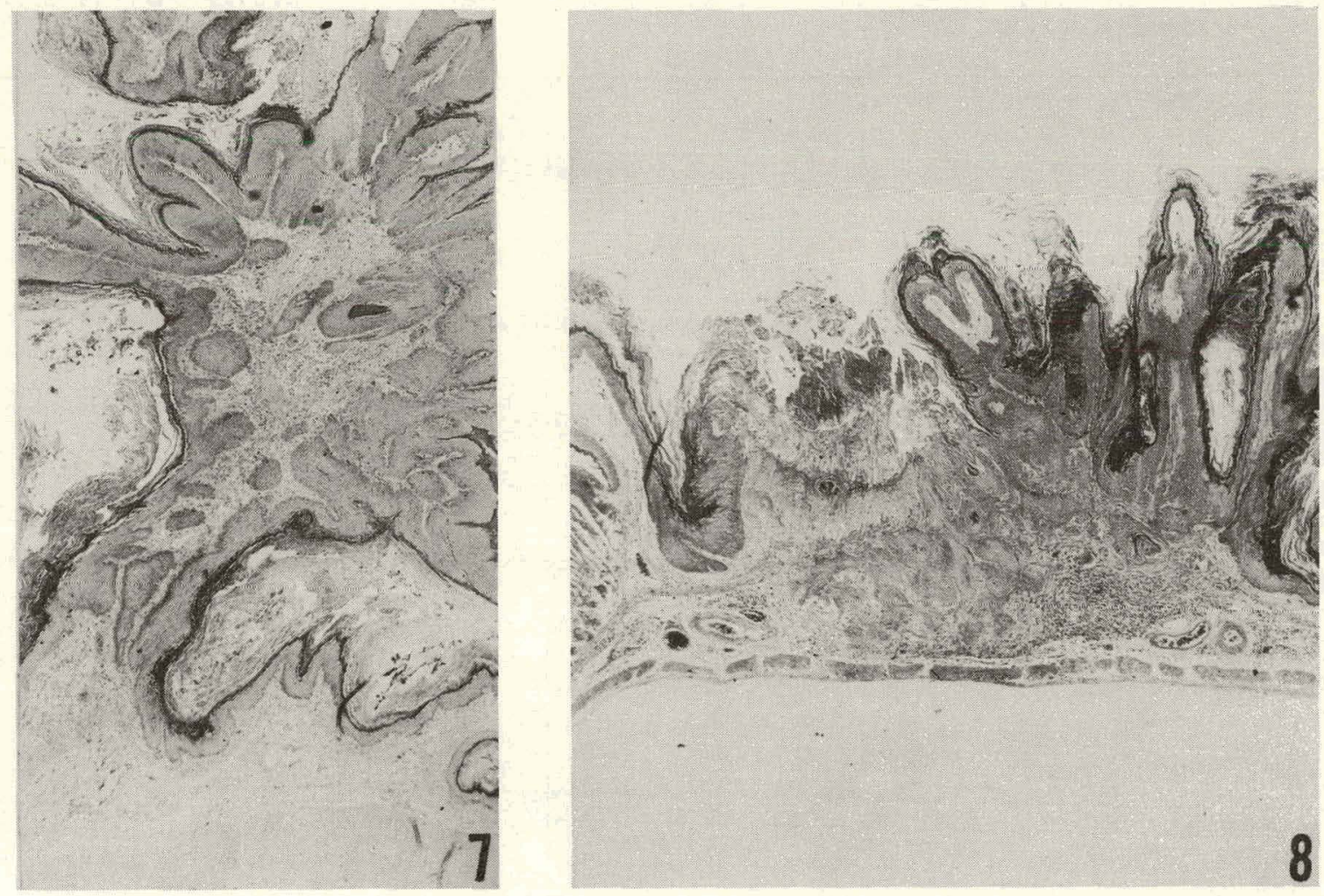

Figure 7. Squamous papilloma of forestomach from Group II animal killed at end of experiment.

Figure 8. Squamous carcinoma of forestomach from Group IV animal killed at end of experiment. Note invasion of the squamous epithelium to a considerable distance below the muscularis mucosae. The overlying squamous epithelium is highly proliferative.

similar sequence of events has been observed in the induction of hepatomas by acetylaminofluorene, in which suppression of the liver cells was first observed, followed by proliferation. The same sequence has been observed in cases of irradiation dermatitis which eventually progress to carcinomas of the skin.

Tween 80 added to methylcholanthrene did not cause the atrophic changes of the glandular stomach to appear earlier in Group IV than in II, nor did it cause an increase in the incidence of atrophic changes in Group IV (Figure 9). In fact, the incidence of atrophic changes in Group II (11.1\%) was higher than that in group IV (3.7\%). However, the inci- 
dence of mortality in Group II was much greater than that in IV in the initial part of the experiment. Since the appearance of atrophic changes was limited to the earlier part of the experiment, the apparently lower incidence of atrophic changes in Group IV may well have been because fewer animals in this group died early in the experiment. Thus, even though there may have been atrophic changes, these would not have been detected but would have progressed to the proliferative changes that were observed in the later part of the experiment.

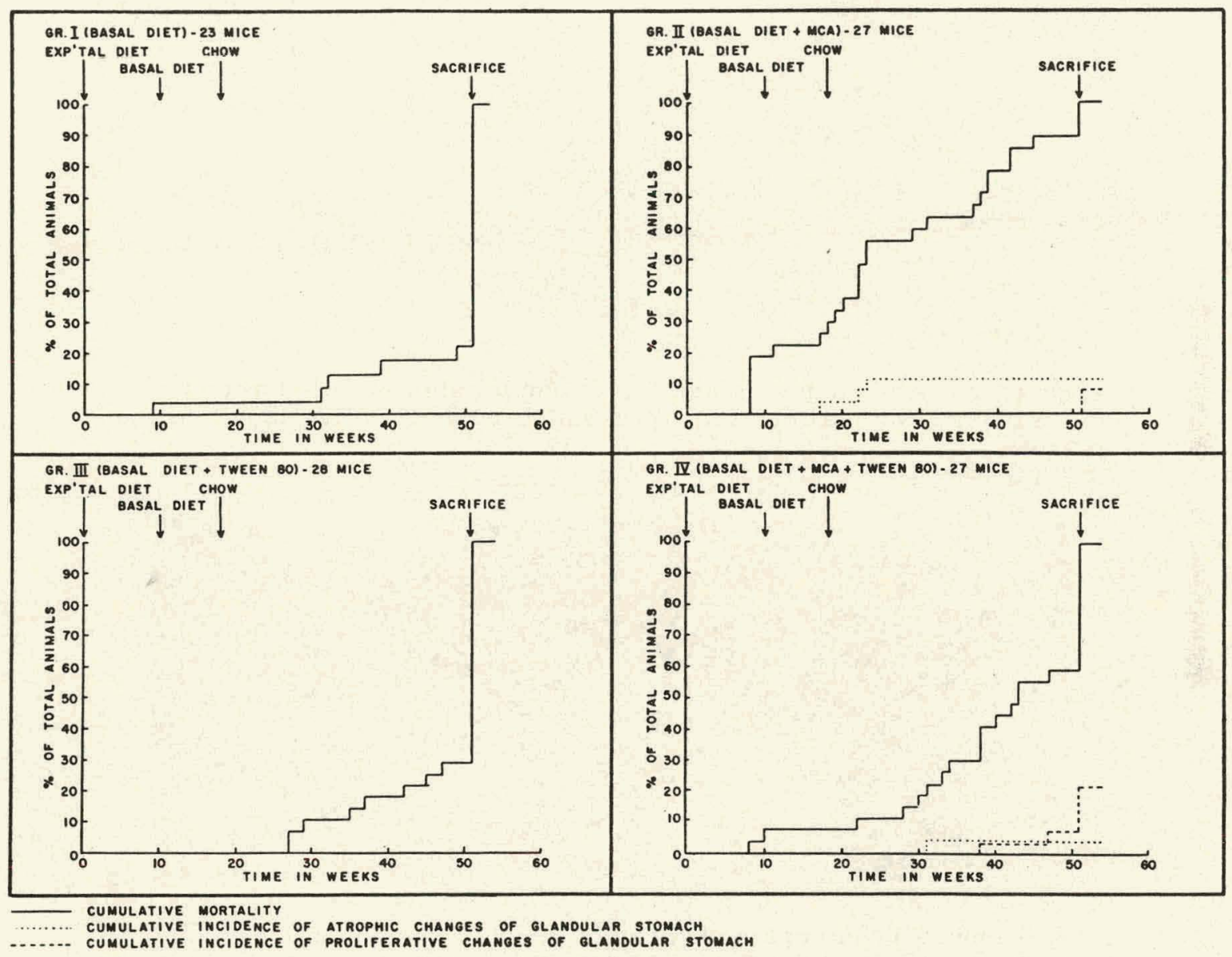

Figure 9. Mortality and incidence of atrophic changes and proliferative changes of glandular stomach plotted as per cent of total animals against time.

The proliferative gastric changes in Group IV (Figure 9) did occur earlier and in greater number than in Group II (week $38 \mathrm{vs}$. week 51). This earlier appearance of proliferative changes in Group IV may not have been significant, since the number of animals involved was small. Furthermore, the greater incidence of proliferative changes in Group IV may be partially explained by the greater number of animals surviving in the last half of the study. However, this may not be a complete explanation, for there was a relatively 
long period before the end of the experiment during which the animals in the 2 groups were dying at about the same rate, yet proliferative changes of the glandular stomach were found only in the animals of Group IV. The final incidence of these proliferative changes was $22.2 \%$ in Group IV and $7.4 \%$ in Group II. In addition to this difference, the final proliferative changes observed in the animals that were killed were generally more severe histologically in Group IV than in II.

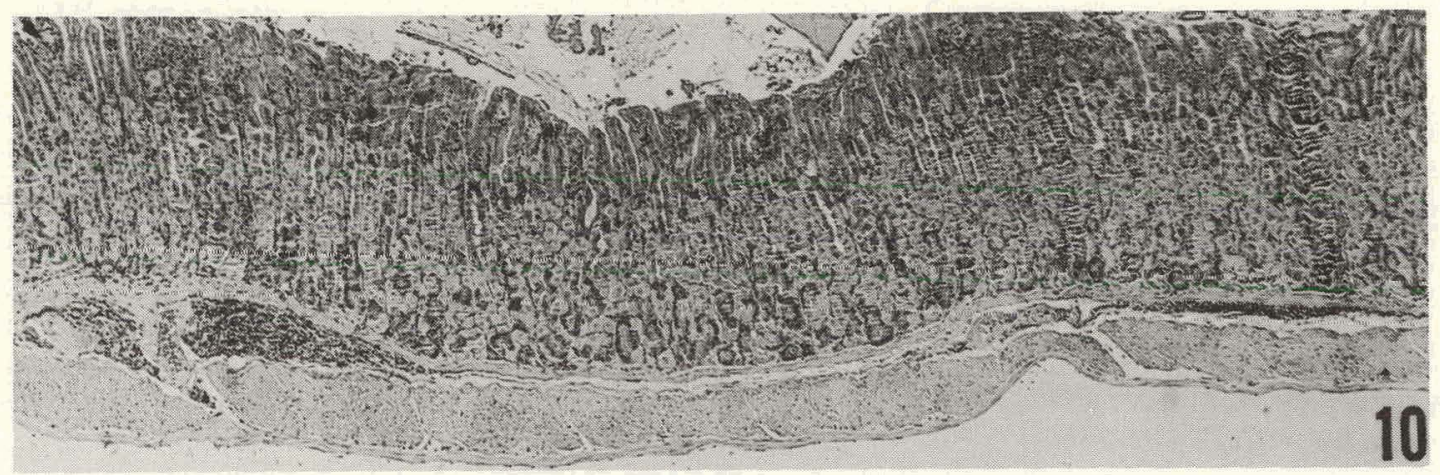

Figure 10. Glandular stomach from Group I animal killed at end of experiment. Parietal cells are present throughout entire length of the mucosa.

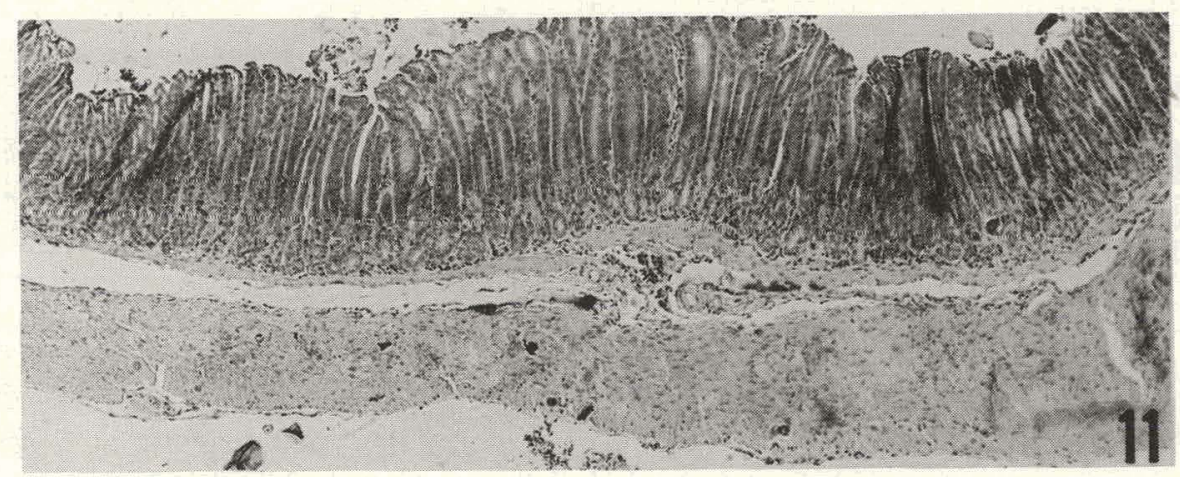

Figure 11. Atrophic changes of glandular stomach from Group IV animal dying in 31 st week of experiment. Note decrease in thickness of the mucosa (see Figure 10, which is a section of the glandular stomach from a Group I animal under same magnification). Note also loss of parietal cells and replacement of the normal gastric glands by mucussecreting glands of the intestinal type.

One interesting finding in connection with the proliferative changes of the glandular stomach was observed in an animal in Group IV that was killed. There was, in addition to severe proliferative changes in the mucosa in the glandular stomach, an invasion of the glands below the muscularis mucosae (Figure 14). Around the invaded areas, the submucosa was infiltrated with chronic inflammatory cells consisting of lymphocytes and plas- 
ma cells. This type of "adenomaluus lesion" has been observed to develop spontaneously in mice of strain I. It has also been seen in mice fed methylcholanthrene and dibenzanthracene in oil emulsions.

The leukemias, both lymphocytic and myelogenous, and other tumors found in the various groups of animals are listed in Table 3. Leukemia occurred most frequently in Group IV, with 4 animals developing this disease, or 14.8 per cent of the group. Of these 4 animals, 3 had myelogenous leukemia and 1 had lymphocytic leukemia. This neoplastic proc-

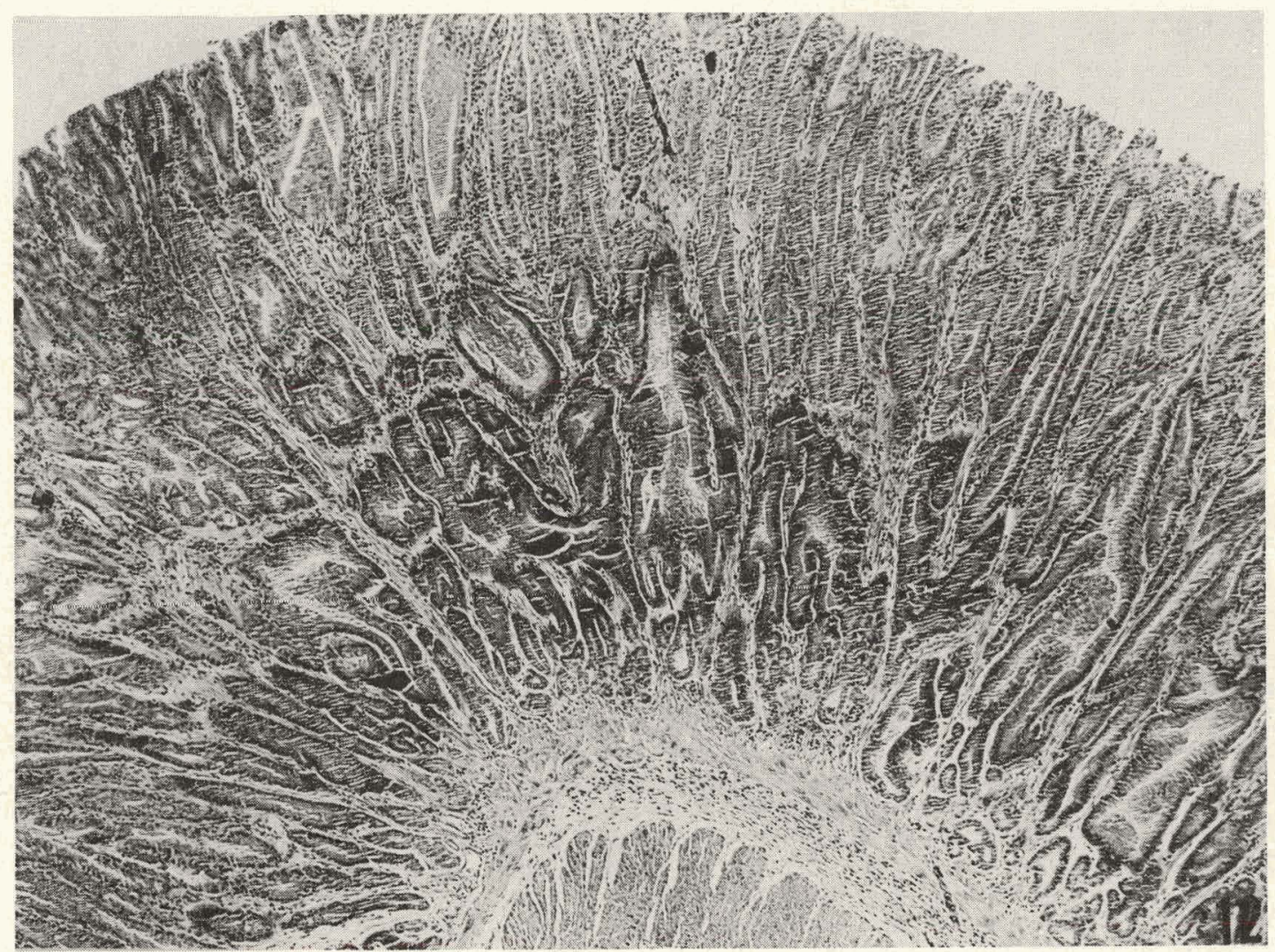

Figure 12. Proliferative changes of glandular stomach from Group IV animal killed at end of experiment. The thickness of the mucosa is about 3 times that of control (see Figure 10). Note highly proliferative intestinal-type of glands, especially in basal layer of the mucosa; distortion of normal glandular pattern; hyperchromatism; and loss of parietal cells.

ess occurred next most frequently in Group II, with 2 animals developing the myelogenous variety and 1 developing the lymphocytic variety. These represent $11.1 \%$ of the animals in the group. In Group II, 1 animal developed myelogenous leukemia and 1 developed a malignant thymoma. The latter demonstrated characteristics of a lymphocytic leukemia, as evidenced by a large quantity of abnormal lymphocytes in the blood. Group I had the lowest incidence of leukemia; 1 animal developed the lymphocytic variety. In view of the small difference in the incidences of leukemia in the various groups and its seemingly spontaneous 
Table 3

INCIDENCE AND TIME OF APPEARANCE OF LEUKEMIAS AND OTHER NEOPLASMS

\begin{tabular}{|c|c|c|c|c|c|c|}
\hline & & & $\begin{array}{l}\text { Group I- } \\
23 \text { mice }\end{array}$ & $\begin{array}{l}\text { Group II- } \\
27 \text { mice }\end{array}$ & $\begin{array}{l}\text { Group III- } \\
28 \text { mice }\end{array}$ & $\begin{array}{l}\text { Group IV- } \\
27 \text { mice }\end{array}$ \\
\hline \multirow{3}{*}{ Leukemia } & \multirow{2}{*}{ Incidence } & Number of mice & 1 & 3 & 1 & 4 \\
\hline & & Per cent of total mice & 4.3 & 11.1 & 3.6 & 14.8 \\
\hline & Time found & & Weeks: 49 & $\begin{array}{c}\text { Weeks: } 22 \text {, } \\
23,51\end{array}$ & Weeks: 29 & $\begin{array}{l}\text { Weeks: } 28 \text {, } \\
31,33,47\end{array}$ \\
\hline \multirow{3}{*}{$\begin{array}{l}\text { Malignant thymoma becoming } \\
\text { leukemia }\end{array}$} & \multirow{2}{*}{ Incidence } & Number of mice & 0 & 0 & 1 & 0 \\
\hline & & Per cent of total mice & 0 & 0 & 3.6 & 0 \\
\hline & Time found & & & & Weeks: 45 & \\
\hline \multirow{3}{*}{ Hepatoma } & \multirow{2}{*}{ Incidence } & Number of mice & 0 & 0 & 1 & 1 \\
\hline & & Per cent of total mice & 0 & 0 & 3.6 & 3.7 \\
\hline & Time found & & & & Weeks: 51 & Weeks: 51 \\
\hline \multirow{3}{*}{ Hemangioendothelioma } & \multirow{2}{*}{ Incidence } & Number of mice & 0 & 0 & 0 & 1 \\
\hline & & Per cent of total mice & 0 & 0 & 0 & 3.7 \\
\hline & Time found & & : & & & Weeks: 51 \\
\hline \multirow{3}{*}{$\begin{array}{l}\text { Squamous-cell carinoma of } \\
\text { skin }\end{array}$} & \multirow{2}{*}{ Incidence } & Number of mice & 0 & 3 & 0 & 2 \\
\hline & & Per cent of total mice & 0 & 11.1 & 0 & 7.4 \\
\hline & Time found & & & $\begin{array}{c}\text { Weeks: } 22 \text {, } \\
23,31\end{array}$ & & $\begin{array}{l}\text { Weeks: } 28, \\
38\end{array}$ \\
\hline \multirow{3}{*}{$\begin{array}{l}\text { Benign, sebaceous-gland } \\
\text { tumor of skin }\end{array}$} & \multirow{2}{*}{ Incidence } & Number of mice & 0 & 1 & 0 & 0 \\
\hline & & Per cent of total mice & 0 & 3.7 & 0 & 0 \\
\hline & Time found & & & Weeks: 51 & & \\
\hline
\end{tabular}


appearance in animals of the 2 control groups, little significance was attached to these findings.

Hepatomas were found only in Groups III (Tween diet) and IV (Tween + methylcholanthrene), with 1 animal in each group developing this tumor (Table 3). Both of these hepatomas may have occurred spontaneously. However, they differed considerably from one another in histologic characteristics. The hepatoma of Group III had comparatively welldifferentiated cells with nuclei that were very uniform in size. There was only slight nuclear hyperchromatism. The hepatoma of Group IV, on the other hand, showed a great

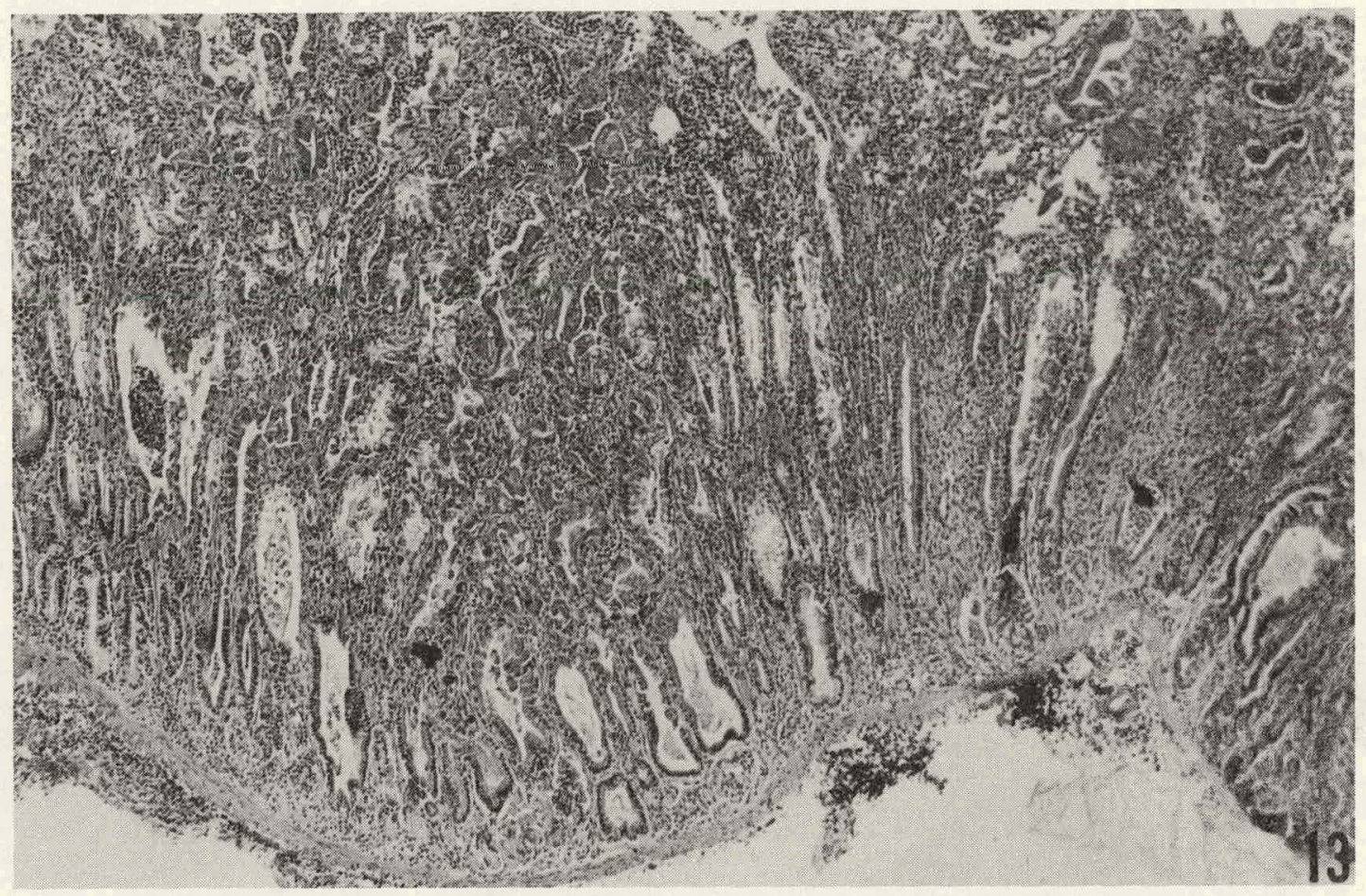

Figure 13. Proliferative changes of glandular stomach from Group IV animal dying in 38th week of experiment. The thickness of the mucosa is 3 to 4 times that of control (see Figure 10, which is a section of glandular stomach from a Group I animal under the same magnification). Note hyperchromatic proliferative glands, with cystic changes and loss of parietal cells.

deal of variation in nuclear and cell size. There were abnormal mitoses with varying degrees of apparent polyploidy of the chromosomes. Hyperchromatic giant nuclei were present. Nuclear "inclusion bodies," probably of viral origin, were found in great numbers in the tumor cells. These "inclusion bodies" were also observed in the liver of animals without hepatoma, particularly those animals receiving methylcholanthrene.

One hemangioendothelioma was found in a Group IV animal in the region of the pancreas. None was found in animals of any other group.

Squamous-cell carcinoma of the skin developed in 3 animals of Group II $(11.1 \%)$ and 
in 2 animals of Group IV (7.4\%). A benign sebaceous-gland tumor of the skin developed in an animal of Group II. It seems likely that these tumors developed as a result of contact of the skin with the carcinogenic diet rather than as a result of absorption of carcinogen from the gastrointestinal tract since they developed at sites of denuded skin caused by fighting among the animals.

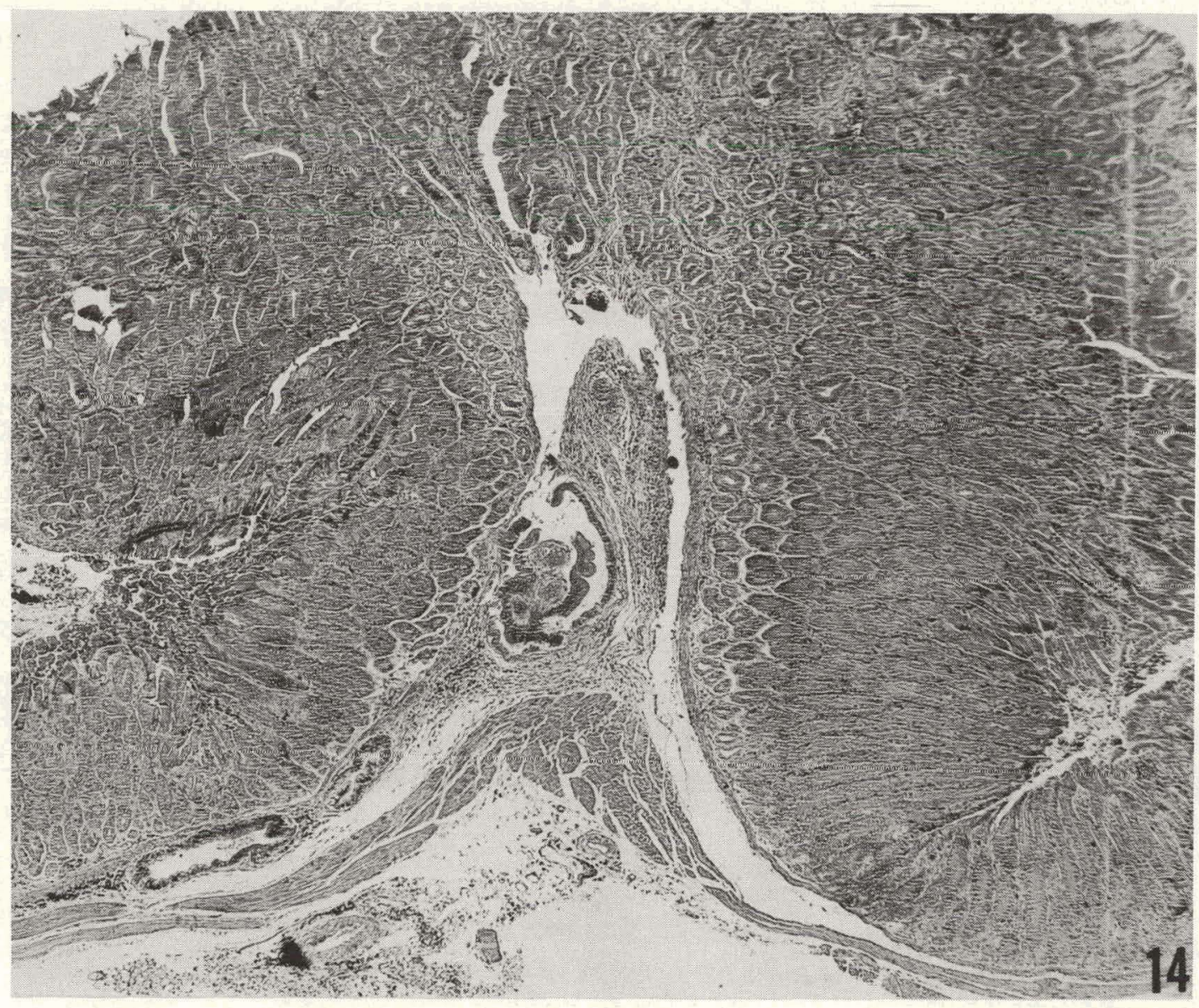

Figure 14. Proliferative changes of glandular stomach from Group IV animal killed at end of experiment. Note the almost polypoid proliferation of mucosa. Note also that, in addition to having those changes listed under Figures $1 \overline{2}$ and 13 , there are invasions of the glands below the muscularis mucosae at three sites. At one of these sites, the invading glands are more proliferative and irregular than those at the other sites.

None of the animals in Groups I or III developed more than 1 primary neoplasm (Table 4). On the other hand, a number of animals in Groups II and IV developed more than 1 primary neoplasm at a time. In Group II there were 6 animals (22.2\%) with multiple primary neoplasms. Each of these had 2 primaries. in Group IV there were 10 animals $(37.0 \%)$ with multiple primary neoplasms. Of these, 8 had 2 primaries and 2 had 3 primaries. Some multiple primary neoplasms were also associated with atrophic or prolif- 
Table 4

INCIDENCE OF MULTIPLE PRIMARY NEOPLASMS IN INDIVIDUAL MICE *

\begin{tabular}{c|c|c|c|c}
\hline \multirow{2}{*}{ Group } & \multicolumn{2}{|c|}{ Two primary neoplasms } & \multicolumn{2}{c}{ Three primary neoplasma } \\
\cline { 2 - 5 } & $\begin{array}{c}\text { Mice } \\
(\text { No.) }\end{array}$ & $\begin{array}{c}\text { Total mice } \\
(\%)\end{array}$ & $\begin{array}{c}\text { Mice } \\
(\text { No. })\end{array}$ & $\begin{array}{c}\text { Total mice } \\
(\%)\end{array}$ \\
\hline I & 0 & 0.0 & 0 & 0.0 \\
II & 6 & 22.2 & 0 & 0.0 \\
III & 0 & 0.0 & 0 & 0.0 \\
IV & 8 & 29.6 & 2 & 7.4 \\
\hline
\end{tabular}

* Skin tumors excluded.

erative changes of the glandular stomach.

The tumor incidence per animal, excluding skin tumors, is summarized in Table 5. Group IV had the highest incidence per animal; next, Group II, Group III, and then Group I. It is notable that the tumor incidence per animal in Group IV is 1.76 times that in Group II.

In examining the sections of liver, it was observed that there were changes in the hepatic nuclei of animals in Groups II and IV not found in animals of Groups I and II (Figures 15 to 17). These changes did not begin to occur until 5 to 6 months after the start of the experiment. Thereafter, they increased in severity with time. These changes consisted of:

Abnormal mitoses. Abnormal mitoses, resulting in irregular distribution of chromosomes and probable polyploidy, were seen in some of the liver sections from animals of Groups II and IV.

Variation in size of cells and nuclei. Variation in the size of the hepatic cells and nuclei in Groups II and IV animals had a general tendency to increase proportionately with the length of time that the animals had lived, with some of the cells and nuclei progressing to giant size and others diminishing to a smaller size than at the beginning of the experiment (Figure 16). This wide range in size was probably dependent on aberrations in mitoses, which led to unequal partition of chromosomes in the daughter cells.

Variation in shape of nuclei. The variation in the shape of the nuclei observed in this experiment seemed to result mainly from amitotic division of the cells, which occurred with unusual frequency in the livers of Groups II and IV animals and led to dumbbell-shaped nuclei or nuclei with polycyclic borders (Figure 17).

The nuclear changes did not correlate statistically with infectious processes or amyloidosis occurring in the liver.

Intranuclear inclusion bodies were seen in the liver cells of all 4 groups of animals, 
Table 5

TOTAL INCIDENCE OF TUMORS PER GROUP AND PER ANIMAL *

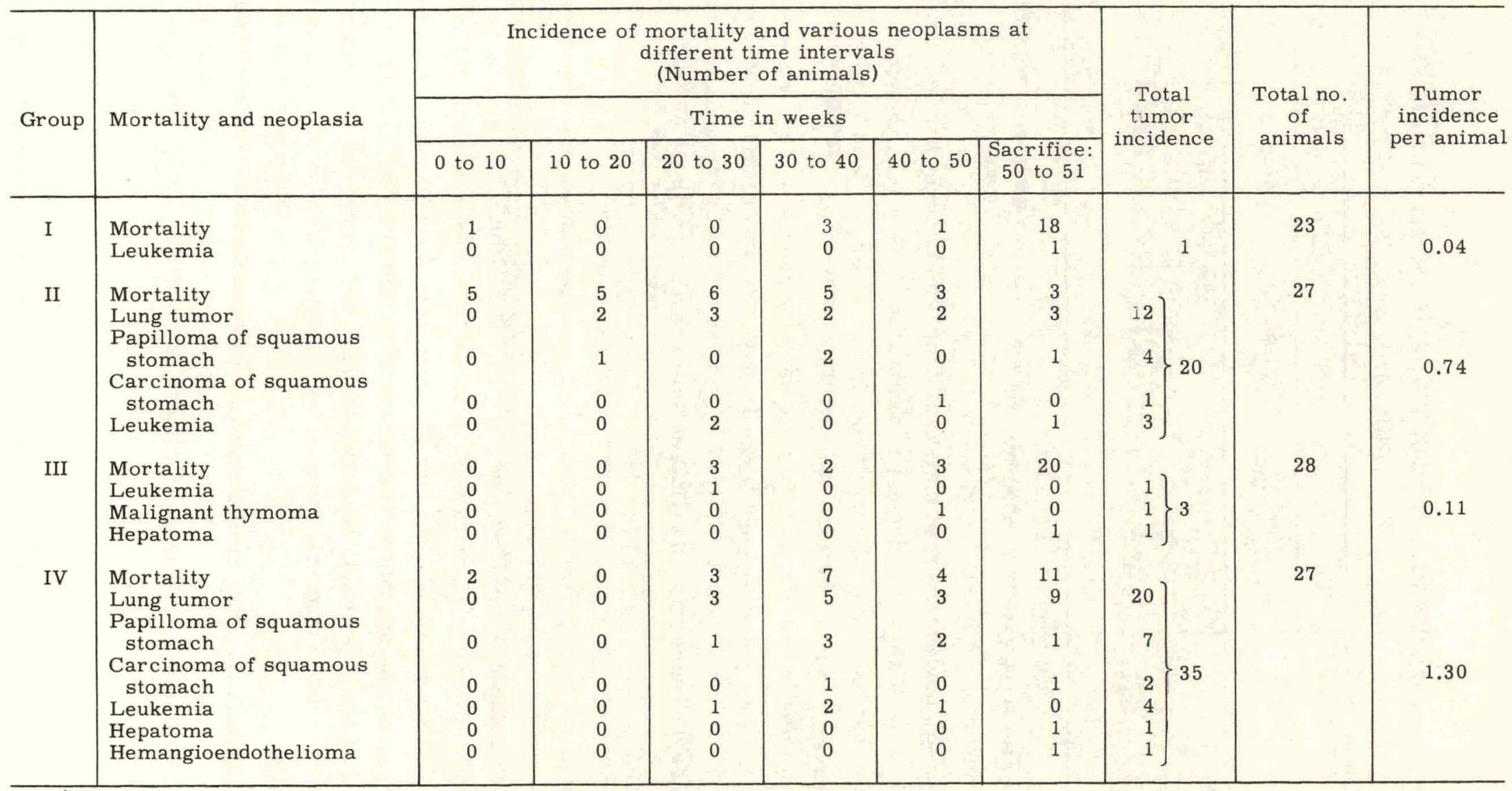

* Skin tumors excluded. 
though a greater number was present in the livers of Groups II and IV. These bodies were found about equally often in Group II and IV animals and were believed to be of viral origin (Figures 18 and 19). The number of these intranuclear inclusion bodies, according to the above observations, would seem to be in some way related to the administration of methylcholanthrene. This brings to mind the theory concerning the etiology of cancer that all exogenous carcinogens, including carcinogenic chemicals, work through viruses in the induction of tumors, as suggested by Rous ${ }^{11}$ and Andrewes ${ }^{12}$ and supported recently by
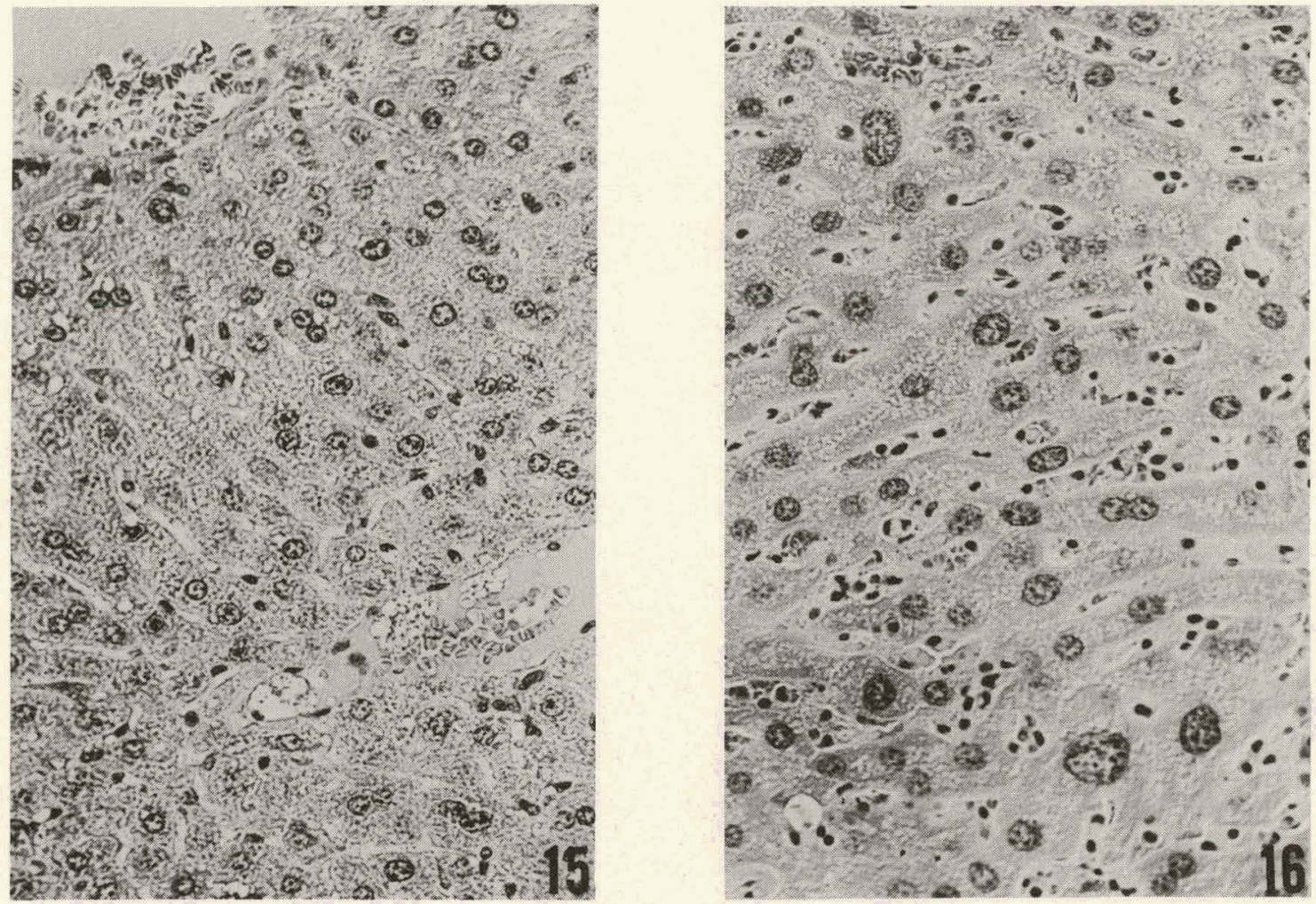

Figure 15. Liver from Group I animal killed at end of experiment. Note regularity in size of cells and nuclei.

Figure 16. Liver from Group IV animal dying in 27 th week of experiment. Note marked variation in size of hepatic nuclei. Compare this with liver from Group I animal in Figure 15 with respect to nuclear size, taken under same magnification.

Oberling and Guérin. ${ }^{13}$ However, the fact that hepatomas were not found any more frequently in the 2 groups of animals fed methylcholanthrene, although these animals had a greater number of viral inclusion bodies in their liver, and the fact that no inclusion bodies were found in the hepatoma of the Group III animal (Tween diet), although they were found in great numbers in the hepatoma of the Group IV animal (methylcholanthrene + Tween), seem to indicate that these viruses were not connected etiologically with the development of hepatomas in the present experiment. On the other hand, it seems more rea- 
sonable to conclude that these exogenous viruses were probably much better able to infect the hepatic cells after the latter were in some way altered by the action of methylcholanthrene. This would explain the presence of a greater number of these inclusion bodies in the hepatic cells of animals fed methylcholanthrene, whether these cells were in a hepatoma or in an ordinary liver.

An important finding in this experiment was the frequent development of widespread amyloidosis. The organs most commonly involved were spleen, liver, kidneys, small intestine, stomach, and cecum, in that order.
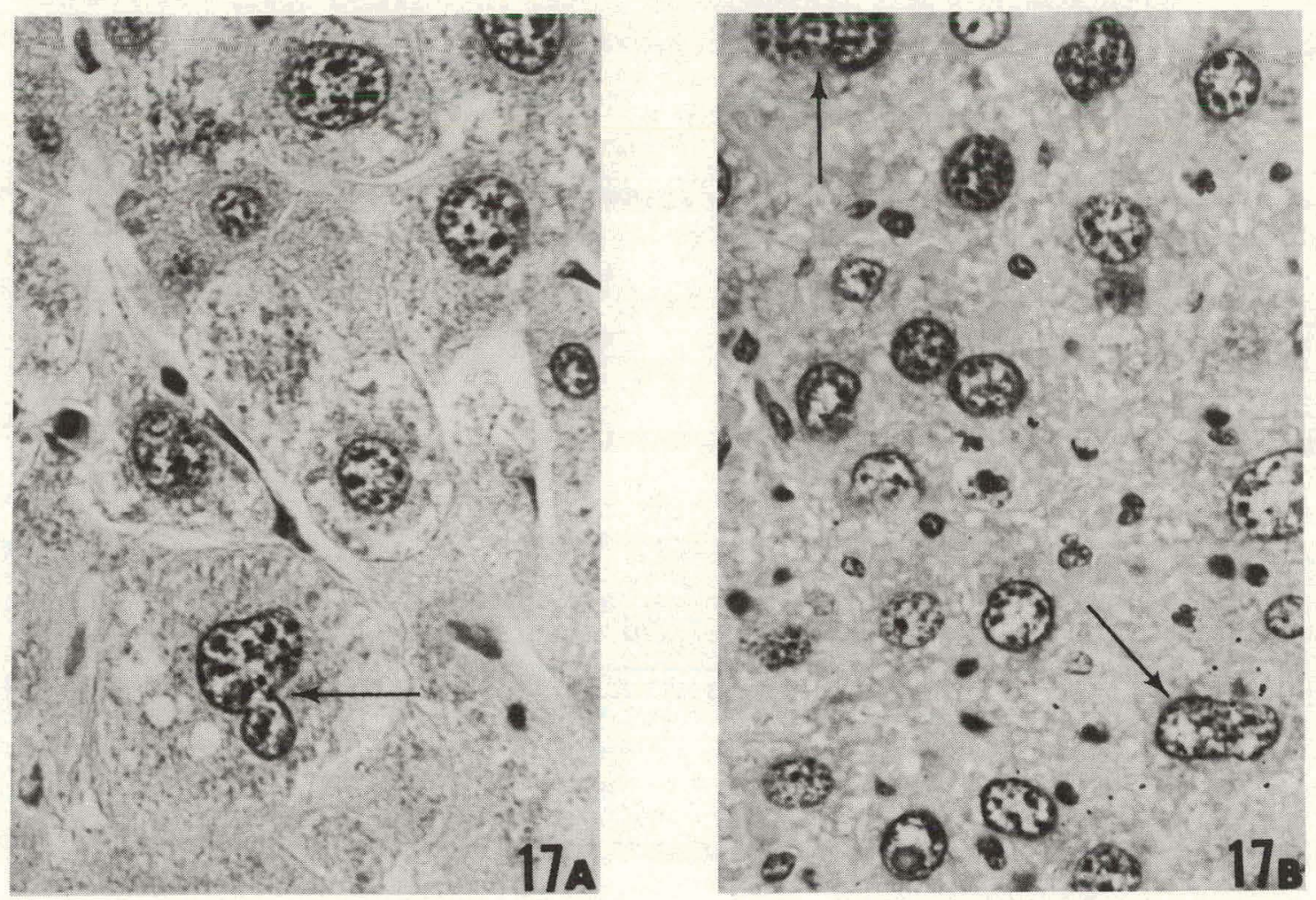

Figures 17A and 17B, A. Liver of Group IV animal killed at end of experiment. B. Liver of Group II animal dying in 36 th week of experiment. Note variation in shape of nuclei, especially at sites of arrows.

The spleen, liver, and kidneys were usually involved concurrently in the process, though occasionally amyloid was found only in the spleen or the liver. In the spleen (Figure 20), the amyloid was characteristically deposited initially around the periphery of the lymph follicles, later on spreading to involve the entire spleen. In the liver (Figure 21), the amyloid was deposited between the endothelial lining cells of the sinusoids and the hepatic cells, as well as in the wall of the blood vessels. In the kidneys, the amyloid was deposited in the glomeruli and blood vessel walls. In the glomeruli, the amyloid was found between the basement membrane and the endothelial lining of the capillaries (Figure 22). 
Amyloidosis of the gastrointestinal tract existed alone or concurrently with severe widespread amyloidosis of the other organs. In the small intestine, the amyloid deposit was almost uniformly found in the lower jejunum or ileum (Figure 23) and never in the duodenum. The stomach was occasionally involved; the cecum, only rarely. In all these sites, the amyloid was deposited in the lamina propria of the mucosa; never in the muscle coat. The small intestine was usually involved more severely than the other gastrointes-

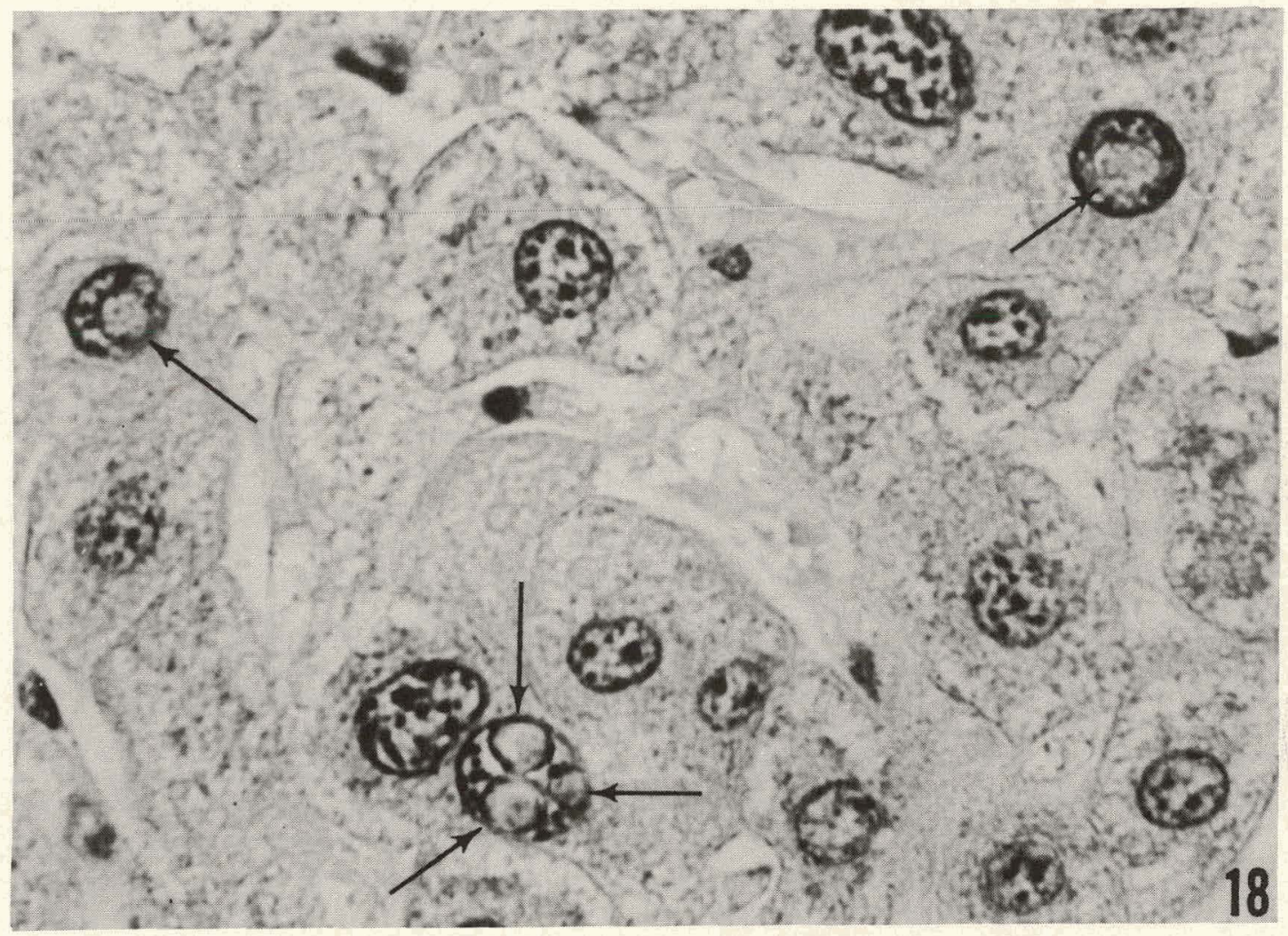

Figure 18. Liver from Group IV animal killed at end of experiment.

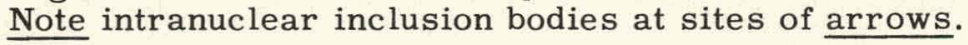

tinal sites. The villi here were usually expanded as a result of the deposit in the lamina propria (Figure 23). Amyloidosis was also occasionally observed in the pancreas; deposited mainly in the connective tissue between the acini. As the pancreas was not among the tissues taken routinely for histologic examination, the relative frequency of amyloidosis in this organ could not be assessed. In one animal, amyloidosis was found in the heart alone.

Amyloidosis was found with about equal frequency in all groups of animals, with the exception of those in Group II. About $65 \%$ of the animals had involvement. In other groups, approximately $50 \%$ of the animals were involved. The high incidence of amyloidosis with severe renal involvement seen in Group II may have been responsible for the unusually 
high mortality in this group in the early part of the experiment. No explanation can be offered for the high incidence of amyloidosis in Group II. Amyloidosis was observed beginning at about the 8th week of the experiment. Thereafter it was found at all time intervals. Its severity did not seem to correlate with the length of time that the animals lived.

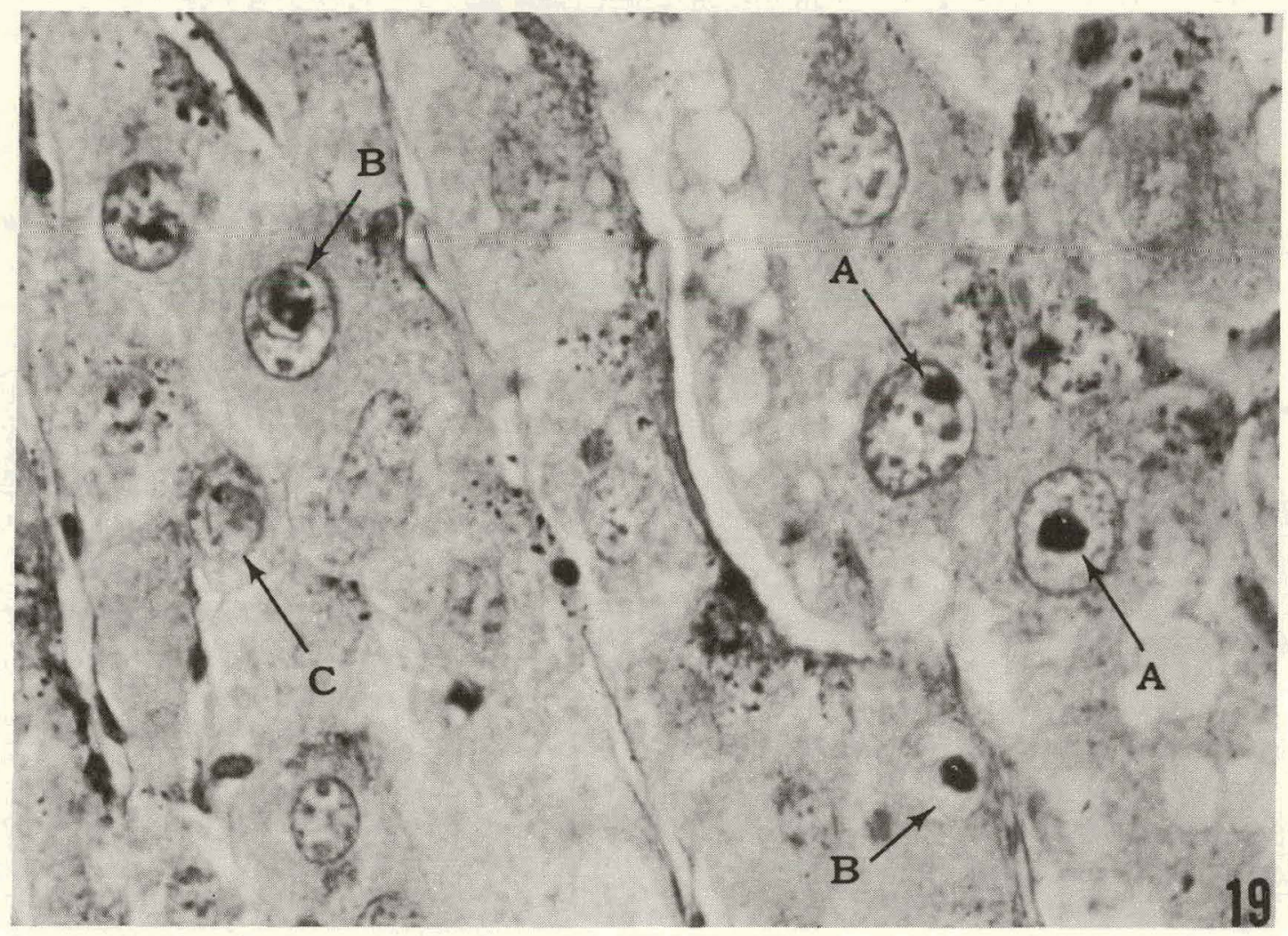

Figure 19. Periodic acid-Schiff stain of a hepatoma section from Group IV animal killed at end of experiment. Note that some intranuclear inclusion bodies are positive for the stain (marked A); others are partially positive (marked B); still others are almost completely negative (marked C).

Three possible factors may have contributed to the condition:

Infection. Amyloidosis of the secondary variety is known to be associated with long-term, chronic infectious processes. In this experiment, there seemed to be no connection between the development of amyloidosis and sporadic cases of Salmonella infection, with chronic hepatic abscesses found in some of the animals.

Tumor-bearing state. Amyloidosis of the secondary variety has been observed in terminal cancer patients as well as in-tumor-bearing mice. In this experiment, the lack of correlation between the over-all tumor incidence and the incidence of amyloidosis in the various groups does not support the tumor-bearing state as the primary causative factor for amyloidosis. 
Casein in diets. Amyloidosis has been produced by subcutaneous injection of sodium caseinate ${ }^{14}$ as well as by feeding casein to mice. ${ }^{15}$ The latter means of producing amyloidosis was reported to be less predictable than the former. ${ }^{16}$ All the diets in the present experiment contained $10 \%$ casein. The fact that 3 out of the 4 groups of animals had about the same incidence of amyloidosis seemed to favor dietary casein as the primary causative factor of amyloidosis in this experiment.
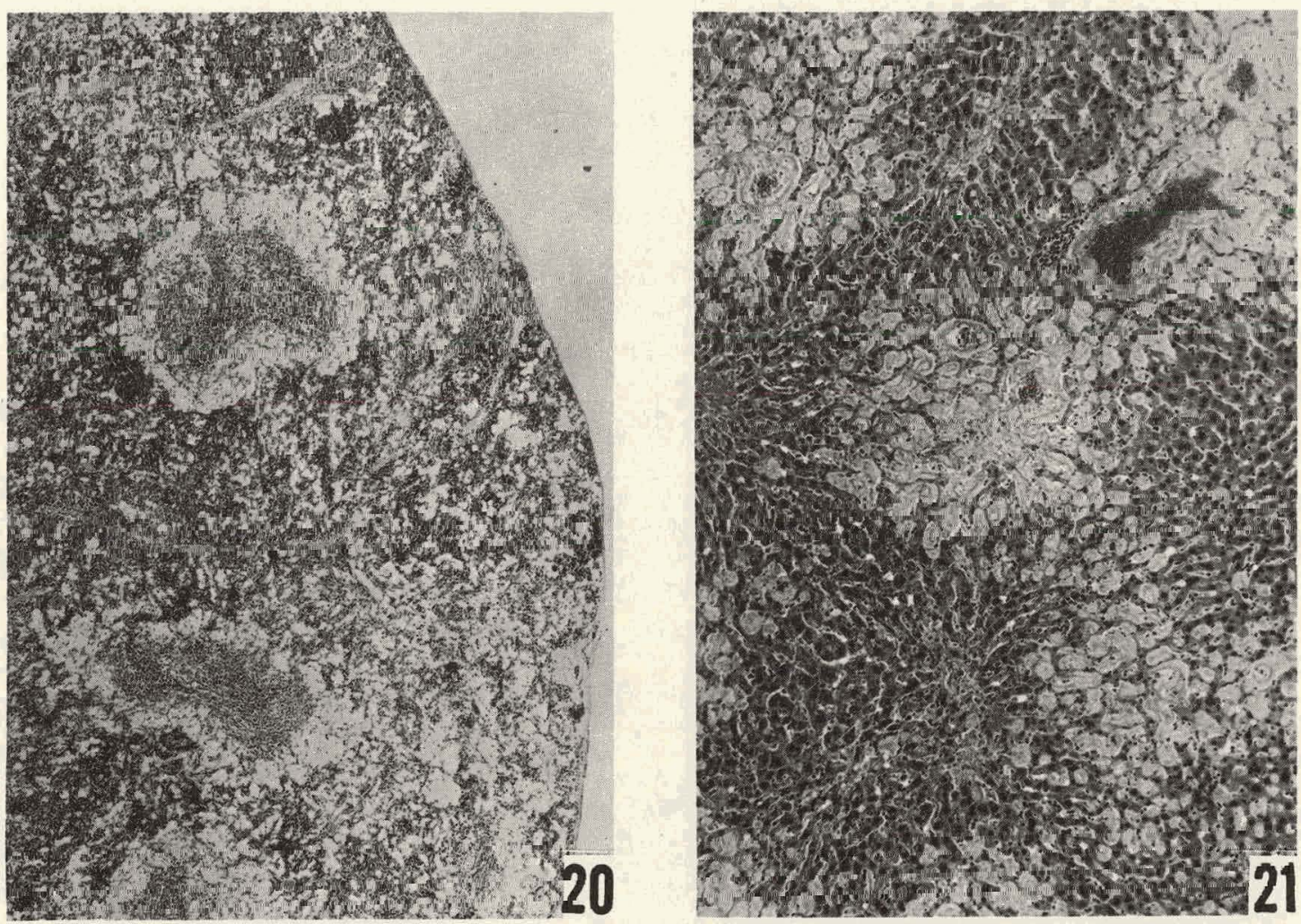

Figure 20. Amyloidosis of spleen from Group II animal dying in 8th week of experiment. Note perifollicular distribution of the amyloid deposit. There is also amyloid in the red pulp.

Figure 21. Amyloidosis of liver from a Group II animal dying in 8th week of experiment. Note deposition of amyloid 1) between endothelial lining cells of sinusoids and hepatic cells, and 2) in wall of blood vessels.

Extramedullary hematopoiesis, predominantly the myeloid variety, was observed in the liver and spleen of about $25 \%$ of the animals in Groups II and IV. The cause for this was not clear, though it could conseivably arise as a result of methylcholanthrene toxicity in the bone marrow. This speculation could not be proved or disproved in the present experiment, since the bone marrow was not studied histologically. However, Lorenz and Stewart, ${ }^{5}$ who continuously fed methylcholanthrene to mice in the form of olive-oil emulsions for about a year, found no appreciable histologic changes in the bone marrow. On 
the other hand, these investigator $\mathrm{s}^{5}$ did find a variable degree of marrow depletion, involving all cell types, in mice fed dibenzanthracene in the same kind of emulsions for 5 months or more.

Tween 80 , when fed concurrently with methylcholanthrene, potentiates the latter's carcinogenicity, in comparison to methylcholanthrene alone, as evidenced by 1) a higher total tumor incidence, 2) a higher incidence of multiple primary neoplasms, and 3) more pronounced proliferative changes of the glandular stomach.
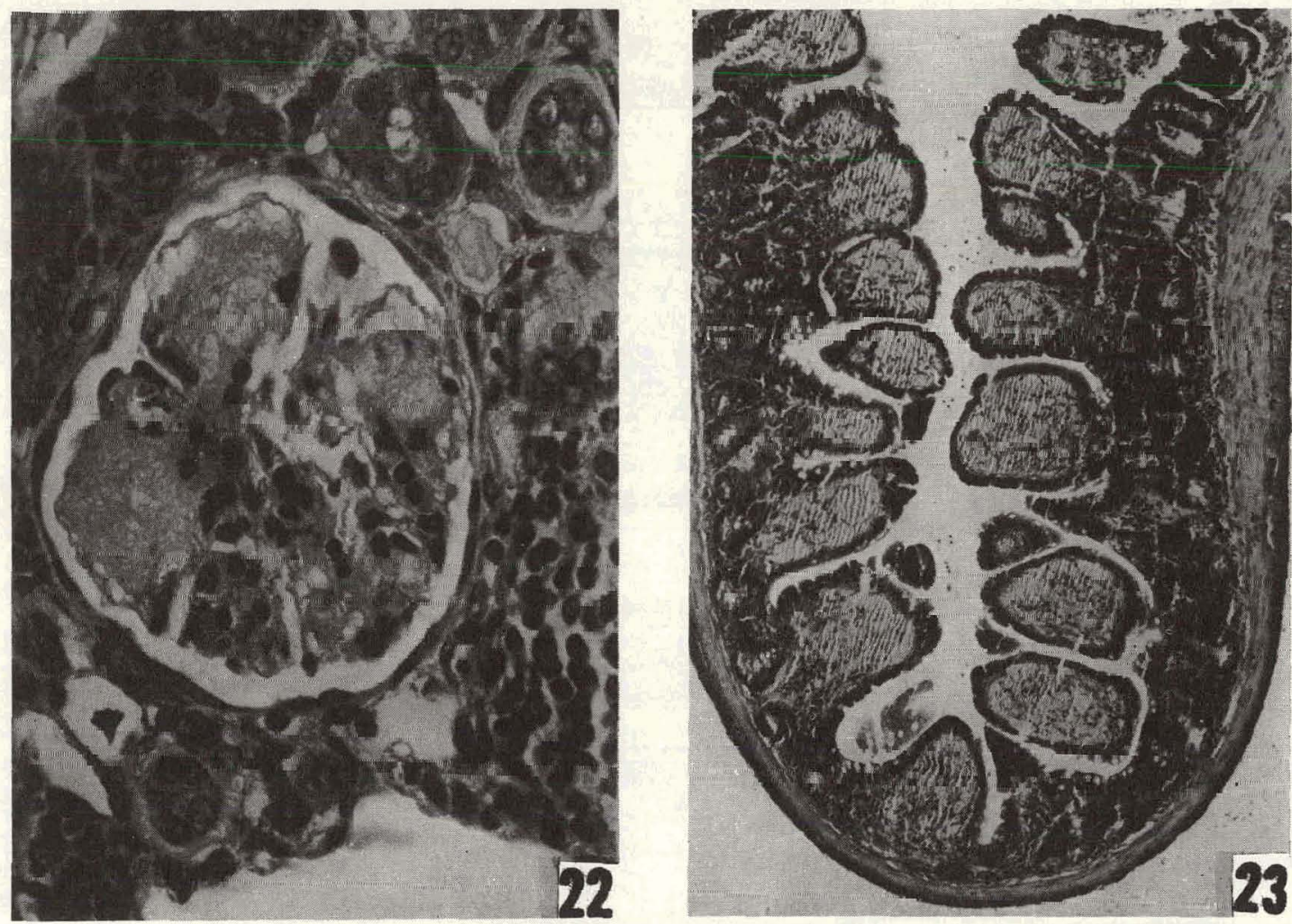

Figure 22. Amyloidosis of kidney from Group IV animal killed at end (51st week) of experiment. Note deposition of amyloid inside glomerulus, between basement membrane and endothelial lining of the capillaries. In this instance, the amyloid deposits are somewhat nodular in appearance.

Figure 23. Amyloidosis of small intestine (ileum) from Group III animal dying in 29 th week of experiment. Note deposition of amyloid in lamina propria, causing expansion of tips of villi, giving them a clublike appearance.

Among the individual tumors that made up the total incidence were lung tumor, squamous papilloma and squamous carcinoma of the forestomach, hepatoma, leukemia, malignant thymoma, and hemangioendothelioma. The difference between the incidence of lung tumors in animals fed the 2 different diets provides the strongest and most consistent evidence for the capacity of Tween $\mathbf{8 0}$ to enhance the carcinogenic quality of methylcholan- 
threne. Differences in the incidence of other tumors, though perhaps not statistically significant when taken individually, do show a trend when taken as a whole and point to the ability of Tween 80 to increase the incidence of tumors produced by methylcholanthrene. In the absence of any evidence that Tween 80 is itself a carcinogen, one must conclude from the results of the present investigation that Tween 80 acts, in part at least, as a cocarcinogen.

In interpreting the data, it has been assumed that all the tumors induced, with the exception of skin tumors, were due to carcinogen absorbed from the gastrointestinal tract. The occurrence of skin tumors raises the question of whether the skin contributed to the absorption of carcinogen by virtue of its contact with carcinogenic food particles and consequently played a part in the induction of internal tumors. Lung tumors have been produced by some investigators by painting carcinogen on the skin. ${ }^{16}$ The fact that only a small number of skin tumors was produced in comparison to the number of lung tumors and the fact that the most of the lung tumors were unaccompanied by any malignant or premalignant changes of the skin do not rule out the possibility that the skin may have been an important organ for the absorption of carcinogen. Considerable experimental evidence definitely indicates that carcinogenic hydrocarbons absorbed from their initial site of application may not induce any tumors in the immediate vicinity of the site of application, but may instead evoke tumors in susceptible tissues in a wholly different part of the body. A notable example of this is the work of Magnus, ${ }^{17}$ who attempted to produce gastric cancer in mice by introducing dibenzanthracene in olive-oil emulsions directly into the stomach. No gastric tumors developed, but tumors of the lung appeared in $95 \%$ of the animals, as against 4 to $8 \%$ in the controls. In the results obtained in our study, there was no correlation between the lung-tumor incidence and the skin-tumor incidence within the individual groups of animals consuming the carcinogenic diets. Furthermore, the skin tumors appeared most frequently in denuded areas of skin. These facts would indicate that skin tumors and internal tumors were not induced by carcinogen derived from the same route, and that the absorption of carcinogen through the skin was not a significant factor in the induction of internal neoplasms.

Assuming that all tumors, except those of the skin, were induced as a result of the absorption of carcinogen from the gastrointestinal tract, there are at least 3 mechanisms by which Tween 80 may act to increase the incidence of tumors produced by methylcholanthrene:

1) By virtue of its surface-active properties, Tween 80 is capable of bringing about a better contact between methylcholanthrene and the gastrointestinal tract mucosa. The enhancing effect of surface-active agents on the gastrointestinal action of carcinogenic hydrocarbons was pointed out early by Lorenz and Stewart. 5-8

Whereas squamous-cell carcinoma of the forestomach can be produced with the aid of surface-active agents, adenocarcinoma of the glandular stomach has not been so produced. The difficulty in bringing the carcinogenic agent into intimate contact with the mucus-covered glandular stomach was suggested in 1939 by Van Prohaska, 
Brunschwig, and Wilson ${ }^{18}$ as the primary cause for their failure to induce gastric adenocarcinoma by feeding methylcholanthrene to mice. Since then, other investigators ${ }^{19-23}$ have made similar postulations from work with such other experimental animals as dogs. This concept of the existence of a "protective mucous barrier" gained experimental support when it was found that implantation. or injection of carcinogenic agents directly into the wall of the glandular stomach, thus bypassing the so-called mucous barrier, resulted in the production of adenocarcinoma. ${ }^{24}$ In our experiment, an attempt was made to study the ability of Tween 80 to bring about surface contact of methylcholanthrene with the glandular stomach despite this mucous barrier. No adenocarcinoma with proved metastases was produced. However, there were proliferative changes in the gastric glandular mucosa as well as invasion of the glands below the muscularis mucosae. The significance of these lesions could not be fully assessed because the regional lymph nodes were not taken for histologic examination. Furthermore, there was no way of predicting how far these lesions would have progressed had the animals lived longer.

2) By virtue of its emulsifying action and its ability to bring about surface contact, Tween 80 is able to increase the absorption and transportation of methylcholanthrene across the gastrointestinal tract mucosa, so that this carcinogenic agent is available in greater quantity for the induction of tumors at sites distant from the gastrointestinal tract.

3) Tween 80 , if absorbed with methylcholanthrene, could conceivably facilitate the penetration of methylcholanthrene into cells of target tissues distant from the gastrointestinal tract, such as the lungs. Krantz et al ${ }^{25}$ indicated that approximately $5 \%$ of the Tween 80 ingested orally by man is in some way absorbed and metabolized by the body. Since only a very small concentration of Tween is needed to solubilize carcinogenic hydrocarbon, ${ }^{3}$ it is not inconceivable that the small amount of Tween 80 absorbed would facilitate the penetration of methylcholanthrene into the cells of target tissues distant from the gastrointestinal tract, thus leading to an increased incidence of tumors in these tissues.

The effect of Tween $\mathbf{8 0}$ on the "induction time" for various tumors caused by methylcholanthrene was not consistent. The so-called induction time for a tumor in this investigation depended on when the animal bearing the particular lesion died.

Few studies have been carried out on the absorption, metabolism, and excretion of orally-administered methylcholanthrene. However, studies on related hydrocarbons show that, in general, when this kind of compound is ingested, most of it is passed unchanged in the feces and part of it is absorbed. The absorbed fraction is partly excreted in the bile and urine, and partly retained in certain tissues, such as adipose tissue and intestinal wall.

When methylcholanthrene is absorbed from the intestinal tract, there are 2 possible routes by which it can reach the general circulation: 1) It can be carried in the blood through the portal system into the systemic venous_circulation, or 2) it can be carried in the lymph through the thoracic duct into the systemic venous circulation. If the first route 
is the primary one, there might be a high incidence of hepatomas, for the liver would be the first target organ. On the other hand, if most of the methylcholanthrene enters the thoracic duct, one would expect a high incidence of lung tumors, for the lungs would then be the first target organs for the absorbed methylcholanthrene, excluding the heart. The unusually high incidence of lung tumors in this experiment $\mathbf{7 4 . 1 \%}$ of the animals in Group IV and $44.4 \%$ in Group II), together with the remarkably low incidence of hepatomas (0\% of the animals of Group II and 3.7\% in Group IV), suggests that methylcholanthrene is absorbed primarily through the lymphatics. However, the high incidence of lung tumors and the low incidence of hepatomas could simply be a reflection of the marked difference in susceptibility of the 2 organs to methylcholanthrene. If one assumes, however, that the methylcholanthrene in the intestine is absorbed through the lymphatics, one could explain the occurrence of chylous ascites and chylothorax in mice fed methylcholanthrene over a prolonged period. This phenomenon was observed in one of our preliminary experiments as well as by Lorenz and Stewart. ${ }^{5}$

It is known that the methylcholanthrene molecule has an affinity for both fat and protein. In the lymphatics that drain the intestinal tract, the fat content of the lymph is high. The methylcholanthrene absorbed therefore tends to remain dissolved in fat. As the lymph from the intestine drains into the thoracic duct, however, its fat content is gradually diluted by the lymph drained from the thoracic region. As a result, the methylcholanthrene may come out of solution and become attached to the protein of the endothelial-lining cells of the lymphatics. Since methylcholanthrene is a cytotoxic agent, it may damage the endothelial cells and cause fibrosis in the wall of the lymphatics. If methylcholanthrene is fed continuously over a long period, the fibrosis thus produced could be severe enough to cause an obstruction of the thoracic duct. As a result, there may be leakage of lymph from the lymphatics proximal to the site of obstruction due to back pressure. It should be recalled that chylous ascites and chylothorax were observed only in animals fed methylcholanthrene over a period of 6 months or more. The conditions were not observed in animals fed methylcholanthrene for 3 months or less. The absence of chylous ascites and chylothorax in the latter animals could have been due to the fact that, as the carcinogen in the diet was withdrawn early, the fibrosis it caused in the thoracic duct would not be severe enough to cause obstruction.

In view of the fact that cholesterol, a structurally similar compound, has been demonstrated to be absorbed from the intestine via the lymphatics, ${ }^{26,27}$. it seems likely that methylcholanthrene would be absorbed in the same fashion.

In conclusion, it should be mentioned that gastric cancer is essentially a human disease, occurring rarely in animals. ${ }^{28-30}$ However, recently, a high incidence of spontaneous carcinoma of the glandular stomach has been reported in a South African rodent. ${ }^{31}$ Although carcinomas have been induced experimentally in the squamous cell-lined forestomach of mice by feeding carcinogenic compounds, adenocarcinomas of the glandular stomach have not been so produced. Thus far, only "hyperplastic" or "adenomatous". lesions have been induced in the stomachs of mice ${ }^{8}$ and monkeys ${ }^{32}$ by the feeding method. 
Nevertheless, the theory that gastric cancer is caused by alimentary carcinogens, perhaps acting on extraordinarily highly susceptible cells, is still the most attractive. It is for this reason that all the experimental efforts thus far expended are justified.

\section{LITERATURE CITED}

1. Wissler, R. W., W. F. Bethard, P. Barker, and H. D. Mori. Proc. Soc. Exp. Biol. Med., 86:170, 1954 .

2. Mori, H. D., P. Barker, D. S. Juras, and R. W. Wissler. Lab. Invest., 6:421, 1957.

3. Ekwall, P., P. Ermala, K. Setälä, and L. Sjöblom. Cancer Res., 11:758, 1951.

4. Setälä, K. Acta path. et microbiol. Scandinav. Supp. 115, 1956.

5. Lorenz; E., and H. L. Stewart. J. Nat. Cancer Inst., 1:17, 1940.

6. . J. Nat. Cancer Inst., 1:273, 1950.

7. . J. Nat. Cancer Inst., 7:227, 1947.

8. Stewart, H. L., and E. Lorenz. J. Nat. Cancer Inst., 10:147, 1949.

9. Kellner, A., J. W. Correll, and A. T. Ladd. Proc. Soc. Exp. Biol. Med., 67:25, 1948.

10. Payne, T. P. B., and G. L. Duff. A.M.A. Arch. Path., 51:379, 1951.

11. Rous, P. J.A.M.A., 122:573, 1943.

12. Andrewes, C. H. Proc. Roy. Soc. Med., 33:75, 1939.

13. Oberling, C., and M. Guërin. Advances Cancer Res., 2:353, 1954.

14. Kuczynski, M. H. Klin. Wchnschr., 2:727, 1923.

15. Klin. Wchnschr., 2:2193, 1923.

16. Murphy, J. B., and E. Sturm. J. Exper. Med., 42:693, 1925.

17. Magnus, H. A. J. Path. Bact., 49:21, 1939.

18. Van Prohaska, J., A. Brunschwig, and H. Wilson. Arch. Surg., 38:328, 1939.

19. Barrett, M. K. J. Nat. Cancer Inst., 7:127, 1946.

20. Denton, R. W., P. Sheldon, and A. C. Ivy. Cancer Res., 10:684, 1950.

21. Hollander, F., B. P. Sonnenblick, and H. A. Sober. J. Nat. Cancer Inst., 7:361, 1947.'

22. Hollander, F., and R. L. Goldfischer. J. Nat. Cancer Inst., 10:339, 1949.

23. Ivy, A. C. J. Nat. Cancer Inst., 5:313, 1945.

24. Stewart, H. L., W. V. Hare, E. Lorenz, and J. G. Bennett. J. Nat. Cancer Inst., 10: $359,1949$.

25. Krantz, J. C., Jr., P. J. Culver, C. J. Carr, and C. M. Jones. Bull. School Med. Univ. Maryland, 36:48, 1951 . 
26. Biggs, M. W., M. Friedman, and S. O. Byers. Proc. Soc. Exp. Biol. Med., 78:641, 1951 .

27. Chaikoff, I. L., B. Bloom, M. D. Siperstein, J. Y. Kijasu, W. O. Reinhardt, W. G. Dauben, and J. F. Eastham. J. Biol. Chem., 194:407, 1952.

28. Wells, H. G., M. Slye, and H. F. Holmes. Am. J. Cancer, 33:223, 1938.

29. Slye, M., H. F. Holmes, and H. G. Wells. J. Cancer Res., 2:401, 1917.

30. Stewart, H. L. In The Physiopathology of Cancer, Homburger, F., and Fishman, W. H., Eds., New York, Paul B. Hoeber, Inc., 1953.

31. Oettlé, A. G. Brit. J. Cancer, 11:415, 1957.

32. Lushbaugh, C. C. Cancer Res., 9:385, 1949. 


\section{LONG-TERM SURVIVAL OF IRRADIATED MICE TREATED WITH HOMOLOGOUS TISSUE SUSPENSIONS ${ }^{*}$}

By

E. L. Simmons, L. O. Jacobson, E. K. Marks, and E. O. Gaston

Recently, Barnes et al. ${ }^{1}$ reported the 150-day survival of 950-r X-irradiated CBA mice treated with spleen or liver suspensions from newborn or unborn C57BL mice. In an attempt to clarify the secondary phase of the irradiation death syndrome, Uphoff ${ }^{2}$ observed the 90-day survival of 800-r X-irradiated (C57BL x DBA/2)F 1 hybrids following injections of suspensions made from C57BL or DBA/2 tissues. She reported that the use of fetal hematopoietic tissues precluded the secondary phase of the irradiation syndrome for 90 days post-irradiation, whereas injection of bone marrow suspensions did not.

In $1956^{3}$ we observed that no secondary deaths occurred when lethally irradiated rabbits were injected with embryonic or newborn mouse tissues, and that rabbits so treated were alive after 150 days. Many of these rabbits are, in fact, still alive after three and one-half years. We had previously reported in $1954^{4}$ that suspensions made from fetal CF No. 1 mouse liver, or spleen and liver from newborn mice, were more effective on a cell count basis than suspensions of mature tissue in enhancing the 30 -day survival of irradiated $(900 \mathrm{r})$ mice of the same strain. CF No. 1 mice which were treated with hematopoietic tissues from young or unborn CF No. 1, C57BL/6, or LAF 1 mice following $750 \mathrm{r}$ total-body $\mathrm{X}$ radiation have now lived out their life span, and the long-term survival results are shown in Table 1. Irradiated CF No. 1 mice survived longer when injected with fetal liver or spleen suspensions from newborn mice than when treated with an equal number of $\mathrm{C} 57 \mathrm{BL} / 6$ or CF No. 1 bone marrow cells.

Although the CF No. 1 strain is no longer maintained by strict inbreeding, postirradiation treatment with CF No. 1 fetal or newborn tissues resulted in longer survival than did similar treatment with $\mathrm{C} 57 \mathrm{BL} / 6$ or $\mathrm{LAF}_{1}$ tissues.

\footnotetext{
${ }^{*}$ Reprint of a paper that appears in Nature, 183:556, 1959.
} 
Table 1

EFFECT OF CF NO. 1, C57BL/6, OR LAF 1 TISSUE SUSPENSIONS ON SURVIVAL OF 10- TO 12-WEEK-OLD CF NO. 1 FEMALE MICE EXPOSED TO $750 \mathrm{r}$ TOTAL-BODY X RADIATION

\begin{tabular}{|c|c|c|c|c|c|c|c|}
\hline \multirow[t]{2}{*}{ Donor tissue } & \multirow{2}{*}{$\begin{array}{c}\text { Mice } \\
\text { treated } \\
\text { (no.) }\end{array}$} & \multicolumn{5}{|c|}{$\begin{array}{l}\text { No. surviving at intervals } \\
\text { shown } \\
\text { (days) }\end{array}$} & \multirow{2}{*}{$\begin{array}{l}\text { Day of last } \\
\text { death }\end{array}$} \\
\hline & & 28 & 150 & 270 & 400 & 500 & \\
\hline $\begin{array}{c}\text { CF No. } 1 \text { bone marrow } \\
\text { (7-8 weeks) }\end{array}$ & 36 & 23 & 20 & 17 & 8 & 2 & 515 \\
\hline $\begin{array}{l}\text { C57 BL/ } 6 \text { bone marrow } \\
(7-8 \text { weeks) }\end{array}$ & 36 & 3 & 0 & 0 & 0 & $\dot{0}$ & 121 \\
\hline CF No. 1 baby spleen & 44 & $24 \bullet$ & 16 & 9 & 4 & 1 & 525 \\
\hline C57BL/ 6 baby spleen & 50 & 30 & 9 & 5 & 1 & 0 & 406 \\
\hline $\mathrm{LAF}_{1}$ baby spleen & 34 & 18 & 11 & 6 & 2 & 0 & 483 \\
\hline CF No. 1 embryo liver & 45 & 34 & 31 & 24 & 16 & 1 & 546 \\
\hline C57BL/6 embryo liver & 69 & 27 & 18 & 11 & 2 & 1 & 497 \\
\hline Locke's solution & 75 & 5 & 3 & 1 & 0 & 0 & 365 \\
\hline Untreated CF No. 1 & 10 & 10 & 10 & 10 & 9 & 7 & $\begin{array}{l}2 \text { still alive } \\
\text { at } 910 \text { days }\end{array}$ \\
\hline
\end{tabular}

\section{LITERATURE CITED}

1. Barnes, D. W. H., P. L. T. Ilbery, and J. F. Loutit. Nature, 181:488, 1958.

2. Uphoff, D. E. J. Nat. Cancer Inst., 20:625, 1958.

3. Jacobson, L. L., E. K. Marks, and E. O. Gaston. Proc. Soc. Exp. Biol. Med., 91:135, 1956.

4. Jacobson, L. O., E. K. Marks, and E. O. Gaston. "Radiology Symposium" 122, Liege, Belgium, 1954. 


\title{
ISOTOPES DECAYING BY ELECTRON CAPTURE:
}

\section{A NEW MODALITY IN BRACHYTHERAPY ${ }^{*}$}

\author{
By \\ P. V. Harper, K. A. Lathrop, L. Baldwin, ${ }^{\dagger}$ Y. Oda, ${ }^{\dagger}$ and L. Kryshtal ${ }^{\dagger}$
}

Several means have been devised for reducing radiation hazards during the surgical implantation of the radioactive material because the surgeon's hands must remain in the radiation field for a substantial length of time.

One means of preventing excessive irradiation is to use an isotope that decays by electron capture, emitting soft characteristic fluorescent $\mathrm{X}$ radiation. A number of considerations limit drastically the choice of radîoactive material. The physical and chemical properties must be suitable. The atomic number must be within a certain range. The characteristic $K$ radiation of high $Z$ elements overlaps the lower end of the gamma-ray range, and one loses the principal advantage of the soft X rays, which is ease of shielding. On the other hand, the low $Z$ elements have very soft characteristic $X$ radiation which is absorbed in tissue in much the same way as beta radiation, and has no obvious advantage over this type of source. These considerations limit $Z$ to values between approximately 45 and 70 . It seems desirable to use a material with a limited half-life, i.e., something less than 2 or 3 weeks and something greater than 2 or 3 days. The isotope chosen cannot emit additional undesirable radiation of significant intensity, or have undesirable activities produced by daughter isotopes. The factors involved in the production of the isotope are, of course, of primary importance. The natural abundance of the precursor isotope should be sufficient enough to avoid the necessity of using an enriched target material, and for financial reasons it would be desirable to use reactor-produced rather t.an accelerator-produced isotopes so that the cross section for thermal neutrons should be sufficiently large and the cross sections of accompanying isotopes of the same element must be sufficiently small to avoid serious flux depression.

Two isotopes which seem to satisfy the above-mentioned criteria are cesium-131 and palladium-103. While both require for production a high thermal neutron flux, it appears that continued development in reactor technology should soon make this readily available, and thus production can be practical at multicurie levels. Preliminary work on production and the development of methods for calibration are described in this paper. Preliminary dosimetric and pathologic studies are also discussed.

Cesium-131 does not form any suitable insoluble compounds that can be used for in-

* Based on paper that will appear in the Proceedings of the Second International Conference on the Peaceful Uses of Atomic Energy, Geneva, 1958'.

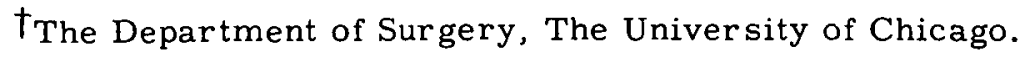


terstitial irradiation, but it may be used in solution in applicators such as those described by Harper et al. ${ }^{1}$ The isotope decays by electron capture to xenon-131, with a half-life of 9.7 days, emitting the characteristic fluorescent radiation of xenon, the principal components of which, the $\mathrm{K}$ alpha and $\mathrm{K}$ beta lines, have energies of about $30 \mathrm{KV}$. The gammaray dose-rate constant for this radiation is $8 \mathrm{r}$ per $\mathrm{hr}$ at $1 \mathrm{~cm}$, and its half-value depth in water, calculated from the true absorption coefficient, is about $5 \mathrm{~cm}$. Thus the dosimetry in an implant of this isotope should not differ radically from that of a conventional implant with a gamma-ray source, and the quantity of isotope necessary for a large implant can be estimated at 200 to $300 \mathrm{mc}$. The advantage of using cesium-131 instead of gammaemitting isotopes is in shielding characteristics, $.2 \mathrm{~mm}$ of lead providing virtually complete shielding of the soft $X$ rays, thereby avoiding the use of heavy clumsy equipment and greatly facilitating handling procedures. The only other radiation emitted by cesium-131 is the very weak inner bremsstrahlung. ${ }^{2}$

Cesium-131 is produced by neutron irradiation of the naturally-occurring barium-130, which captures a neutron, becoming barium-131. This then decays with a 11.5-day halflife to cesium-131, which subsequently decays with a 9.7-day half-life to stable xenon-131. The natural abundance of the precursor barium-130 is low (.101 per cent). A value of the thermal neutron cross section for the reaction $\mathrm{Ba}^{130} \stackrel{\mathrm{n}, \gamma}{\longrightarrow} \mathrm{Ba}^{131}$ of about 30 millibarns has been reported by Yaffe and his coworkers. ${ }^{3}$ This was at first generally accepted, ${ }^{4-6}$ although an earlier report by Katcoff ${ }^{7}$ gave a much higher value of 6 barns for this cross section. Katcoff based his estimate of the cross section on the assay of cesium-131 by measuring the $\mathrm{K}$ radiation, assuming a counting efficiency of 1 per cent. A soft component of the radiation was interpreted by Katcoff as $L$ radiation, and no evidence of gamma-ray activity was found. The smaller cross section found by Yaffe et al. ${ }^{3}$ was based on the earlier observations of Fu-Chun Yu et al. ${ }^{8}$ that the soft component of the radiation of cesium131 represented conversion electrons from a highly (97 per cent) converted $145-\mathrm{KV}$ gamma ray. Basing their assay on this decay scheme and apparently measuring the soft radiation on the assumption that it was conversion electrons, they found a cross section smaller by a factor of 200 than that of Katcoff. A detailed analysis by Cork et al. ${ }^{9}$ of the decay scheme of barium-131, using an enriched barium-130 sample for activation, revealed no evidence whatever of the $145-\mathrm{KV}$ gamma ray found by the Fu-Chun Yu group. A report by Kondaiah ${ }^{10}$ indicates that the conversion electrons, believed to originate in cesium-131, actually came from the parent barium-131.

Our own measurements were performed on a cesium-131 sample separated from barium nitrate that was irradiated with thermal neutrons at Oak Ridge National Laboratory. The barium was removed as the sulfate, by precipitation, and the supernatant containing the cesium was evaporated to dryness. Measurements of radioactivity were made with a thin-window Geiger tube. The absorption curve in aluminum (Figure 1) was almost identical with that published by Yaffe and his associates. The soft component has a mass absorption coefficient in aluminum that corresponds to a wave length of about $3 \AA$. The absorption coefficient of this component in polyethylene sheeting ( 86 per cent carbon) corresponds 


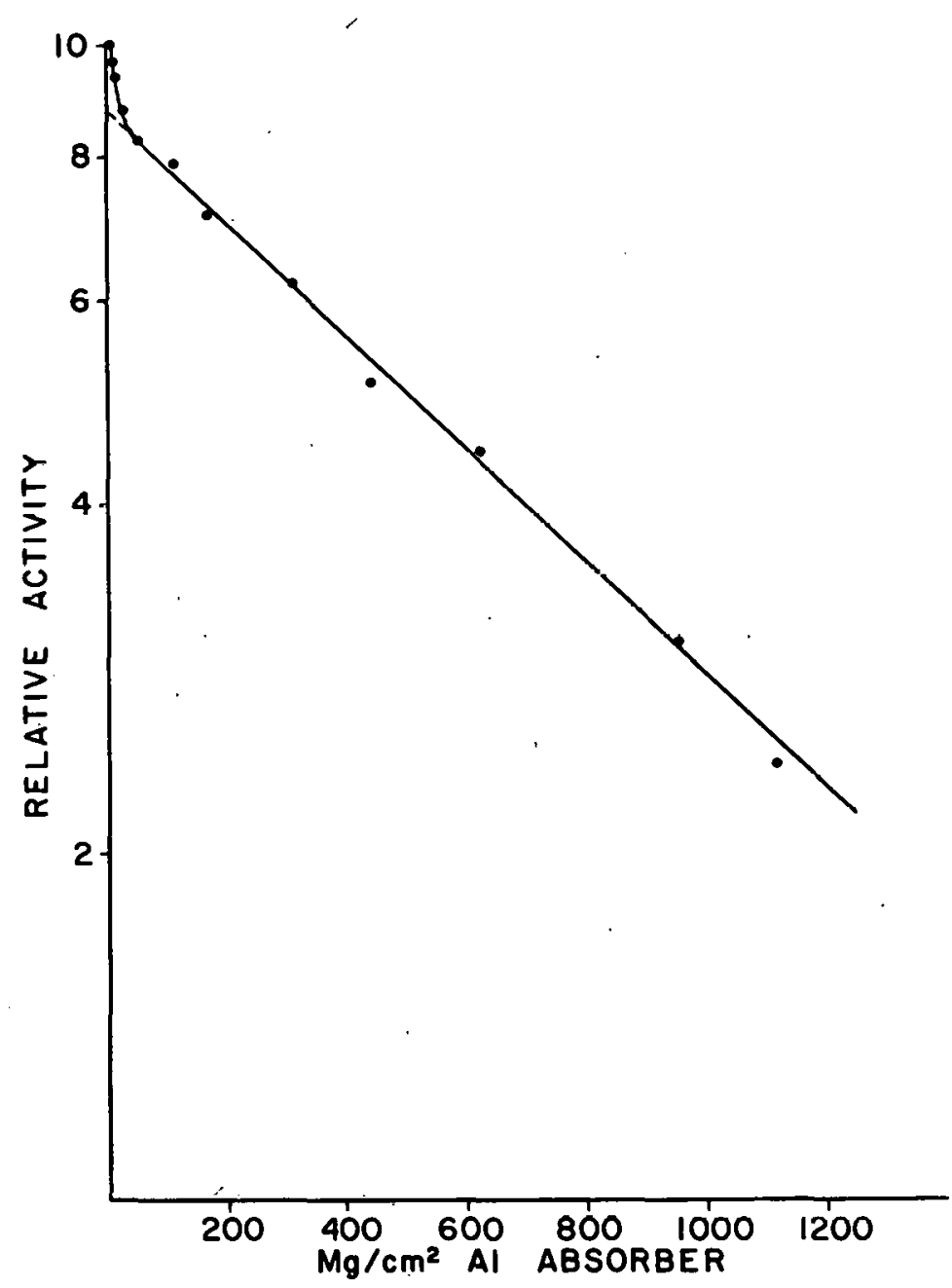

Figure 1. Aluminum absorption curve of radiation from Cs 131 source. A thin-window, heliumfilled G-M tube was used. (Tracer-Lab TGC-2)

to a wave length of $2.7 \AA$ (Figure 2). This observation can be explained only on the basis that the radiation is electromagnetic rather than conversion electrons. The characteristic $L$ radiation lines of xenon are between 2.3 and $2.6 \AA$, which is in fair agreement with the absorption measurements. Passing the radiation from the cesium-131 sample through a 3000-gauss magnetic field (Figure 2) did not alter the soft component of the radiation, again indicating that the soft component is electromagnetic in nature and not composed of conversion electrons. It was therefore concluded that the 30-millibarn cross section was in error and that the 6-barn cross section was more nearly correct. Using the latter figure, the activation of a mole of natural barium for 4 weeks in a flux of $2 \times 10^{13}$ neutrons per $\mathrm{cm}^{2}$ per second, should produce about a curie of cesium-131. The absorption cross section of natural barium is sufficiently low, 1.38 barns, to avoid serious flux depression even with this large mass of material, and no other noxious isotope is formed in signifi- 


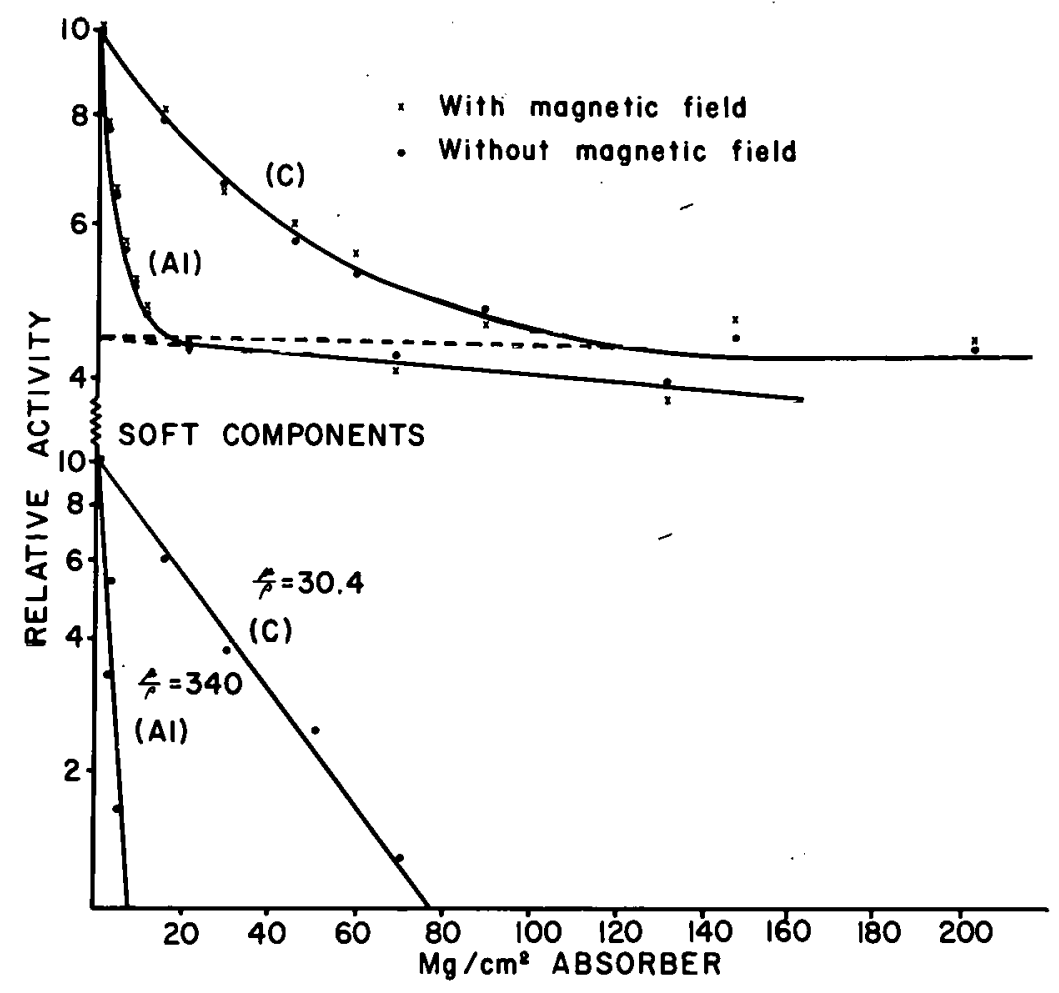

Figure 2. Aluminum and carbon absorption curves of radiation from $\mathrm{Cs}^{131}$ source. A thin-window, argon-filled G-M tube was used. (Tracer Lab TG-C $3 \mathrm{~A})$. Note that the relative counting efficiency of the soft component is several times greater than that obtained with helium-filled tube. Passing radiation through 3000-Gauss magnetic field has no appreciable effect.

cant quantities. Thus, the production of the isotope appeared practical.

Since the radiation from cesium-131, as judged by means of a thin-window argonfilled Geiger tube, appeared to consist almost solely of $\mathrm{K}$ and $\mathrm{L}$ radiation, it seemed feasible to use $\mathrm{K}, \mathrm{L}$ coincidence measurements as a method of assay. The $\mathrm{L}$ radiation is completely separated from the $\mathrm{K}$ radiation by $20 \mathrm{mg}$ per $\mathrm{cm}^{2}$ of aluminum, while the mica window of the tube shields out $M$ and $N$ radiations and Auger electrons. It was necessary to make additional corrections since only $\mathrm{K}$ alpha photons are accompanied by coincident $\mathrm{L}$ photons. $\mathrm{K}$ photons are extraneous, and a number of extraneous $\mathrm{L}$ photons arise from $\mathrm{L}$ capture (14.6 per cent) and from the Auger transitions involving the $\mathrm{L}$ shell. The relative strengths of these transitions have been measured ${ }^{11}$ so these corrections can be made, and thus absolute assay of cesium-131 samples of the order of $1 \mu \mathrm{c}$ can be done. It was possible to confirm measurements made in this way by measuring directly the ionization produced by the $\mathrm{K}$ radiation, using 100-200 $\mu \mathrm{c}$ quantities of cesium-131. The sample was placed in the center of an open air chamber modified to increase the sensitive volume as 
shown in Figure 3. Corrections were made for self-absorption in the source, L capture, and fluorescence yield. Although these measurements fall 30 per cent above the coincidence measurements, the order of magnitude of the activity appears to be firmly established. Using these methods of assay, the cross section of barium-130 for pile neutrons lies between 5 and 10 barns.

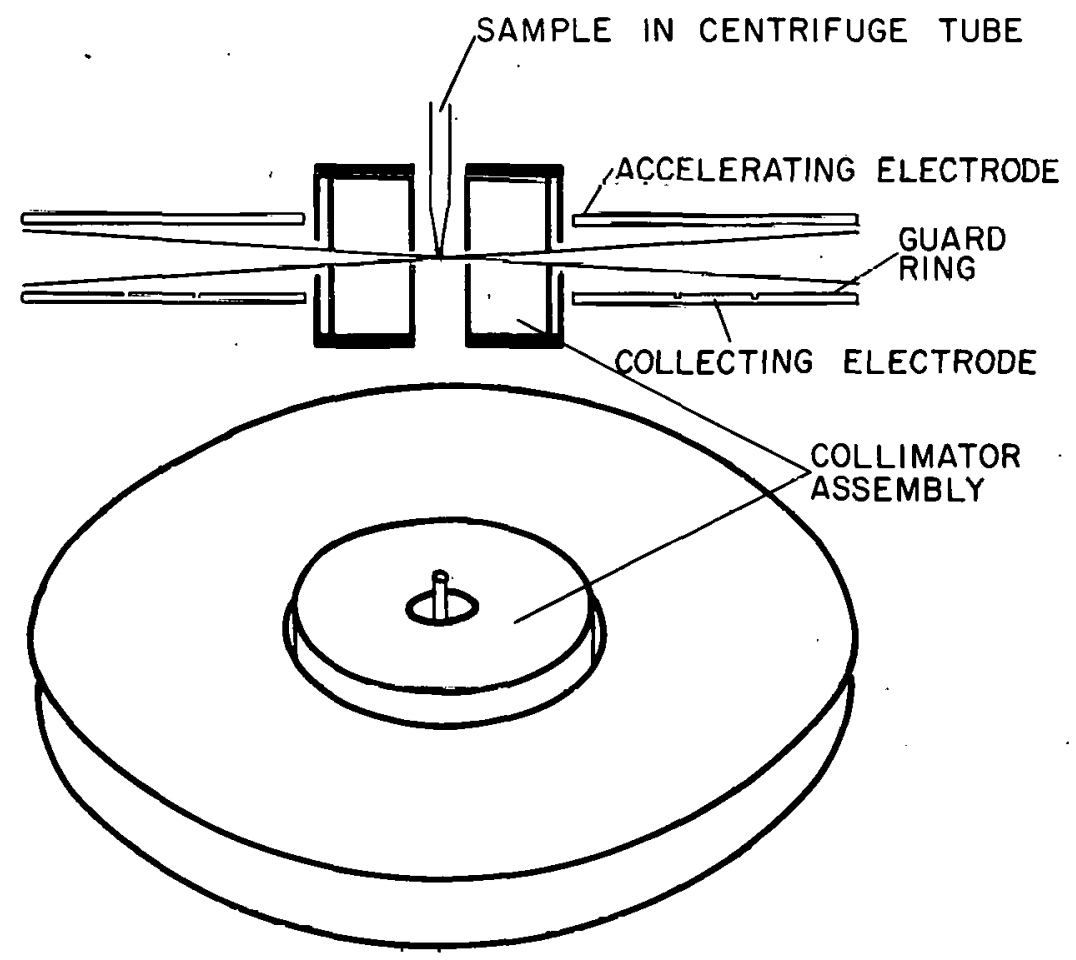

Figure 3. Modified open air chamber for measuring Cs $131 \mathrm{~K}$ radiation. Modification preserves standard geometry and increases sensitive volume approximating 100 fold.

The production of cesium-131 in curie quantities presented some problems in the processing of $100-\mathrm{g}$ quantities of barium. It was found possible to accomplish this without using elaborate facilities by irradiating barium in the form of metal and then distilling off the daughter cesium in an inert atmosphere. The barium was first prepared by melting it in a steel pipe, one end of which was welded shut. Helium was bubbled through the molten barium, and it carried with it the volatile impurities. The barium slug was then removed from the pipe, sealed in aluminum, and irradiated. Following irradiation, it was placed in a distillation apparatus (Figure 4). The vessel was purged with helium, and distillation was carried out at $850^{\circ} \mathrm{C}$. The distillation proceeded very rapidly, being complete in an hour. Experiments were carried out with a barium magnesium alloy that has a eutectic melting point at $380^{\circ} \mathrm{C} .{ }^{12}$ Although this method was fairly successful, significant amounts of magnesium distilled over with the cesium and caused some difficulties in handling. It was nec- 
essary to use helium for the inert atmosphere during the distillation because argon produced considerable convection. It was found convenient, however, to substitute the heavier argon for helium in the distillation chamber after it had cooled before opening the chamber in order to reduce access of air to the reactive barium metal. The cesium, together with some barium that condensed as a white deposit, was removed by washing the cold finger in a large lead glass test tube containing dilute nitric acid. Carrier cesium was added, and then the cesium activity was precipitated with perchloric acid and ethanol. In view of the explosive nature of perchloric acid it seems desirable to use another method of separation at this point. The cesium perchlorate precipitate was then reduced to the chloride by heating, in which form it was ready for assay or use.

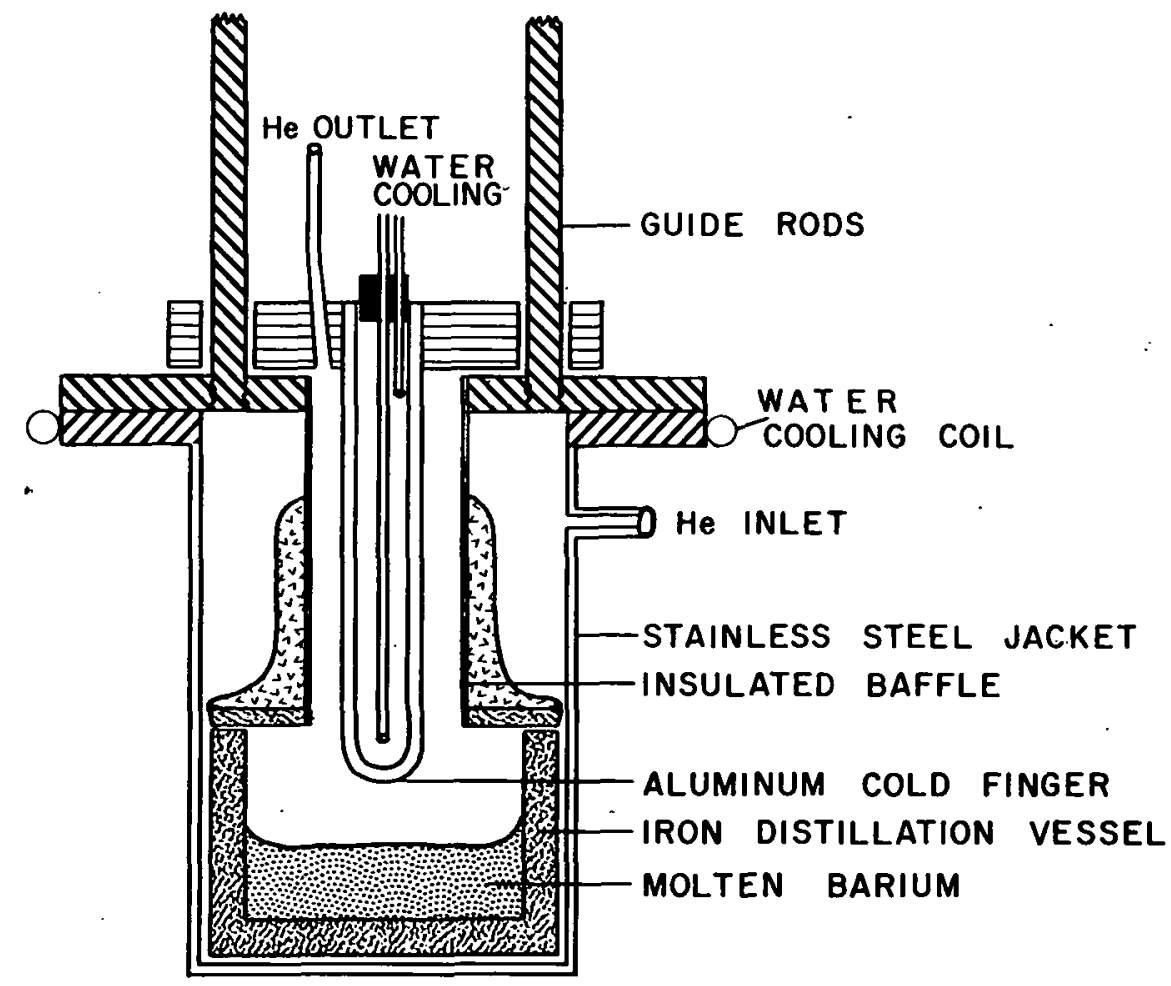

Figure 4. Apparatus for recovering daughter $\mathrm{Cs}^{131}$ from melted barium metal by distillation at $850^{\circ} \mathrm{C}$.

Because of the very large scattering coefficient in water for the $30-\mathrm{KV} X$ rays, it was of considerable interest to measure dose ratios in air and water at various distances from a small source of cesium-131. This was done by using small cylindrical lucite ionization chambers with aquadag electrodes. The results are shown in Figure 5 and are compared with similar measurements for radium. ${ }^{13}$ Clearly evident is the marked effect of backscatter; which has the net result of increasing the localization of the radiation field surrounding the point source.

Substantial implants, using cesium-131, were implanted in plastic applicators into ex- 
perimental animals. ${ }^{14}$ The ease of handling the isotope as compared with similar procedures using gamma-emitting isotopes was very impressive as far as radiation exposure to the operator was concerned. As far as the dosimetry is concerned, for small implants of the order of $2 \mathrm{~cm}$ or so in greatest dimension, no modification of conventional dosimetry seems necessary. For larger implants, modification might be desirable in order to maintain an even radiation field.

In the event of an accident in which the entire isotopic contents of an implant might be distributed throughout the body, the radiation dosage to the entire body would not approach dangerous levels even though the isotope remained within the body.

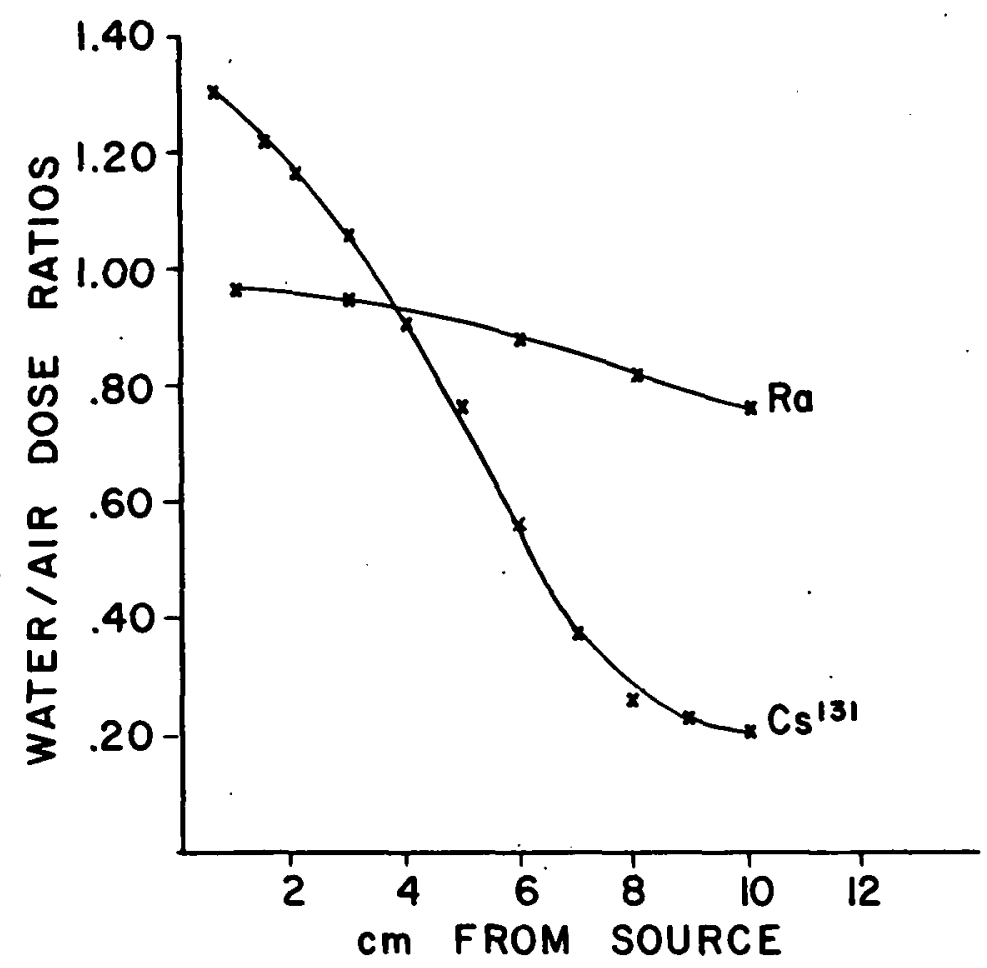

Figure 5. Water/air dose ratios at various distances from small sources of $\mathrm{Ra}$ and $\mathrm{Cs} 131$.

The other isotope under consideration, palladium-103, has a half-life of 17 days, decaying entirely by electron capture. This is accompanied by a number of very weak gamma rays with intensities of $10^{-3}$ to $10^{-6}$ photons per disintegration. ${ }^{15}$ These are negligible from the point of view of radiation dosage. The daughter, rhodium-103, has a 54-minute metastable state emitting a $40-\mathrm{KV}$ gamma ray that is almost completely converted in the $\dot{L}$ shell, so that for all practical purposes the only radiations of significance are the characteristic $20-\mathrm{KV}$ radiation of rhodium and the $37-\mathrm{KV}$ conversion electrons whose range in tissue is approximately $30 \mu$.

The $20-\mathrm{KV}$ X radiation has a half-value depth in tissue of approximately $1 \mathrm{~cm}$, and the 
photoelectric absorption cross section, unlike the radiation from cesium, is much greater than the scattering cross section, so that the true absorption coefficient gives a good approximation for attenuation.

$\mathrm{Pd}^{103}$ is produced by irradiation of palladium metal. The precursor isotope palladium-102 has a natural abundance of 1.0 per cent, and the cross section for thermal neutron activation is 4.8 barns. ${ }^{16}$ Other activities that are induced in the palladium are the 13.6-

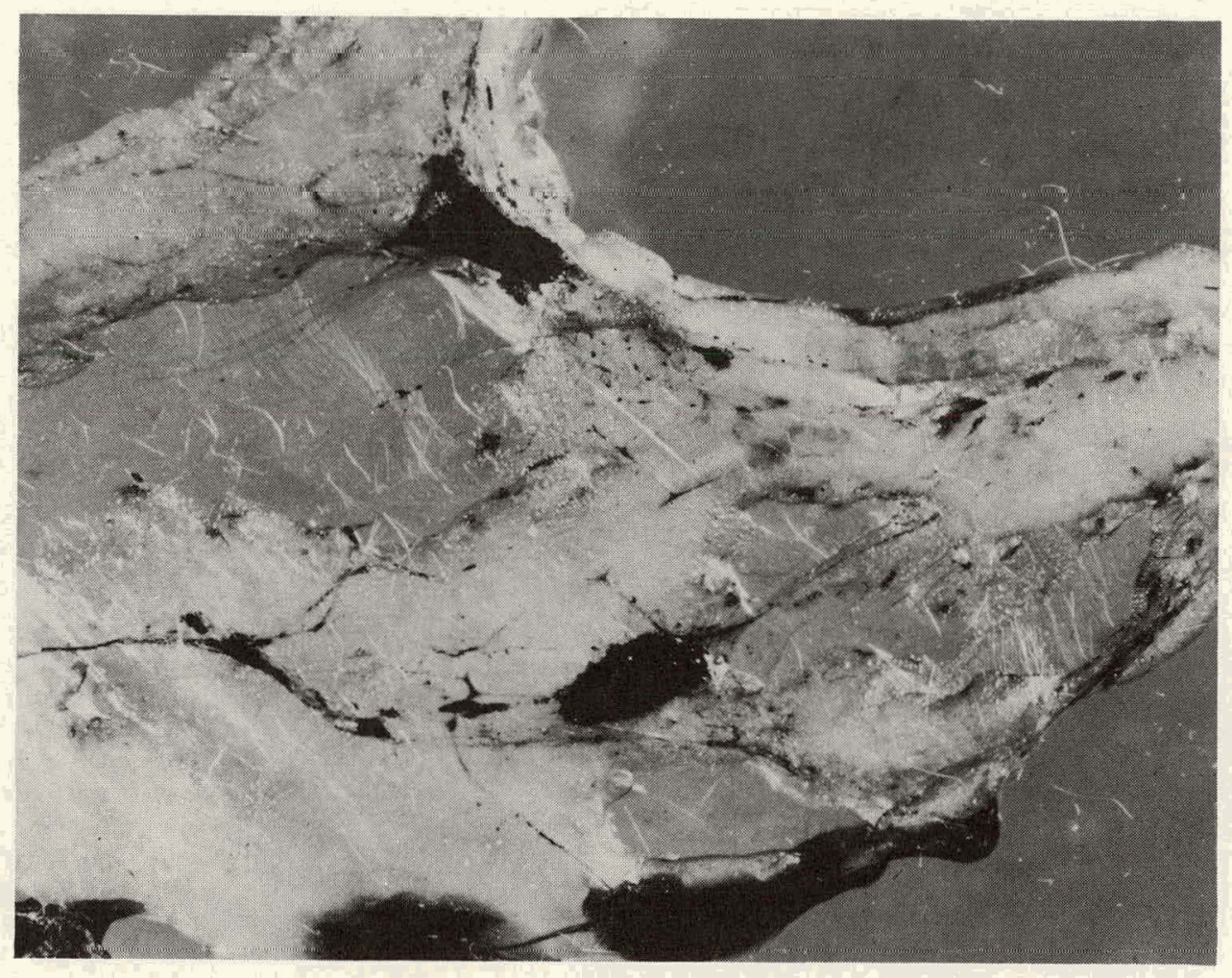

Figure 6. Inert palladium black suspension in 6 per cent gelatin injected into rat 100 days previously. Omentum showing slow migration in large lymphatics.

hour palladium-109 and the 22-minute palladium-111, which decays to 7.5-day silver-111. Thus, before using irradiated palladium, it is necessary to allow the 13.6-hour activity to decay and to separate chemically the silver activity. In addition, particular attention must be paid to impurities in the platinum group, especially that of iridium which has a long half-life and a high cross section for thermal neutron activation. We have found that even when using palladium of the highest commercial purity available (99.95 per cent), it was still necessary to carry out glyoxime precipitation from a neutral solution in order to remove traces of iridium activity from the final product. This is best done prior to irradiation. Removing the silver activity presents no great difficulty. The irradiated sample is dissolved in warm aqua regia; it is diluted and then scavenged with repeated small quan- 
tities of silver nitrate. The silver-111 is carried down with the silver chloride precipitate, leaving the final solution free from detectable silver activity.

Assay of the palladium has been done by determining the silver-111 content after separation from the palladium, using geometrical beta counting and then calculating the palladium activity from the cross sections.

In using palladium-103 therapeutically it seems unlikely that it will be possible to ob-

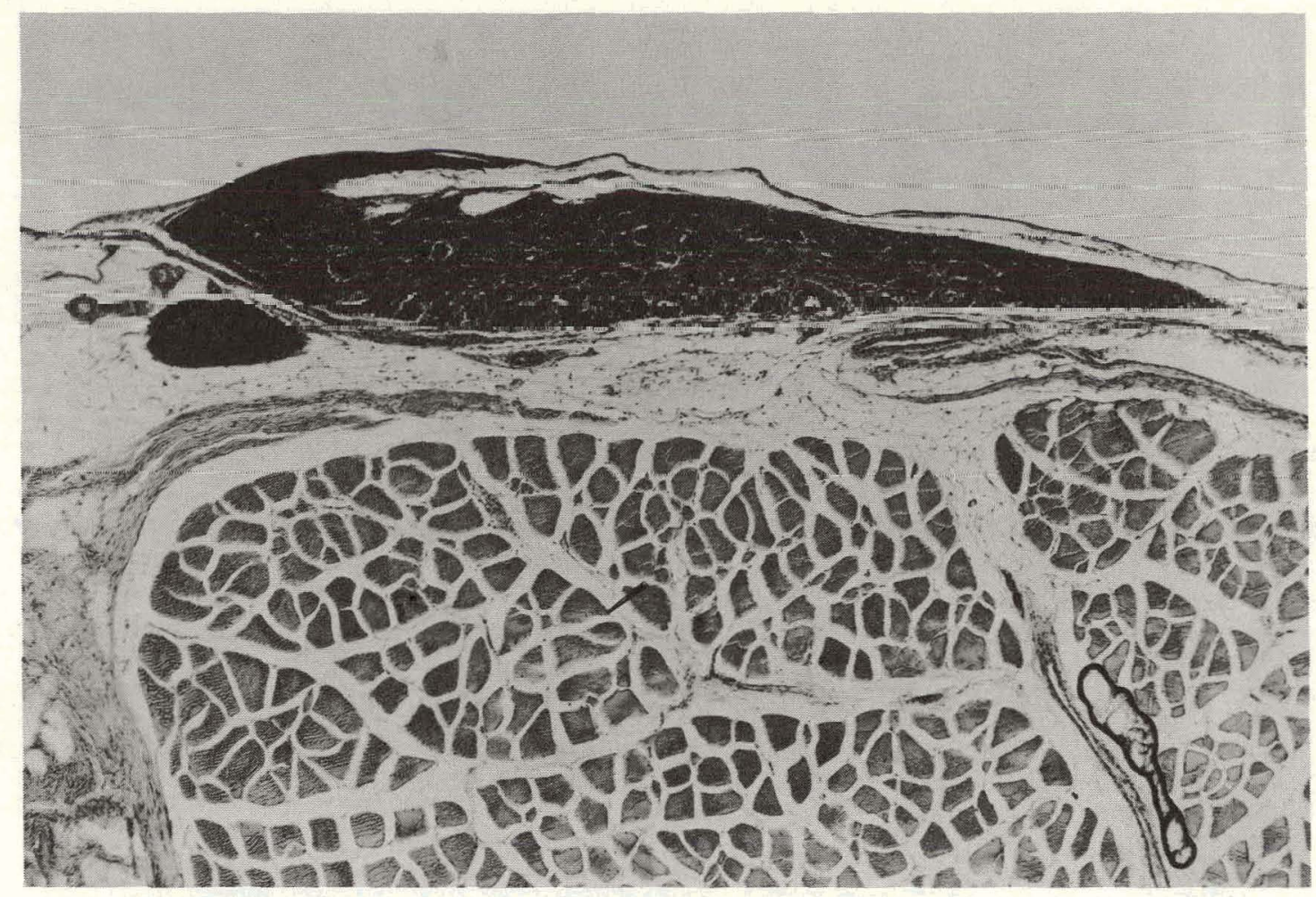

Figure 7. Inert palladium black suspension in 6 per cent gelatin injected into rat 100 days previously. Serosal surface of abdominal wall showing nature of granuloma formation around palladium.

tain a specific activity that is high enough to use the material in plastic applicators in which very small volumes of solution are required. However, palladium can, with ease, be precipitated as palladium black, which can be injected into tissue as a suspension. If the suspension is sufficiently coarse it should remain more or less where it is placed so that the location of the radiation field should be adequately controlled. Preliminary experiments in which suspensions of palladium black in gelatin were injected into experimental animals indicate very little reaction of the tissue to the injected material, and while there appears to be some migration, it is slow (Figures 6, 7, and 8).

In considering the radiation dosimetry of palladium-103, each disintegration releases into the surrounding medium $17 \mathrm{KV}$ of energy as characteristic $\mathrm{K} \mathrm{X}$ radiation, and about 
$40 \mathrm{KV}$ of energy as conversion electrons, principally the $37-\mathrm{KV}$ line. Other radiations such as the L X rays and the very weak gamma rays are ignored in these considerations. In a continuous distribution as with the isotope in solution, the $37-\mathrm{KV}$ conversion electrons can not be ignored, but with the isotope distributed as discrete sources through the tissue the range of the conversion electrons (about $30 \mu$ ) becomes negligible.

If we consider a very large implant, there will be a region in the center in which radiation leaving the region will be replaced by radiation from the surrounding regions, so that dose calculations may be carried out in the same way as for an evenly distributed

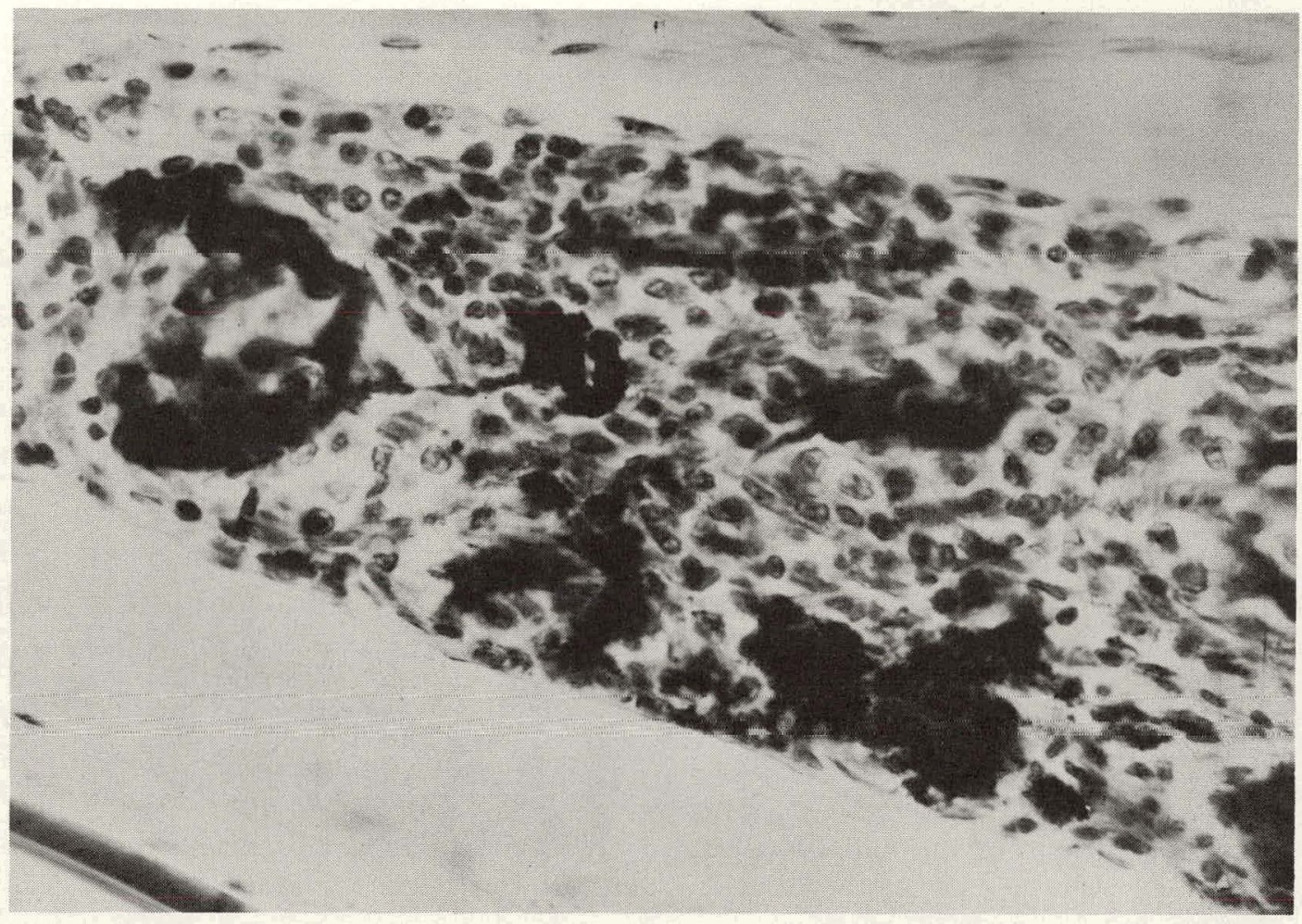

Figure 8. Inert palladium black suspension in 6 per cent gelatin injected into rat 100 days previously. Serosal surface of abdominal wall showing nature of granuloma formation around palladium.

beta source. Thus, a uniform distribution of palladium with an isotope density of $1 \mathrm{mc}$ per cc would give a radiation dosage of approximately 20,000 rads per mc. In order to achieve this isotope density, it would be necessary to have 2 or $3 \mathrm{mg}$ of palladium distributed per cc of implant. If we consider a very small implant in which the absorption in tissue becomes negligible, then 3 to 4 times as much isotope per cc are required to produce the same dosage from soft $X$ radiation as in the central region in the very large implant. These are the limits between which we must work in establishing dose distribution for implants of various sizes, and the upper limit appears to be well within the range of practical possibility. 
These calculations are based on a uniform distribution for the large implant; Paterson-Parker distribution is assumed for the small implant. When the distributed sources are condensed into discrete sources placed in a $1-\mathrm{cm}$ lattice, the radiation field at the lowest point in the lattice drops about 40 per cent. Thus a more or less even dose distribution is maintained in such an implant in sharp contrast to that produced by a beta emitter under similar circumstances, where the dose distribution varies by many factors of 10 .

It must be remembered that palladium has a mass absorption coefficient of about 10 for $20-\mathrm{KV} X$ radiation, so that there may be considerable self-shielding within the implant. In a continuous distribution this becomes negligible. With discrete sources this is not necessarily true. In order to test this, cylindrical implants in gelatin were made $12 \mathrm{~cm}$ in diameter and $6-\mathrm{cm}$ high. One of the se contained $1 \mathrm{mg}$ per cc of palladium in solution, the second contained a similar amount of palladium in an even suspension as palladium black, and in the third the palladium suspension was placed in the gelatin in .1-cc volumes arranged in a $1-\mathrm{cm}$ lattice. Photographic measurements of the radiation field at the cylinder ends were made to permit comparison. The solution and evenly distributed suspension gave equal readings. The reading for the lattice distribution was 60 per cent of this, indicating no appreciable self-absorption in the palladium under these conditions.

While the $20-\mathrm{KV} X$ radiation from palladium-103 is in a range not usually considered satisfactory for film dosimetry because of energy dependence of the film, we felt that it might be possible to use film to measure relative dosages because of the monochromatic nature of the radiation. The scattered radiation should not be degraded appreciably as the change in energy in Compton scattering is very slight at this wave length. In order to test this, radiation from a palladium sample was recorded with a 256 -channel Argonne type pulse height analyzer, and then, without changing the geometry otherwise, $6.4 \mathrm{~cm}$ of lucite was placed between the source and the scintillation head which reduced the radiation to 3 per cent of its original intensity. The shift in energy was very slight. (Figure 9).

Our investigations of the dosage problems involved in use of palladium-103 indicate that it should be possible to use the material clinically with reasonably certain estimates of the radiation dosage being administered. Figure 10 shows the effect of a palladium-103 implant in subcutaneous tissue of a rat. Injection of the material into the retroperitoneal tissues in the pelvis of a rabbit resulted in only traces of activity in the liver after 2 weeks $(.002-.004$ per cent of the injected dose/g).

Our first thought in clinical application of this material was in connection with carcinoma of the cervix and prostate. Infiltration of the parametria ${ }^{17}$ and prostate ${ }^{18}$ with radioactive gold has been carried out, and while dose calculations under these circumstances are made assuming uniform distribution, we are not convinced that the se are accurate, since distribution for a beta emitter must be at a cellular level in order for it to be truly effective, as in the thyroid gland. We feel that a suspension of palladium-103 should give a much more even and more effective radiation field in the regions under consideration than gold198 colloid. In addition, there is no problem of gamma radiation. Extension of this type of an approach to inoperable tumors of the abdominal and chest cavities becomes much more 


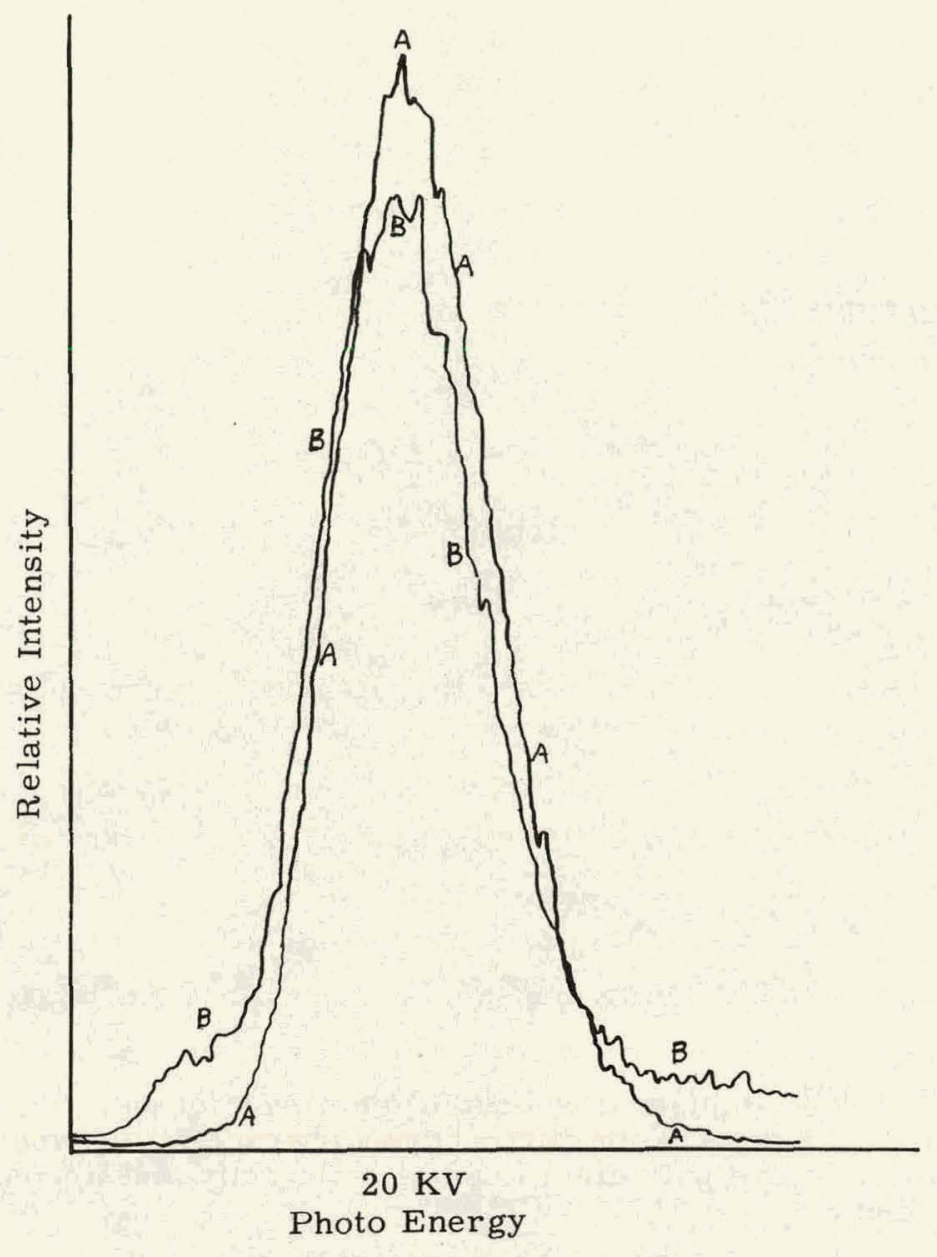

Figure $9 . \mathrm{Rh}^{103} \mathrm{~K}$ radiation before and after traversing $6.4-\mathrm{cm}$ lucite absorber.

Curve A. Pd103 source recorded for 1 minute without absorber.

Curve B. Same source and geometry; recorded for 24 minutes with $6.4-\mathrm{cm}$ lucite $\mathrm{ab}$ sorber.

Note only slight shift in energy with 97 per cent attenuation. (Argonne-type 256-channel pulse height analyzer).

feasible using palladium-103 because of the reduced problems of exposure and handling.

Precise measurements are desirable in order to confirm calculated radiation dosages. Absolute dose measurements of soft $X$ rays present special problems. A very promising method appears to be the use of the $\mathrm{Fe}^{++}-\mathrm{Fe}^{+++}$system stabilized with benzoic acid as described by Adams and Balkwell. ${ }^{19}$ This is several times more sensitive than the conventional $\mathrm{Fe}^{++}-\mathrm{Fe}^{+++}$system, and we have been able to show, using Grenz rays, that the lack of energy dependence characteristic of the conventional system is retained in the benzoic acid system down to radiation with a half-value depth in water of $.7 \mathrm{~mm}(30 \mathrm{KV}$, unfiltered). 




Figure 10. $\mathrm{Pd}^{103}$ implant in subcutaneous tissue of rat. $2.5 \mathrm{mg} \mathrm{Pd}$, $180 \mu \mathrm{c} \mathrm{Pd} 103,56$ days. Note difference in character of granuloma as compared to inactive palladium (loss of cellularity and fibrosis). See Figures 7 and 8.

It thus appears that we have the means necessary to make substantial use of $\mathrm{K}$-capture isotopes for implant work. The advantages of this in institutional practice at least seem to outweigh the disadvantages, and the prospects for establishing this approach as a routine as well as an experimental procedure appear excellent.

\section{LITERATURE CITED}

1. Harper, P. V., K. A. Lathrop, R. W. Harrison, G. G. Thurston, T. T. Kennedy, and J. F. Mullan. Surgery, 40:270, 1956.

2. Saraf, B. Physical Reviews, 94:642, 1954.

3. Yaffe, L., M. Kirsh, S. Standil, and J. M. Greenlund. Physical Reviews, 75:699, 1949.

4. Chart of the Nuclides, Knolls Atomic Power Laboratory, Fourth Edition, 1952.

5. Hughes, D. J. Neutron Cross Sections. A Compilation of the A.E.C. Advisory Committee on Neutron Cross Sections, AECU-2040.

6. Bureau of Standards Circular 499. Nuclear Data.

7. Katcoff, S. Physical Reviews, 72:1160, 1947. 
8. Fu-Chun Yu, D. Gideon, and J. D. Kurbatoy. Physical Reviews, 71:382, 1947.

9. Cork, J. M., J. M. LeBlanc, W. H. Nester, and M. K. Brice. Physical Reviews, 91: $76,1953$.

10. Kondaiah, E. Arkiv Fysik, 2:295, 1950-51.

11. Siegbahn, Kai. Beta and Gamma-Ray Spectroscopy, pp. 624-34, Inter science Publishers, Inc., New York, 1955.

12. Klemm, W., and F. Dinkelacker. Z. anorg. Chem., 255:2, 1947.

13. Wootton, P., R. J. Shalek, and G. H. Fletcher. Am. J. Roentgenol. Radium Therapy Nuclear Med., 71:683, 1954.

14. Harper, P. V., W. E. Adams, E. E. Schwartz, K. A. Lathrop, and R. W. Harrison. Surgical Forum, 6:419, 1956.

15. Avignon, P., A. Michalowicz, and R. Bouchez. Le Journal de Physique et le Radium, $16: 404,1955$.

16. Meinke, W. W. Physical Reviews, 90:410, 1953.

17. Ter-Pogossian, M., and A. I. Sherman. Am. J. Roentgenol. Radium Therapy Nuclear Med., 74:116, 1955.

18. Flocks, R. H., H. B. Elkins, and D. Culp. J. Urology, 77:505, 1957.

19. Adams, G. D., and W. R. Balkwell. Radiation Res., 7:298, 1957. 


\title{
THE DISTRIBUTION OF INTRAPERITONEAL RADIOCOLLOIDS *
}

\section{By}

\author{
P. V. Harper and K. A. Lathrop
}

The frequent use of colloidal gold-198, yttrium-90, and chromic phosphate for the treatment of tumor ascites and for the destruction of tumor cells seeded at operation led us to investigate the distribution of such substances in the peritoneal cavity. A good deal is known ${ }^{1-4}$ about the movement of radioactive colloidal material from the peritoneal cavity and about the concentration of isotopes in various intra-abdominal organs following intraperitoneal injection. Radioautographic studies ${ }^{5,6}$ have shown that these materials tend to deposit irregularly upon the serosal surfaces within the peritoneal cavity. To the best of our knowledge, no systematic studies have been made of the variations in distribution upon peritoneal surfaces as influenced by various experimental factors. Interest in this problem evolved during our work on the prevention of intraperitoneal tumor implants with intraperitoneal implantation of radioactive colloidal material, such as radioactive gold ${ }^{7}$ and yttrium.

Radioactive colloidal gold and radioactive yttrium chloride were injected intraperitoneally into 250 -g rats under various circumstances. After sacrifice, the abdominal wall and viscera were laid out on a sheet of filter paper and then sealed in a polyethylene envelope, which was laid on photographic film to obtain gross radioautographs of the actual organs. Ten-minute exposures to the film were adequate for specimens from rats that had received approximately $100 \mu \mathrm{c}$ of $\mathrm{Y}^{90}$. The factors which were studied were time, carrier level, nature and volume of solvent, and presence of inflammation.

Radioautographs of the various preparations give a qualitative but striking demonstration of the intra-abdominal distribution of the radioactive material.

A comparison of Figures 1, 2, and 3 reveals the intra-abdominal distribution at 1, 3, and 6 days following the injection of $1 \mathrm{mg}$ of carrier yttrium as $\mathrm{YCl}_{3}, \mathrm{pH}_{5}$, in $1.0 \mathrm{ml}$ of 0.9 per cent $\mathrm{NaCl}$. A marked uptake is seen in the omentum and in the lymphatics and lymph nodes of the mesentery. With this level of carrier, a moderate parenchymal uptake in the liver and spleen is also visible. It is easy to distinguish between the activity deposited on the surfaces of the organs, which gives dark irregular patches, and the parenchymal deposition, which gives a diffuse, even-darkening on the film. Darkened areas that appear to be engorged lymphatics are readily discernible. There is no dramatic difference between the 1 - and 3 -day preparations, but at 6 days there is a marked translocation to the liver and especially to the spleen. The same pattern of uptake in the omentum and

\footnotetext{
* Based on a paper that will appear in the Proceedings of the Second International Conference on the Peaceful Uses of Atomic Energy, Geneva, 1958.
} 


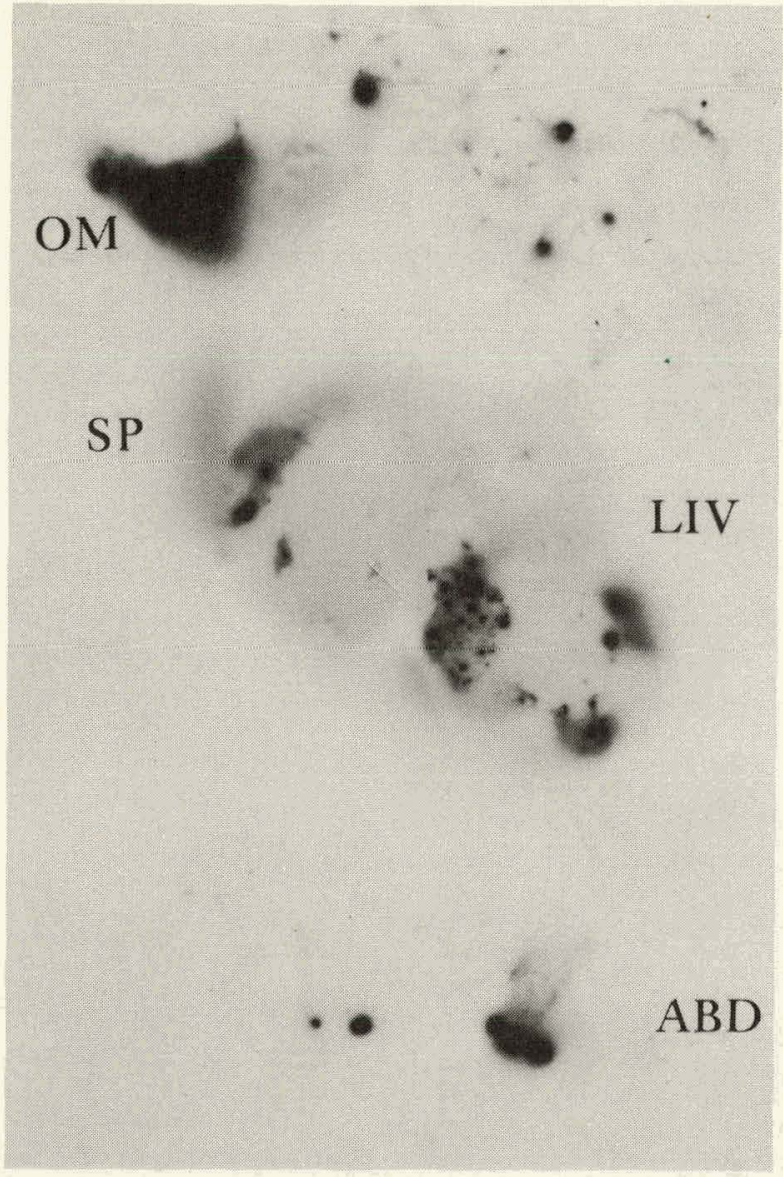

Figure 1. Gross radioautograph of intra-abdominal organs of rats following intraperitoneal injection of $\mathrm{Y}^{90} \mathrm{Cl}_{3}$ in $1 \mathrm{ml}$ of .9 per cent $\mathrm{NaCl}$ with $1 \mathrm{mg}$ of $\mathrm{Y}^{+++}$carrier: 1 day following injection.

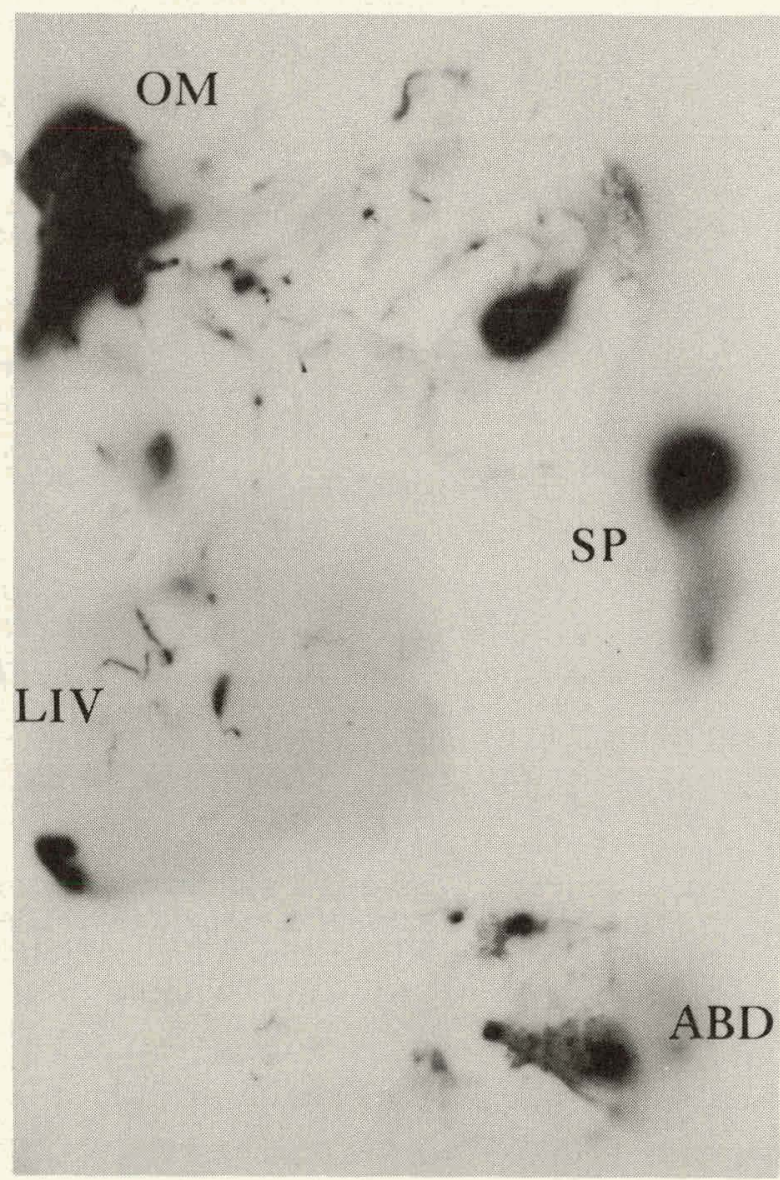

Marked uptake is evident in the omentum and in the lymphatics and lymph nodes of the mesentery. There is a moderate parenchymal uptake in the liver and spleen which becomes more marked with time. Localization in the abdominal wall is not marked.

LIV = liver; $\mathrm{SP}=$ spleen; $\mathrm{OM}=$ omentum; $\mathrm{ABD}=$ abdominal wall. 


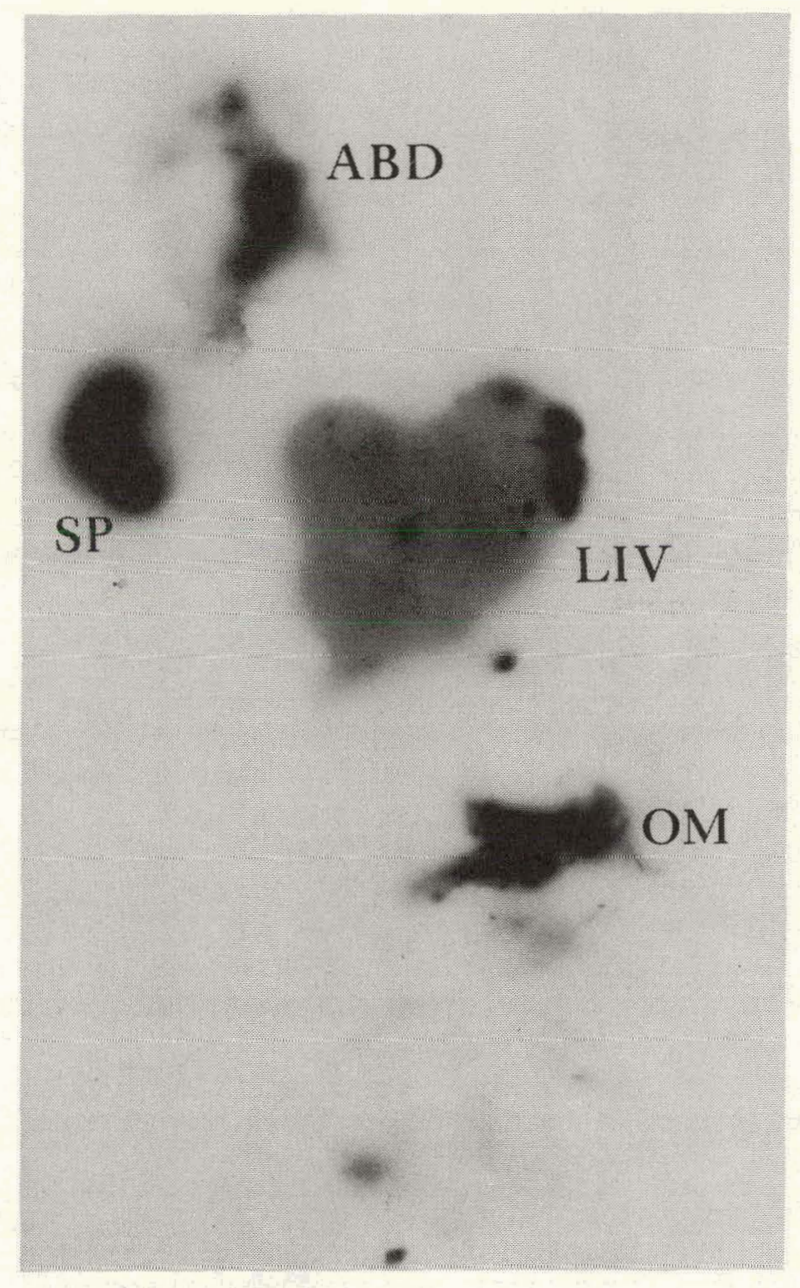

Figure 3. Gross radioautograph of intra-abdominal organs of rats following intraperitoneal injection of $\mathrm{Y}^{90} \mathrm{Cl}_{3}$ in $1 \mathrm{ml}$ of .9 per cent $\mathrm{NaCl}$ with $1 \mathrm{mg}$ of $\mathrm{Y}^{+++}$carrier: 6 days following injection.

Marked uptake is evident in the omentum and in the lymphatics and lymph nodes of the mesentery. There is a moderate parenchymal uptake in the liver and spleen which becomes more marked with time. Localization in the abdominal wall is not marked.

lymphatics was seen within one-half hour or less, and subsequent changes were relatively slow. In point of fact the one-half and 24-hour preparations were almost indistinguishable. In Figures 4, 5, 6, and 7 is shown the effect of varying the amount of carrier yttrium with other factors remaining constant. The isotope was injected in $1 \mathrm{ml}$ of 0.9 per cent $\mathrm{NaCl}, \mathrm{pH}_{5}$. In Figure 4 (carrier-free), the most marked localization is shown to be in the liver, but the whole picture is less distinct. In contrast, $1 \mathrm{mg}, 3 \mathrm{mg}$, and $10 \mathrm{mg}$ of carrier produce a decreasing tendency to parenchymal localization, and a greater tendency to 


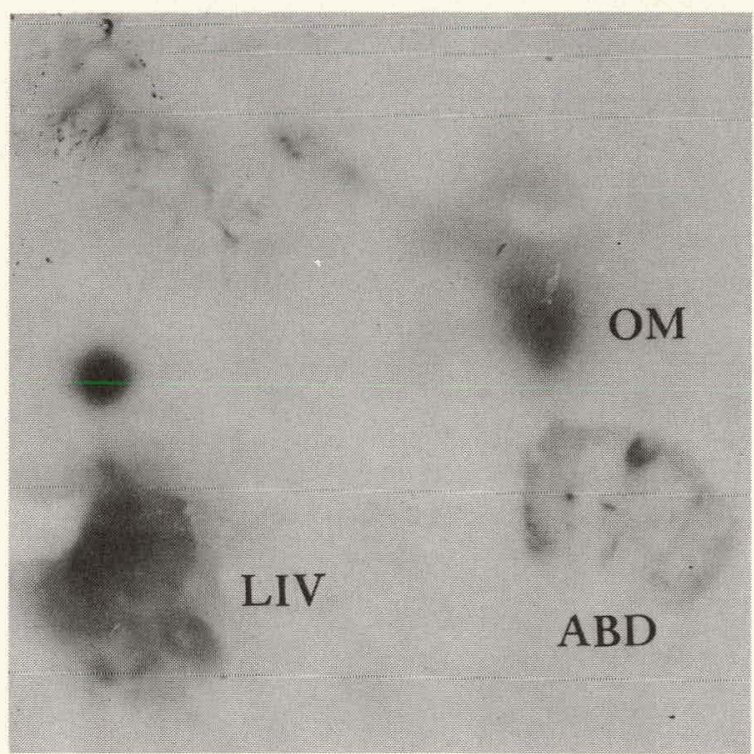

Figure 4. Gross radioautograph showing effect of carrier $\mathrm{Y}^{+++}$on intraperitoneal distribution. Material injected in $1.0 \mathrm{ml}$ of 0.9 per cent $\mathrm{NaCl}$, carrierfree: 24 hours following injection.

Figure 5. Gross radioautograph showing effect of carrier $\mathrm{Y}^{+++}$on intraperitoneal distribution. Material injected in $1.0 \mathrm{ml}$ of 0.9 per cent $\mathrm{NaCl}, 1 \mathrm{mg}$ carrier $\mathrm{Y}^{+++}$: 72 hours following injection.

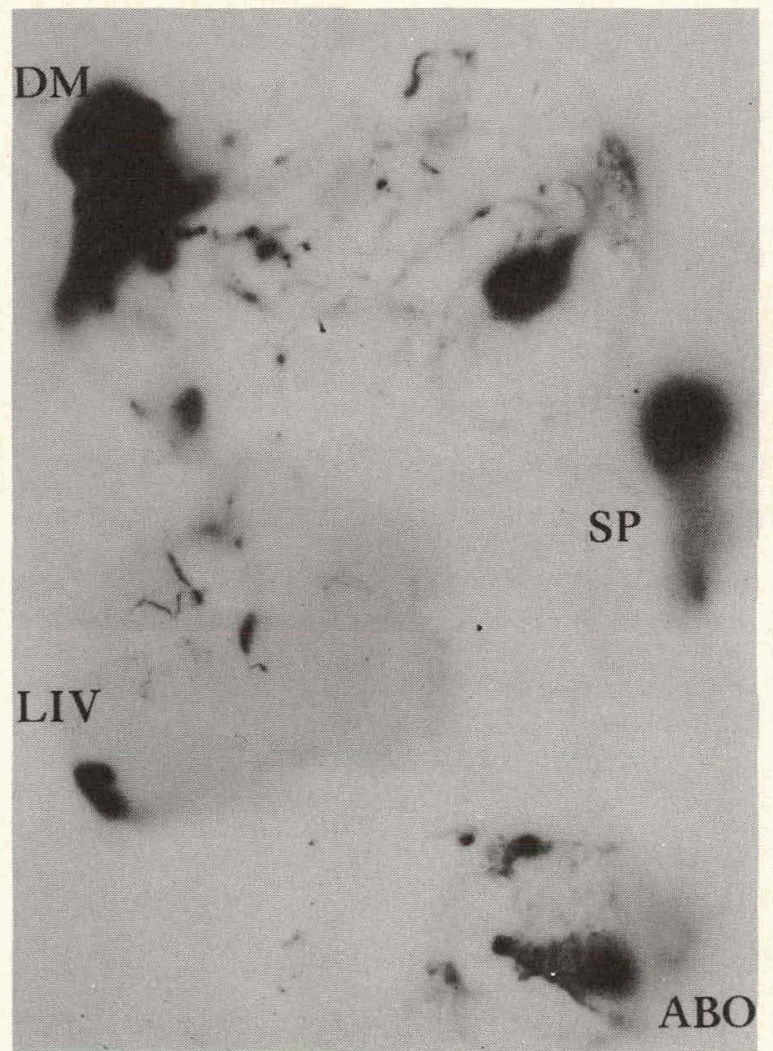

Increasing the amount of carrier reduces the amount of parenchymal localization in the liver evident with carrier-free yttrium and $1 \mathrm{mg}$ of carrier $\mathrm{Y}^{+++}$. Further increases of carrier level result in patchy distribution of isotope on surfaces in areas of localized fibrinous peritonitis. 


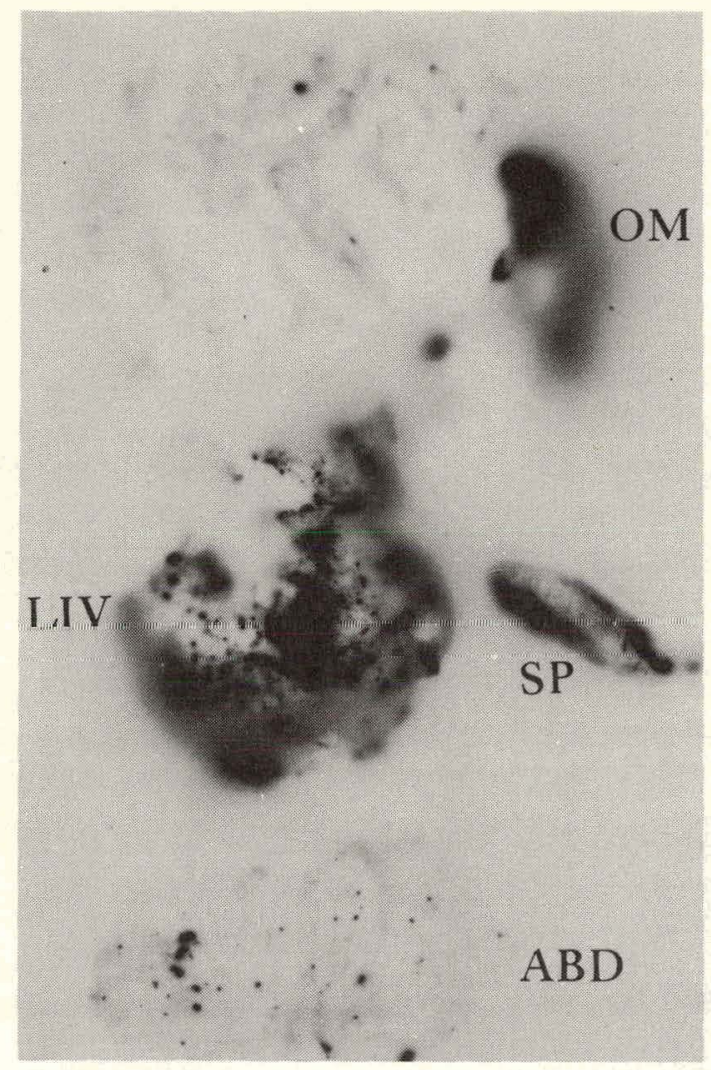

Figure 6. Gross radioautograph showing effect of carrier $\mathrm{Y}^{+++}$on intraperitoneal distribution. Material injected in $1.0 \mathrm{ml}$ of 0.9 per cent $\mathrm{NaCl}, 3 \mathrm{mg}$ carrier $\mathrm{Y}^{+++}: 72$ hours following injection.

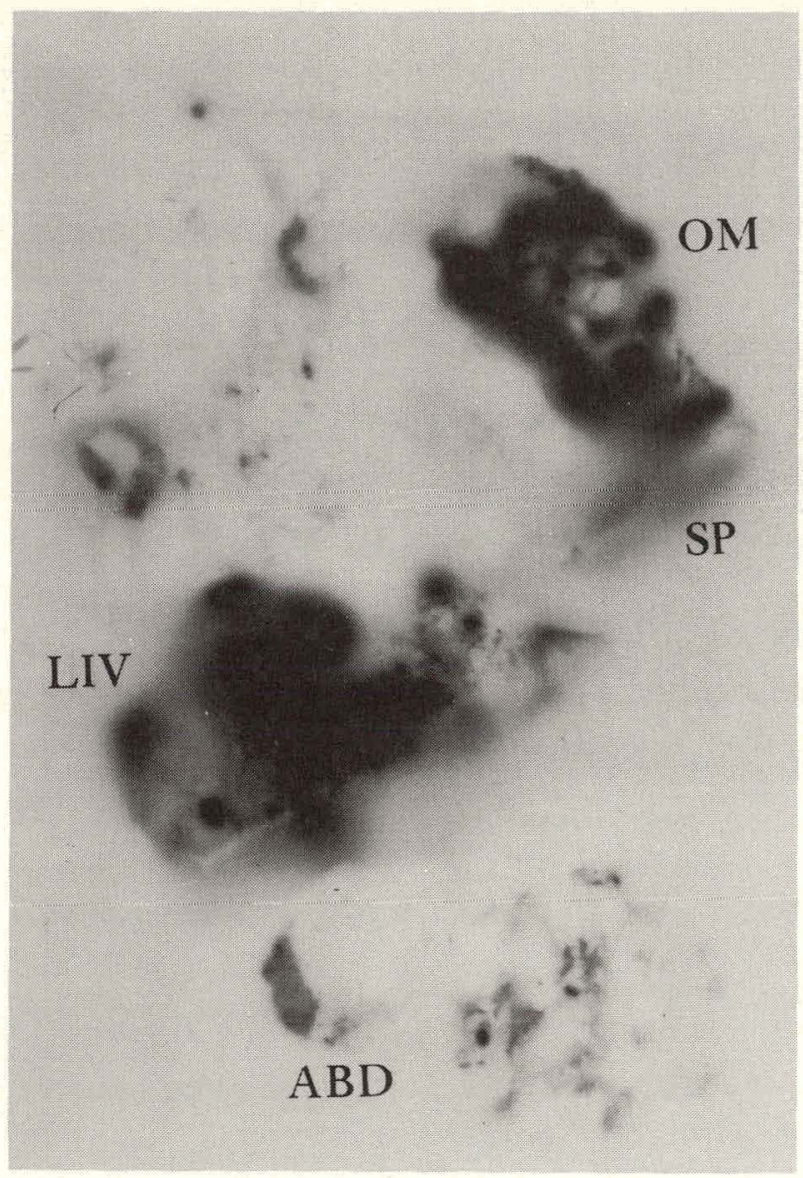

Figure 7. Gross radioautograph showing effect of carrier $\mathrm{Y}^{+++}$on intraperitoneal distribution. $\mathrm{Ma}$ terial injected in $1.0 \mathrm{ml}$ of 0.9 per cent $\mathrm{NaCl}, 10 \mathrm{mg}$ carrier $\mathrm{Y}^{+++}: 72$ hours following injection.

Increasing the amount of carrier reduces the amount of parenchymal localization in the liver evident with carrier-free yttrium and $1 \mathrm{mg}$ of carrier $\mathrm{Y}^{+++}$. Further increases of carrier level result in patchy distribution of isotope on surfaces in areas of localized fibrinous peritonitis. 
localize on peritoneal surfaces, especially of the liver. The gross appearance of the specimens is consistent with the radioautographic results; white patches of yttrium hydroxide being evident on the peritoneal surfaces, especially of the liver. With $10 \mathrm{mg}$ of yttrium, there was a substantial chemical peritonitis, with patches of fibrinous exudate on the peritoneal surfaces. The activity appeared to be incorporated in these areas areas as illustrated by the radioautograph of the abdominal wall (Figure 7). The effect of local peritonitis

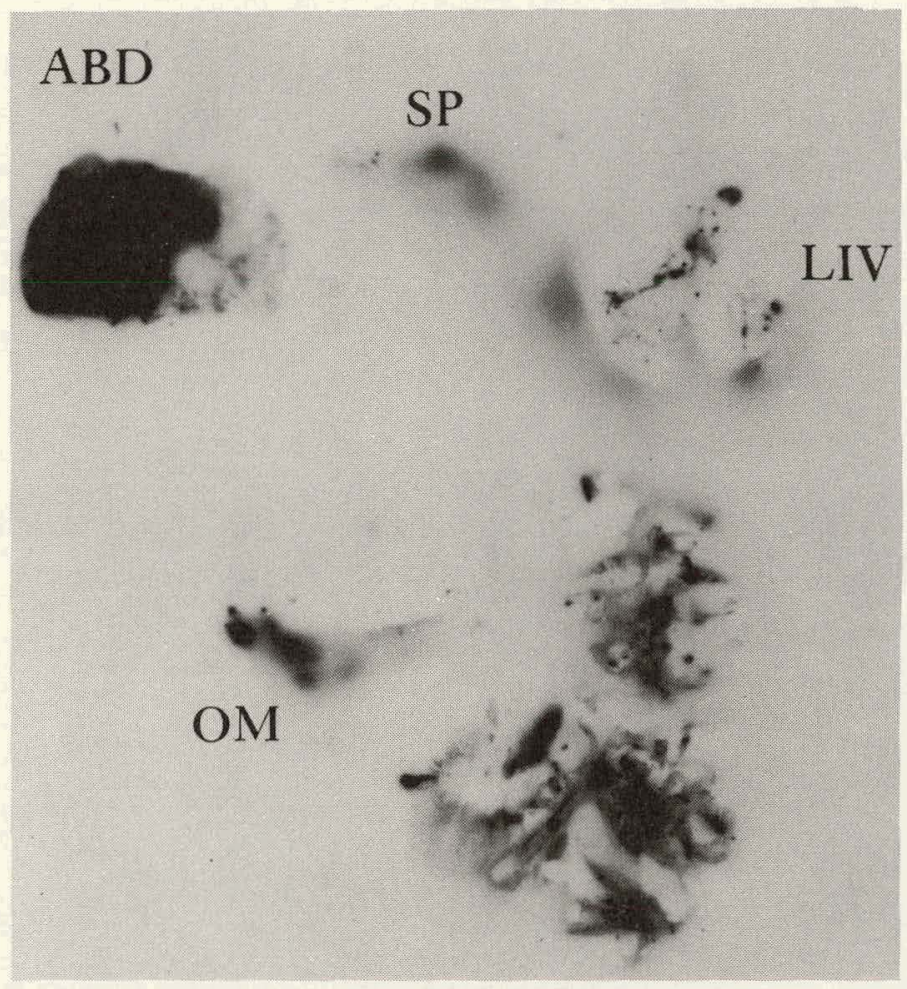

Figure 8 .

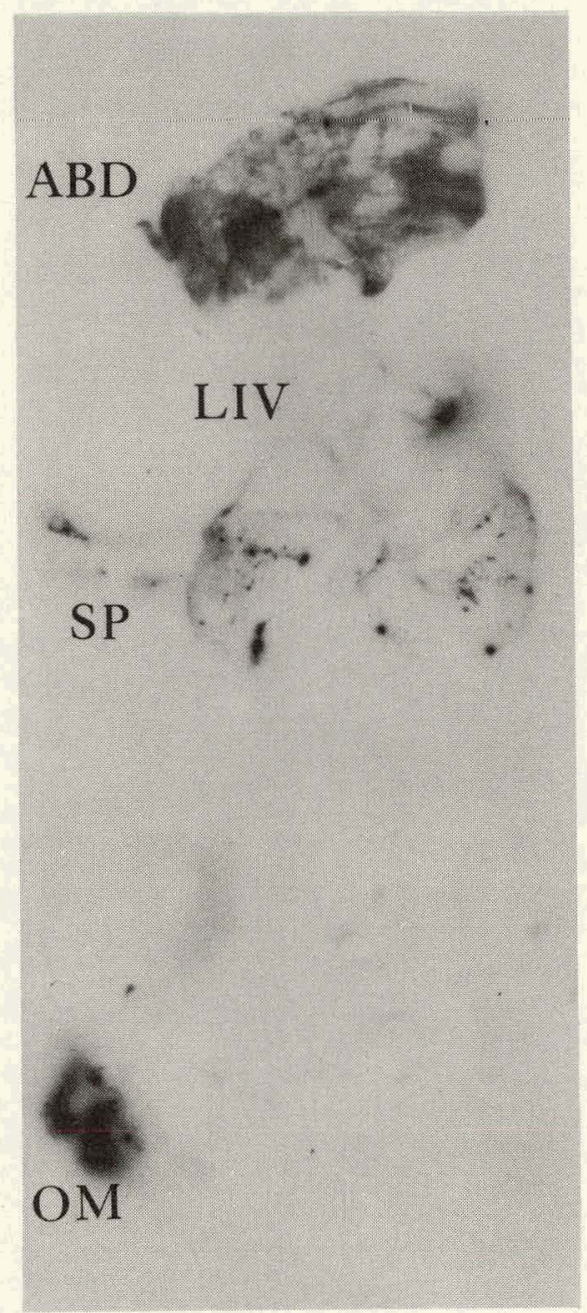

Figure 9.

Figure 8. Radioautograph showing marked localization of activity in region of laparotomy wound of rat following intraperitoneal injection of 1.0 $\mathrm{ml}$ of 0.9 per cent $\mathrm{NaCl}$ containing $\mathrm{Y}^{90}+3.0 \mathrm{mg}$ carrier. Injection made one-half hour following closure of wound: animal sacrificed $24 \mathrm{hrs}$ following injection.

Figure 9. Marked localization of $\mathrm{Y}^{90}$ in anterior abdominal wall of rat $24 \mathrm{hrs}$ after intraperitoneal injection of $\mathrm{Y}^{90}+3.0 \mathrm{mg}$ of carrier in 6.0 $\mathrm{ml} 0.9$ per cent $\mathrm{NaCl}$. 
was studied further (Figure 8). Experimental animals were subjected to laparotomy onehalf hour before they were injected with $\mathrm{Y}^{90}$ with $3 \mathrm{mg}$ of carrier $\mathrm{Y}^{+++}$in $1 \mathrm{ml}$ of 0.9 per cent saline. A very marked localization of the isotope was observed in the abdominal wall, in the region of the fresh laparotomy wound. The contrast with the deposition pattern shown in Figure 6 is obvious.

When the volume of the solution containing yttrium was increased to $6 \mathrm{ml}$, the remark-

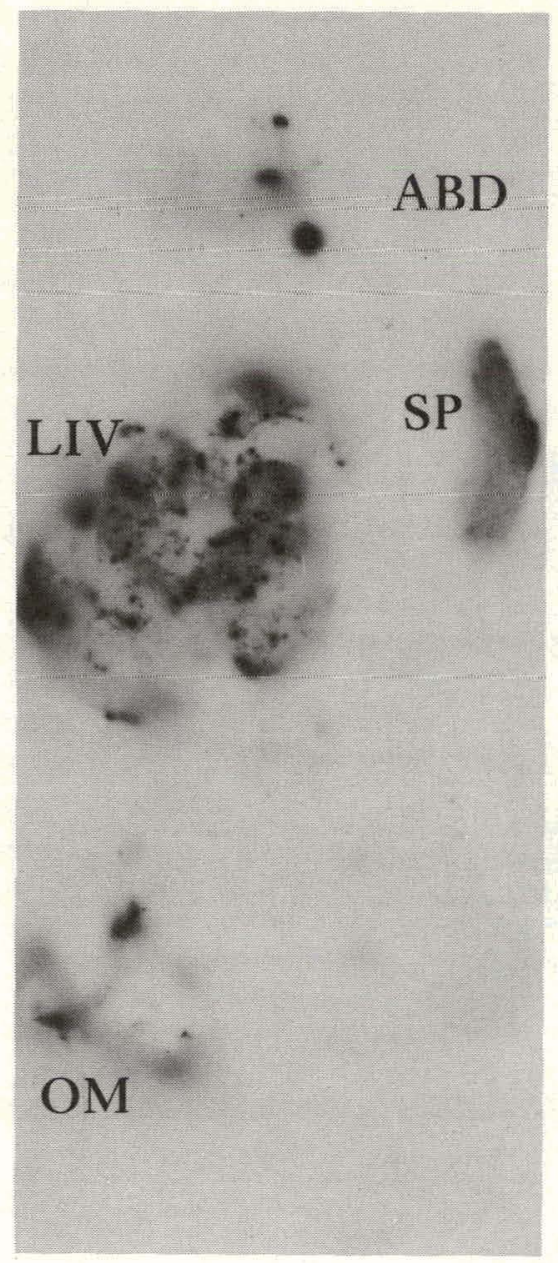

Figure 10.

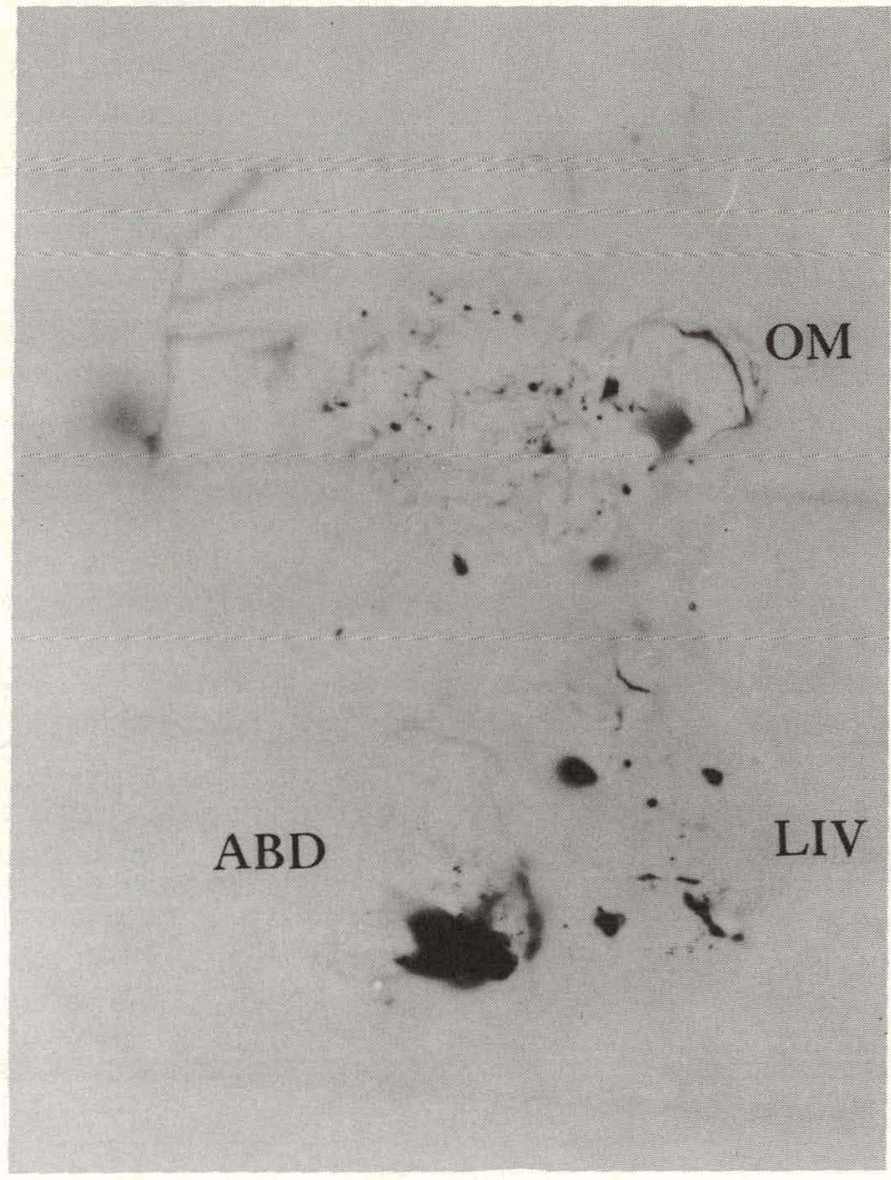

Figure 11.

Figure 10. Radioautograph $24 \mathrm{hrs}$ after intraperitoneal injection of $\mathrm{Y}^{90}$ $+3.0 \mathrm{mg}$ of carrier in $6.0 \mathrm{ml}$ of human serum. Contrast this with Figure 9. There is marked parenchymal localization in the presence of serum protein which is almost completely absent when the isotope is dissolved in 0.9 per cent $\mathrm{NaCl}$. This is probably due to chelation of the carrier yttrium by the protein.

Figure 11. Radioautograph $24 \mathrm{hrs}$ following intraperitoneal injection of $0.2 \mathrm{ml}$ colloidal gold (Aurcoloid, Abbott). Contrast this with radioautographs of animals injected with $\mathrm{Y}^{90}$. Note translocation of isotope into liver after $72 \mathrm{hrs}$. 
able effect that is shown in Figure 9 was obtained. We can only interpret this as evidence that yttrium hydroxide precipitate had collected in the most dependent portion of the abdominal cavity, with the resultant translocation of isotope into the adjacent abdominal wall lymphatics, outlining the muscle fibers as shown. Injecting the isotope dissolved in $6 \mathrm{cc}$ of serum gave the result shown in Figure 10. There is a very substantial increase in the parenchymal localization as compared with Figure 9, and the localization in the abdominal wall is completely absent. This experiment was done in an effort to simulate treatment of tumor ascites, and the result is probably due to chelation of the injected yttrium with the serum protein.

Figures 11 and 12 show the effect of $0.2 \mathrm{ml}$ of radioactive gold colloid (Aurcoloid). There is a rather different pattern of distribution, with some activity still in the peritoneal fluid at $24 \mathrm{hrs}$, and a conspicuous absence of omental uptake. At $72 \mathrm{hrs}$, the parenchymal uptake in the liver is evident. These differences are probably a function of particle size



Figure 12. Radioautograph $72 \mathrm{hrs}$ following intraperitoneal injection of $0.2 \mathrm{ml}$ colloidal gold (Aurcoloid, Abbott). Contrast this with radioautographs of animals injected with Y ${ }^{90}$. Note translocation of isotope into liver after $72 \mathrm{hrs}$. 
since intraperitoneally-injected India ink gives the same pattern of localization that yttrium does.

The localization of intraperitoneal colloidal and particulate material evidently depends on a number of factors, the most important of which appear to be the nature of the material, its quantity, and the presence of inflammation. The marked localization of yttrium chloride in the omentum, mesenteric nodes, and in the laparotomy wound follows the pathway of other particulate material such as carbon particles, and indeed, of tumor cells. Walker 256 sarcoma injected intraperitoneally into rats also localizes in these areas. On the basis of these observations it appears that yttrium chloride should prove effective in suppressing the growth of tumor cells seeded at operation. On the other hand, the behavior of yttrium in serum suggests that its use in tumor ascites in which there is a fairly rapid protein turnover might lead to extensive translocation of the isotope unless very large amounts of carrier are used. Radioactive gold-198, which is non-reactive chemically, should therefore be preferable to yttrium chlorides in the treatment of tumor ascites.

\section{LITERATURE CITED}

1. Lewin, R., H. E. Hart, J. Greenberg, H. Spencer, K. G. Stern, and D. Laszlo. Science, 119:880, 1954 .

2. Root, S. W., M. P. Tyor, G. A. Andrews, and R. M. Kniseley. Radiology, 63:251, 1954.

3. Kyker, G. C., C. A. Cress, and G. I. Gleason. Federation Proc., 13:245, 1954.

4. Scheer, K. E. Strahlentherapie, 101:283, 1956.

5. Andrews, G. A., R. M. Kniseley, E. L. Palmer, and A. L. Kretchmar. Proceedings of the International Conference on the Peaceful Uses of Atomic Energy, Vol. 10, Radioisotopes and Nuclear Radiations in Medicine, p. 122, Geneva, 1955.

6. Laszlo, D. Distribution of Lanthanum and Yttrium in the Mammalian Organism, Rare Earths in Biochemical and Medical Research, ORINS-12, 193-221, Oak Ridge Institute of Nuclear Studies, Inc., Oak Ridge, Tennessee.

7. Woodward, E. R., and P. V. Harper. Annals of Surgery, 140:206, 1954. 


\title{
ACQUIRED TOLERANCE TO A MOUSE LEUKEMIA IN THE RAT ${ }^{*}$
}

\section{By}

\author{
J. S. Thompson ${ }^{\dagger}$ and C. W. Gurney
}

Lymphatic leukemia, P1534, is indigenous to the DBA/2 inbred strain of mice. Successful passage may be accomplished in the adult DBA/2 mouse either by subcutaneous trocar implantation of whole tumor pieces or by the intraperitoneal or subcutaneous injection of a suspension of gently homogenized liver or spleen obtained from animals bearing the ascitic form. Growth of this tumor occurs occasionally in the DBA/1 and BALB/c strains of mice and in the untreated golden hamster, but heterotransplantation to the untreated rat has not been reported.

The successful heterotransplantation of the P1534 mouse leukemia into albino rats of either the Wistar or Holtzman strains was the purpose of this research.

Newborn Holtzman rats were injected subcutaneously with $.1 \mathrm{ml}$ of adult DBA/2 spleen cells, prepared by gentle manipulation in a glass homogenizer, suspended in Tyrodes solution. The concentration was adjusted so that approximately 20,000,000 nucleated cells were transferred. All initial injections were performed during the first 24 hours of life. The rats were then subdivided, one half receiving a second injection on the $3 \mathrm{rd}$ day of life and the other half, on the 5th day. Both groups were given "reinforcing injections" every 4 days thereafter until the rats were 1 month old. Of 81 newborn so treated, only 20 survived to 5 weeks of age, the majority dying during the 1st week. Among the surviving animals, 6 were distinctly smaller than their litter mates of the same age. A comparison of the weights revealed that these animals weighed only one-half as much as the other survivors. The hair was ruffled and sparse, yet the animals appeared active and otherwise grossly similar. During the 8 th week, each of the 20 animals was injected subcutaneously with approximately 300,000,000 P1534 cells suspended in Tyrodes solution. Progressive growth did not occur, nor did it occur in 15 eight-week-old control Holtzman animals injected subcutaneously or in 15 injected intraperitoneally. Passage of 20,000,000 cells from this same pool proved to be fatal to adult DBA/2 mice within 14 days.

The considerable mortality and the inability of the Holtzman rat to demonstrate acquired tolerance to the heterotransplant led to the selection of the Wistar strain as the host in subsequent trials. Using the same techniques of preparation and dosage as before, 42 newborn Wistar rats received the initial injection of adult DBA/2 spleen cells within 24 hours postpartum. The rats were divided into 2 groups, and an injection schedule similar to that listed above was followed. Fourteen animals survived to the time of tumor challenge

\footnotetext{
* Summary of a paper that has been accepted for publication in the Transplantation Bulletin.

${ }^{\dagger}$ Public Health Service Research Fellow of the National Cancer Institute, USPHS.
} 
Again neither this group nor a control group of 20 rats developed progressive tumor growth. Of particular interest, however, was the reoccurrence of "runts" similar to those seen in the original trial. We believe these runts may be different from those described previously because of their more hearty condition. An extensive investigation of the Wistar runt is now underway in our laboratory.

In these experiments, approximately 20,000,000 nucleated cells from the spleens of DBA/ 2 mice bearing the leukemic form of P1534 were injected subcutaneously into newborn Wistar rats. Litters 1 and 2 were born on the same day and one-half of the newborn of each litter was interchanged. Animals in one such adjusted litter were injected on the 1st day postpartum, the others on the third. Litters 3,4 , and 5 were born on the same day, and two-thirds of each of these litters were interchanged. In this case, the adjusted litters received the tumor; litter 3 on the 1 st day, litter 4 on the 2 nd day, and litter 5 on the 3 rd day. Table 1 summarizes the results. Progressive tumor growth occurred only in those animals that had been treated within 24 hours of birth. In several instances, small masses,

Table 1

THE INCIDENCE OF PROGRESSIVE GROWTH OF P1534 DBA/2 LYMPHOMA IN THE NEWBORN WISTAR RAT

\begin{tabular}{c|c|c||c|c|c}
\hline No. of original litter & 1 & 2 & 3 & 4 & 5 \\
\hline No. of animals in altered litters & 7 & 7 & 10 & 9 & 10 \\
$\begin{array}{c}\text { Day of life tumor was implanted } \\
\text { No. of animals with progressive } \\
\text { tumor growth }\end{array}$ & 1 & 3 & 1 & 2 & 3 \\
\hline
\end{tabular}

measuring less than $0.5 \times 0.5 \mathrm{~cm}$, appeared in animals inoculated on the 2 nd or $3 \mathrm{rd}$ day of life, but these had regressed by the 21st day after inoculation. Progressive growth first appeared from 14 to 28 days after inoculation. Figure 1 gives the typical microscopic appearance of the tumor in the rat, where it attained considerable size locally, measuring $3 \times 3 \mathrm{~cm}$ in some instances. Microscopic examination of the spleen, liver, and mesenteric lymph node revealed no abnormality. No leukemic cells were seen in peripheral blood smears examined after staining with Wright's stain.

It has been suggested that the newborn rat is less mature immunologically at birth than other species. It must be stressed, however, that this applies for one test system; i.e., the production of tolerance in Wistar rats to Long Evans tissue. The facts that pretreatment with normal tissue, even considerable amounts over a period of 1 month, did not produce acquired immunologic tolerance to the P1534 tumor heterograft and that successful transplantation occurred only when the tumor itself was administered within the first 24 hours of life suggest that when heterologous antigens are involved, the period dur- 


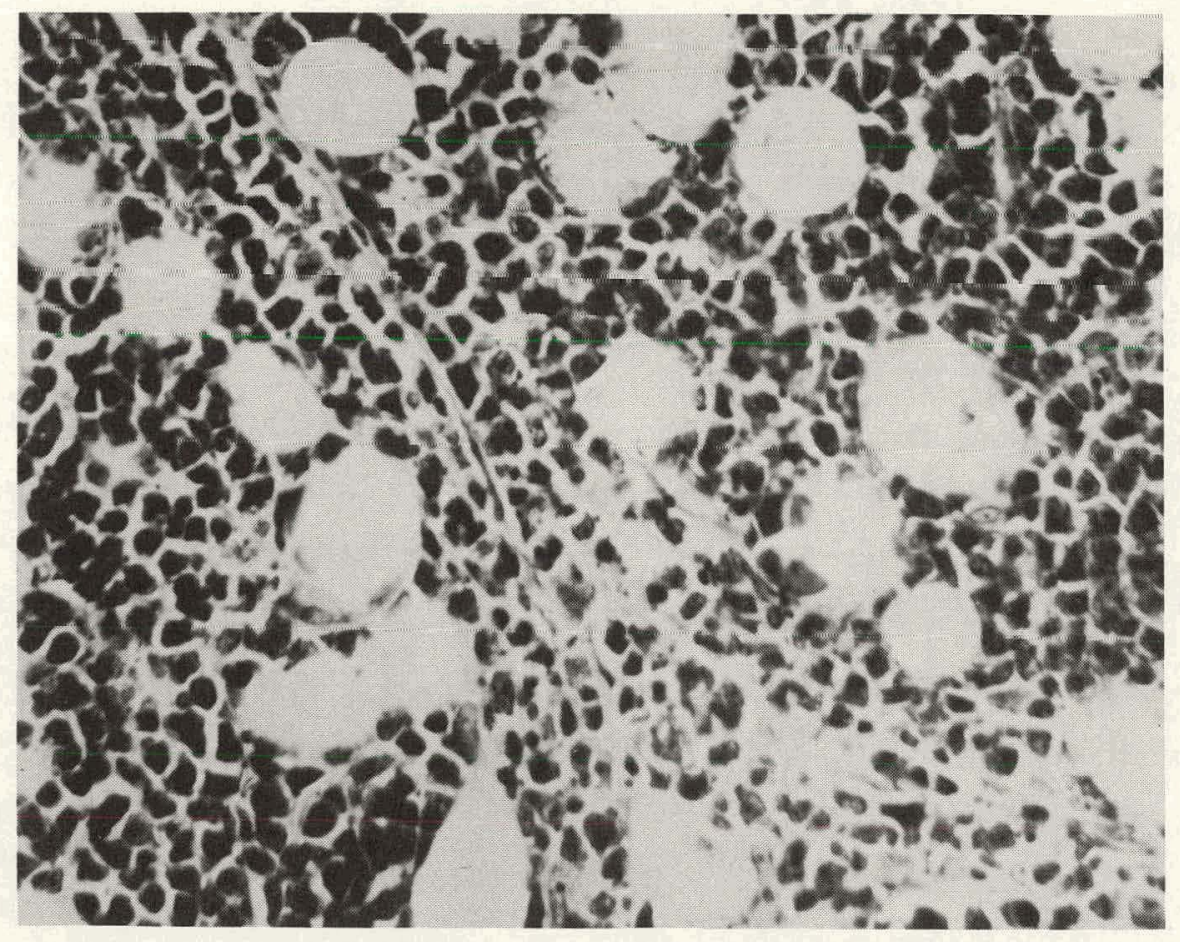

Figure 1. Photomicrograph of DBA/2 mouse lymphoma growing subcutaneously in the Wistar rat. Hematoxylineosin-azure stain.

ing which tolerance can be produced is critically shortened. Although this may represent the effect of qualitatively different antigens, the additional evidence obtained by others suggests another interpretation. It has been shown that whereas tolerance to skin homografting cannot be initiated in the newborn rabbit, a nonreactive state to a single soluble antigen can be readily produced. This suggests that an important factor might be the number of antigens involved in any donor-host combination, that is, the greater the number of antigens presented to the immature host, the less likely that tolerance will be produced and the more critical the time and the method of its production will be. 


\title{
THE METABOLITES OF CARDIAC GLYCOSIDES IN HUMAN URINE*
}

\author{
By \\ J. J. Ashley, ${ }^{+}$B. T. Brown, ${ }^{+}$G. T. Okita, and S. E. Wright ${ }^{+}$
}

We have made a qualitative study of the cardioactive substances present in human urine after oral administration of digoxin, digitoxin, and lanatoside $\mathrm{C}$ and have compared the metabolites present with those found in rat urine. Previously we presented evidence that indicated that hydroxylation occurred at C-12 in the digitoxin molecule in human beings and in rats, thereby producing a urinary metabolite that could not be separated from the glycoside digoxin. This evidence was based on experiments in which paper chromatography and $\mathrm{C}^{14}$-digitoxin were used. The details of this work are presented in this paper.

Healthy adults were each given orally $1 \mathrm{mg}$ of each glycoside, and the 12-hour urine collections were pooled. The pooled urine was treated with 40 per cent lead acetate solution until no further precipitation occurred. The precipitate was removed by centrifuging, and the supernatant liquid was extracted by rolling approximately $200 \mathrm{ml}$ with three successive portions of $150 \mathrm{ml}$ of chloroform in 1-liter bottles for 2 hours. The chloroform extract was pigmented too heavily to allow direct application to paper chromatograms, and the following procedure was employed to remove the bulk of the pigment. The chloroform extract was evaporated to small bulk under reduced pressure, absorbed on $250 \mathrm{mg}$ of washed Super-Cel, and dried. A partition column was prepared by adding $1 \mathrm{~g}$ of water to $1 \mathrm{~g}$ of Super-Cel and packed into a column $8 \mathrm{~mm}$ in diameter, filled with water-saturated benzene, and allowed to equilibrate with this solvent. The urine extract was then packed on top of the column and eluted with 15-ml fractions of each of the following water-saturated solvents, a) benzene; b) benzene 9 , chloroform 1 ; c) benzene 4, chloroform 1 ; d) benzene 2 , chloroform 1 ; e) benzene 1 , chloroform 2 ; ) chloroform. The use of this partition column reduced pigment concentration and permitted the subsequent paper chromatography of the urinary extracts. Each fraction was evaporated to dryness, redissolved in chloroformmethanol, and chromatographed on paper strips $3 \times 27 \mathrm{~cm}$. Fractions obtained from solvents $\underline{a}$ ) to $\underline{d}$ ) were chromatographed by using System 3 , and fractions $\underline{e}$ ) and $\underline{f}$ ) with System 1. The glycosides or metabolites were located by treating a narrow marginal strip cut from each chromatogram with alkaline $\underline{m}$-dinitrobenzene, and these were used as markers for cutting away the metabolite or glycoside areas in the main strip. These areas were dried at $60^{\circ}$ in a current of air and eluted with methanol for further tests or rechromatography.

\footnotetext{
* Summary of a paper that appears in The Journal of Biochemistry, 232:315, 1958.

${ }^{+}$Department of Pharmacology and Pharmacy, University of Sydney, Sydney, Australia.
} 
Systems 1, 2, and 3 were used to develop formamide-impregnated paper. Whatman No. 4 paper was dipped in a mixture of 25 per cent formamide in methanol or acetone and dried between sheets of absorbent paper. The chromatograms were run horizontally.

System 1-Benzene 78, chloroform 12, butanol 5, saturated with formamide.

System 2-Tetrahydrofuran 1, chloroform 1, saturated with formamide.

System 3-Methyl isobutyl ketone 4, isopropyl ether 1, saturated with formamide.

Systems 4 and 5 were reversed phase systems, and were used for further identification.

System 4-Ethyl hexanol-amyl alcohol-water-formamide $(6: 2: 8: 2)$.

System 5-Ethyl hexanol-amyl alcohol-water-for mamide $(6: 2: 1: 4)$.

System 6-Chloroform, ethyl acetate, benzene, saturated with water.

Between 1 and $3 \mathrm{mg}$ of pure glycoside or aglycone were dissolved in $40 \mathrm{ml}$ of 98 per cent sulfuric acid, and the ultraviolet absorption spectra were recorded after 30 minutes and again about 16 hours later. The metabolite areas of the paper chromatograms being investigated were eluted with methanol and, after removal of the methanol, $2 \mathrm{ml}$ of 98 per cent sulfuric acid were added and the ultraviolet absorption spectra were measured. The sulfuric acid spectra of a methanol extract of an equivalent area of blank paper were recorded for comparison.

Two rats, weighing $200 \mathrm{~g}$ each, were injected with $46,000 \mathrm{dpm}$ of biosynthetically prepared $\mathrm{C}^{14}$-digitoxin, and at the same time with $2 \gamma$ per $\mathrm{g}$ of non-radioactive digitoxin. The urine was collected for 12 hours, extracted, and counted by means of an internal gas-flow Geiger counter. The extract was then chromatographed on formamide-impregnated strips, $4 \mathrm{~cm}$ wide, with use of System 1 . One-fifth of the strip was cut away and treated with alkaline $\underline{m}$-dinitrobenzene. The areas on the untreated strip corresponding to the glycoside and metabolites were cut, dried, and eluted with methanol, and each solution was counted. Ten $\mathrm{mg}$ of normal digoxin were added to the eluate of Metabolite G (Figure 1), and the whole was recrystallized to radiochemical purity.

Twelve $\mathrm{mg}$ of lanatoside $\mathrm{C}$ was given to each of 12 subjects, and the pooled 12-hour urine collections were treated by the method described. Paper chromatography revealed the presence of two substances that produced a blue color with $\underline{m}$-dinitrobenzene characteristic of the butenolide ring. The first of these metabolites was rechromatographed with

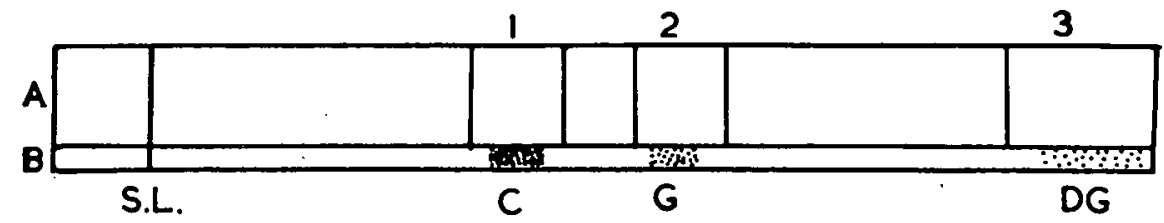

Figure 1. Paper chromatogram of rat urinary excretory products after digitoxin and $\mathrm{C}^{14}$-digitoxin administration; A, strip for elution; $B$, strip for visualization; Band $C$, Metabolite C zone; Band G, Metabolite G zone; Band DG, digitoxin zone; Zones $1,2,3=$ the areas eluted for counting. 
digoxin on Systems 1 and 6 and did not separate. The second metabolite was rechromatographed with a sample of Metabolite B obtained from rat urine on System 1 and failed to separate.

Lanatoside $\mathrm{C}$ could not be detected in eluates, owing to the retention of this glycoside on the water partition column. To overcome this difficulty, a portion of the chloroform extract of the urine was chromatographed directly on paper (System 1), and unchanged lanatoside $\mathrm{C}$ was detected free from urinary pigment.

Eleven persons each received $11 \mathrm{mg}$ of digoxin. Paper chromatography revealed the presence of two substances, which were compared with authentic digoxin and with a sample of rat urine Metabolite B, respectively, on Systems 1 and 6. No separations were observed.

A total of $7.5 \mathrm{mg}$ of this digitoxin was administered to each of 8 persons. Three substances were detected on paper chromatograms. The first, present only in trace amounts, was found to be similar to unchanged digitoxin by paper chromatography. The other two metabolites were compared with Metabolites $\mathrm{C}$ and $\mathrm{G}$, which are present in rat urine, and would not separate from them on Systems 1, 3, and 6 (Table I).

Table 1

METABOLITES PRESENT IN HUMAN URINE AFTER ADMINISTRATION OF DIGITALIS GLYCOSIDES

\begin{tabular}{l|l}
\hline Glycoside & Glycoside and metabolites detected in urine \\
\hline Lanatoside C & Lanatoside C, digoxin, Metabolite B \\
Digoxin & Digoxin, Metabolite B \\
Digitoxin & Digitoxin, Metabolite C, digoxin, Metabolite G \\
\hline
\end{tabular}

Although chromatography on formamide-impregnated paper does not in general give consistent $R_{F}$ values, it was noted that Metabolite $G$ present in rat or human urine after digitoxin administration moved as digoxin does when chromatographed on System 1. This metabolite was eluted and chromatographed together with digoxin on Systems 1, 2, and 3 without any separation occurring. Comparisons were also made on the reverse phase Systems 4 and 5 , and again no separation was obtained.

Metabolite $G$ eluates were hydrolyzed by refluxing with 0.5 per cent $\mathrm{HCl}$ and 50 per cent ethanol. The chloroform extract was chromatographed on Systems 1 and 3 with an authentic sample of digoxigenin without any separation occurring.

The ultraviolet absorption spectra in sulfuric acid of digoxin, digoxigenin, Metabolite G, hydrolyzed Metabolite G, sarmentogenin, and episarmentogenin are shown in Figures 2 and 3. Prominent maxima at 390 and $490 \mathrm{~m} \mu$ are present for digoxin, digoxigenin, $\mathrm{Me}-$ tabolite G, and hydrolyzed Metabolite G. Sarmentogenin and episarmentogenin had a characteristic maximum at $415 \mathrm{~m} \mu$, which was not the case with digoxin, digoxigenin, or $\mathrm{Me}-$ 
tabolite G.

The radioactivity of the total chloroform extract of the bulked urine of two rats injected with a dose of $92,000 \mathrm{dpm}$ of $\mathrm{C}^{14}$-digitoxin was $3110 \mathrm{dpm}$. This extract, when chromatographed on System 1, showed three areas of cardioactive material (Figure 1). After drying and elution with methanol, the radioactive areas gave the following counts: a) digitoxin area $240 \mathrm{dpm}$; b) Metabolite G area $408 \mathrm{dpm}$; and c) Metabolite $\mathrm{C}$ area $980 \mathrm{dpm}$. Ten $\mathrm{mg}$ of digoxin were added to the Metabolite $\mathrm{G}$ area, and the whole was recrystallized 5 times from chloroform-ether. This gave the following specific activities (disintegrations per minute per $\mathrm{mg}$ ) after correction for self-absorption: first recrystallization $(9 \mathrm{mg})$, 22.6; second (7.0 mg), 20.8; third $(6.0 \mathrm{mg}), 22.0$; fourth $(5 \mathrm{mg}), 21.0$; fifth $(3.0 \mathrm{mg}), 20.4$; m.p. of recovered digoxin, $255-260^{\circ}$ (authentic sample m.p. $=255-257^{\circ}$ ).

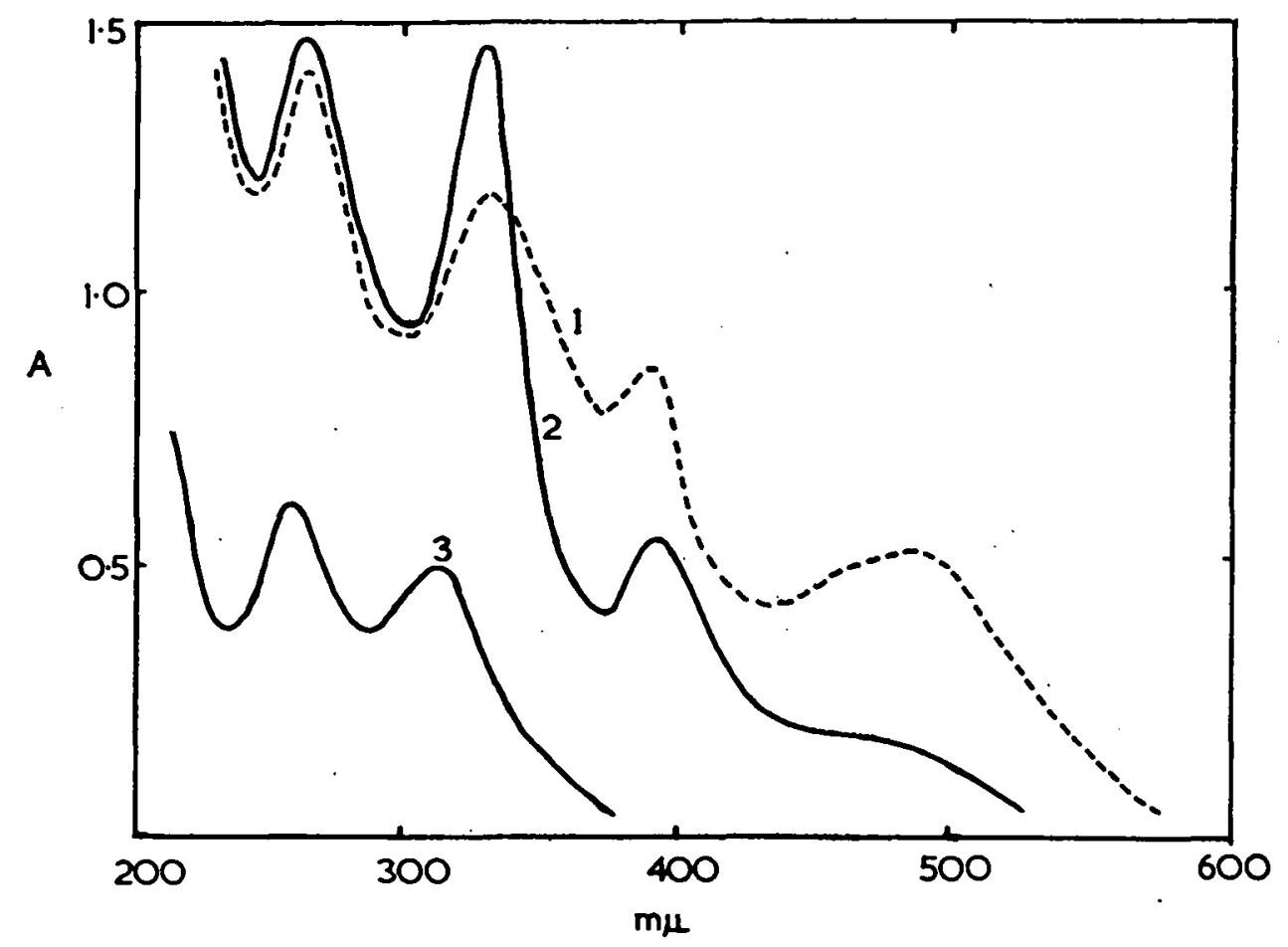

Figure 2. Ultraviolet absorption spectra in sulfuric acid. Curve 1, eluate of Metabolite G; Curve 2, eluate of hydrolyzed Metabolite G; Curve 3, eluate of filter paper blank; A, optical density (1 cm cell).

Both metabolites showed a blue fluorescence in ultraviolet light after treatment with trichloroacetic acid and traveled similarly on paper chromatograms. When chromatographed together on System 1, no separation occurred. Both Metabolite B and Metabolite $\mathrm{C}$ after hydrolysis with dilute acid could not be separated from digoxigenin.

It is apparent that the metabolism of the cardiac glycosides digoxin, digitoxin, and lanatoside $\mathrm{C}$ is qualitatively similar in rats and human beings. No metabolites were found in human urine that were not present in rat urine. Quantitative estimation of the human 
urine metabolites was not attempted, but the paper chromatograms indicated that, after digitoxin administration, the major cardioactive constituent of the urine was not unchanged glycoside, but was the substance that we have termed Metabolite $\mathrm{C}$ in rat urine. Smaller amounts of the Metabolite $G$ of rat urine and free digitoxin were detected.

The fact that Metabolite $G$ could not be separated from the glycoside digoxin on five systems of paper chromatography indicates that it must be very similar to, if not identical with, this substance. The apparent non-separation of digoxin from the $\mathrm{C}^{14}$-labeled Metabolite $G$ excreted in rat urine after five recrystallizations is also evidence that these substances are the same compounds. Paper chromatographic evidence indicates that Metabolite $B$, found in human and rat urine after administration of digoxin and which has been shown to be a conjugate of digoxigenin, is identical with digitoxin Metabolite $\mathrm{C}$.

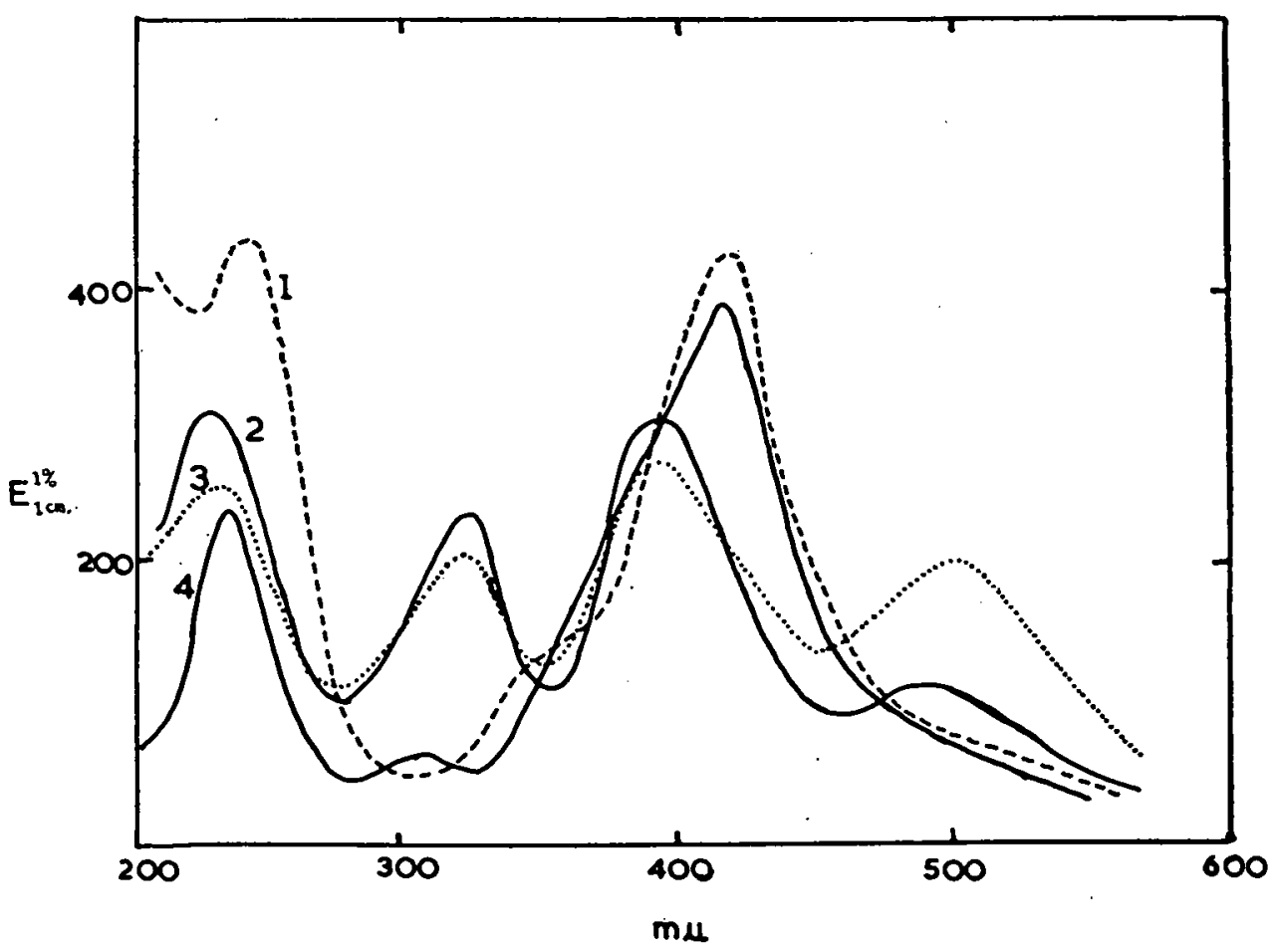

Figure 3. Ultraviolet absorption spectra in sulfuric acid. Curve 1, sarmentogenin; Curve 2, digoxigenin; Curve 3, digoxin; Curve 4 , episarmentogenin.

The formation of digoxin from digitoxin involves hydroxylation of the steroid genin at $\mathrm{C}-12$ in the $\beta$ position. Although $\alpha$ hydroxylation at position 12 in the steroid nucleus occurs in the formation of bile acids and has been shown to take place in man after the administration of cholesterol, $\beta$ hydroxylation in this position does not appear to have been observed previously in animals. The cardiac glycosides are unique-among naturally-occurring steroids in having rings $\mathrm{C}$ and $\mathrm{D}$ arranged cis to one another. Under these conditions the $\beta$ position at $\mathrm{C}-12$ is equatorial and hence the more favored configuration. 
It is possible that hydroxylation could have occurred at position 11 in the digitoxin molecule, the resulting product being inseparable from digoxin by paper chromatography or recrystallization. A comparison of the ultraviolet absorption spectra of digoxigenin, digoxin, and Metabolite $G$ in concentrated sulfuric acid with that of sarmentogenin $(11-a-$ hydroxyldigitoxigenin) with episarmentogenin (11- $\beta$-hydroxydigitoxigenin) indicates that Metabolite $\mathrm{G}$ is not an 11-hydroxyl compound.

The sulfuric acid absorption spectra of sarmentogenin and 11-episarmentogenin are identical. These two compounds, though separable, are very close to one another on paper chromatograms, which suggests that $12-a$-hydroxydigitoxin and $12-\beta$-hydroxydigitoxin (digoxin) would also be difficult to distinguish from each other. However, judging on the basis of the constant radioactivity obtained upon recrystallization and on the basis of conformational factors, we prefer the identification of Metabolite $G$ with digoxin rather than with 12-epidigoxin. 


\section{STAFF ' PUBLICATIONS}

1. Beutler, E., and R. K. Blaisdell. Iron enzymes in iron deficiency. III. Catalase in rat red cells and liver with some further observations on cytochrome C. J. Lab. Clin. Med., 52:694, 1958 .

2. Beutler, E. The hemolytic effect of primaquine and related compounds: a review. Blood, 14:103, 1959.

3. Beutler, E. The red cell indices in the diagnosis of iron-deficiency anemia. Ann. Intern. Med., 50:313, 1959.

4. Beutler, E., M. K. Y. Yeh, and T. Necheles. The incidence of the erythrocytic defect associated with drug-sensitivity among oriental subjects. Nature, 183:684, 1959.

5. Dahl, J. R., R. K. Blaisdell, and E. Beutler. Gastric ulceration in experimentallyinduced polycythemia. Clin. Res., 7:70, 1959 (Abstract).

6. Harper, P. V., K. A. Lathrop, L. Baldwin, Y. Oda, and L. Kryshtal. Palladium ${ }^{103}$ : a new isotope for interstitial implantation at operation. Ann. Surg., 148:606, 1958.

7. Kabara, J. J., G. T. Okita, and G. V. LeRoy. Simultaneous use of $\mathrm{H}^{3}$ and $\mathrm{C}^{14}$ compounds to study cholesterol metabolism, Liquid Scintillation Counting, p. 191, Pergamon Press, New York, 1958.

8. Kappas, A., L. Hellman, D. K. Fukushima, and T. F. Gallagher. The thermogenic effect and metabolic fate of etiocholanolone in man. J. Clin. Endocrinol. Metabolism, $18: 1043,1958$.

9. Landau, R. L., and K. Lugibihl. Inhibition of the sodium-retaining influence of aldosterone by progesterone. J. Clin. Endocrinol. and Metabolism, 18:1237, 1958.

10. Lanzl, L. H., and L. S. Skaggs. Radiation characteristics of a kilocurie revolving cobalt -60 therapy unit. Am. J. Roentgenol., Radium Therapy and Nuclear Med., 80: 851,1958 .

11. Necheles, T., and E. Beutler. Investigations of the site of action of thyroid hormone: studies in human erythrocytes. J. Lab. Clin. Med., 52:931, 1958 (Abstract).

12. Okita, G. T., and F. Richardson. Effect of borneol amine derivatives of nitrogen mustard on tumor-bearing mice. Federation Proc., 17:400, 1958 (Abstract).

13. Rabinovitch, B., and R. Bartosiewicz. A method for assaying for glycoprotein in column fractionation. Proc. Soc. Exp. Biol. Med., 99:42, 1958.

14. Rabinovitch, B., and F. Carreon. Effect of bovine fraction VI on thyroid function in the rat. Proc. Soc. Exp. Biol. Med., 99:564, 1958.

15. Rabinovitch, B., F. J. Star, and D. E. Clark. Thyroid depressant activity in bovine fraction VI. Proc. Soc. Exp. Biol. Med., 99:567, 1958.

16. Rosse, W. F., and C. W. Gurney. The Pelger-Huët anomaly in three families and its use in determining the disappearance of transfused neutrophils from the peripheral blood. Blood, 14:170, 1959.

17. Spratt, J. L., and G. T. Okita. Electrophoretic studies on protein-binding of digitoxin. Federation Proc., 17:412, 1958 (Abstract). 
18. Stein, J. A., and M. L. Griem. Effect of triodothyronine on radiosensitivity. Nature, $182: 1681,1958$.

19. Wong, T-W., D. S. Juras, and R. W. Wissler. Effect of concurrent feeding of Tween 80 on the carcinogenicity of orally administered 3-methylcholanthrene. J. Natl. Cancer Inst., 22:363, 1959 .

Compiled by Mrs. Frances J. Skozen 